\title{
Young onset dementia
}

Citation for published version (APA):

Millenaar, J. K. (2016). Young onset dementia: towards a better understanding of care needs and experiences. [Doctoral Thesis, Maastricht University]. NeuroPsych Publishers. https://doi.org/10.26481/dis.20161222jm

Document status and date:

Published: 01/01/2016

DOI:

10.26481/dis.20161222jm

Document Version:

Publisher's PDF, also known as Version of record

\section{Please check the document version of this publication:}

- A submitted manuscript is the version of the article upon submission and before peer-review. There can be important differences between the submitted version and the official published version of record.

People interested in the research are advised to contact the author for the final version of the publication, or visit the DOI to the publisher's website.

- The final author version and the galley proof are versions of the publication after peer review.

- The final published version features the final layout of the paper including the volume, issue and page numbers.

Link to publication

\footnotetext{
General rights rights.

- You may freely distribute the URL identifying the publication in the public portal. please follow below link for the End User Agreement:

www.umlib.nl/taverne-license

Take down policy

If you believe that this document breaches copyright please contact us at:

repository@maastrichtuniversity.nl

providing details and we will investigate your claim.
}

Copyright and moral rights for the publications made accessible in the public portal are retained by the authors and/or other copyright owners and it is a condition of accessing publications that users recognise and abide by the legal requirements associated with these

- Users may download and print one copy of any publication from the public portal for the purpose of private study or research.

- You may not further distribute the material or use it for any profit-making activity or commercial gain

If the publication is distributed under the terms of Article $25 \mathrm{fa}$ of the Dutch Copyright Act, indicated by the "Taverne" license above, 


\section{Young onset dementia}

Towards a better understanding of care needs and experiences 
C Joany K. Millenaar, Maastricht 2016

All rights reserved. No part of this book may be reproduced or transmitted in any form or by any means, without prior permission in writing by the author, or when appropriate, by the publishers of the publication.

Design and lay-out: Ralph Blomberg

Printing: Ridderprint BV

Publisher: $\quad$ NeuroPsych Publishers

ISBN: $\quad$ 978-94-6299-490-4 


\section{Young onset dementia \\ Towards a better understanding of care needs and experiences}

\section{PROEFSCHRIFT}

Ter verkrijging van de graad van doctor aan de Universiteit Maastricht, op gezag van de Rector Magnificus, Prof. dr. Rianne M Letschert, volgens het besluit van het College van Decanen, in het openbaar te verdedigen op donderdag 22 december 2016 om 16.00 uur

door

Joany Katrina Millenaar

Geboren op 6 september 1988 te Maastricht 


\section{Promotores:}

Prof. dr. F.R.J. Verhey

Prof. dr. R. Koopmans (Radboud UMC, Nijmegen)

\section{Co-promotores:}

Dr. M.E. de Vugt

Dr. C. Bakker

\section{Beoordelingscommissie:}

Prof. dr. J. Schols (voorzitter)

Dr. P. Aalten

Dr. D. Gerritsen (Radboud UMC, Nijmegen)

Prof. dr. R. Ponds

Prof. dr. S. Zuidema (UMC Groningen)

The research described in this thesis was performed at the School for Mental Health and Neuroscience, Department of Psychiatry \& Neuropsychology, Maastricht University and Alzheimer Centre Limburg, Maastricht, the Netherlands.

alzheimer

nederland

Printing this thesis was kindly supported by Alzheimer Nederland 


\section{Contents}

$\begin{array}{lll}\text { Chapter } 1 & \text { Introduction } & 7\end{array}$

Chapter 2 The care needs and experiences with the use of services of people with young onset dementia and their caregivers: a systematic review.

International Journal of Geriatric Psychiatry, 2016

Chapter 3 Exploring perspectives of young onset dementia caregivers with high versus low unmet needs.

Submitted

Chapter 4 The experiences and needs of children living with a parent with young onset dementia.

International Psychogeriatrics, 2014

Chapter 5 The impact of young onset dementia on informal caregivers compared to late onset dementia.

The American Journal of Geriatric Psychiatry, 2016

Chapter 6 Predictors of quality of life in young onset Alzheimer's

disease and Frontotemporal dementia - results from a

European multicenter assessment.

Aging and Mental Health, 2016

Chapter 7 Discussion

Summary

Samenvatting

Knowledge valorization

Dankwoord

Curriculum Vitae

List of publications

Thesis defences from MHeNS 


\section{Chapter}

Introduction 


\section{Young onset dementia: definition and epidemiology}

Dementia is a worldwide public health priority and in 2015 the number of people with dementia is estimated at 47.5 million $^{1}$. Age is the most important risk factor for developing dementia ${ }^{2}$, therefore it is most prevalent in the elderly and often associated with advanced age. However, even though it is rare, some individuals develop symptoms of the disease before the age of 65 . This is most commonly referred to as young onset dementia (YOD). The cut-off age of 65 is arbitrary and has no biological foundation ${ }^{3}$. It is purely based on a sociological division and originated because of life phase specific changes people go trough as they reach the retirement age. Estimations on the occurrence of YOD in the population are scarce and prevalence rates vary from 81 to 113 cases per 100.000 for 45-64 year olds ${ }^{4}$. In the Netherlands it is estimated that 10.000-15.000 individuals have $\mathrm{YOD}^{5}$. However, these numbers are most likely an underestimation as there are insufficient studies on the epidemiology of YOD and most studies are registry based, reflecting only the number of people who have had contact with (health) care services ${ }^{6}$.

Compared to late onset dementia (LOD), people with YOD more often have a rare dementia subtype, a broader differential diagnosis and the burden of genetic disease is higher ${ }^{7}$. They are more likely to have a form of dementia other than Alzheimer's dementia $(\mathrm{AD})^{8}$. However, both in the elderly and in younger individuals, AD is the most common etiology, followed by other neurodegenerative diseases including vascular dementia, frontotemporal dementia (FTD) and dementia with Lewy bodies (DLB) ${ }^{8}$. This is not the case in the group of individuals with a dementia onset at even younger ages (before the age of 45), as for them a neurodegenerative etiology is more rare and they have more autoimmune, metabolic, inflammatory and infectious causes ${ }^{8}$.

\section{Social and psychological challenges}

Over the last decades YOD is recognized as a condition with great impact due to the burden it places on the young individuals and their environment ${ }^{9}$. The onset of the dementia is in an active stage of life when people usually expect many productive years ahead of them. The functional and cognitive decline affects different societal roles and obligations. Before the age of 65 , most people are still working and the dementia symptoms affect their ability to remain employed ${ }^{10}$. This might not only cause financial difficulties, but it can also lower their sense of purpose and engagement in daily living ${ }^{11}$. Together with the cognitive, behavioral and functional symptoms it can significantly affect their general well-being and quality of life (QOL) ${ }^{12}$. Furthermore, not being able to perform daily tasks and the accompanying loss of independence might disturb family relationships, including their parental role $^{13}$, and increase feelings of social isolation ${ }^{14}$. 
Because of these changes people with YOD have to revise their expectations of life and make necessary adjustments in future plans. It is essential to adapt to these changes and cope with the physical, emotional and social challenges they face, in order to continue to function with fulfillment ${ }^{15}$. However, not everyone is able to adapt to the consequences of dementia, adversely affecting their QOL.

\section{Informal caregivers}

YOD has an enormous impact on the environment of the individual with dementia as well. The greater part of care in YOD is provided by family and relatives ${ }^{16}$ and these informal caregivers are often dedicated to provide care by themselves for as long as possible $^{17}$. On average people with YOD are cared for at home for nine years after symptom onset, more than twice as long compared to people with $\mathrm{LOD}^{18}$. A significant predictor for institutionalization is the caregivers' competence in caring ${ }^{18}$, but in general, most family caregivers feel like they are not sufficiently prepared for their role as caregiver ${ }^{19}$. This might be even more common in YOD caregivers, as dementia at a younger age is rare and often not considered as a possibility. The daily care for someone with dementia requires continuous adaptation to changing and demanding situations for an extensive period of time $\mathrm{e}^{20}$ and can result in adverse physical and psychological outcomes ${ }^{21,22}$. These negative consequences are often described as caregiver burden. Caregiver burden denotes both subjective and objective burden. Objective burden refers to practical aspects of caring such as hours spent caring and number of caregiving tasks, while subjective burden refers to the emotional reaction of the caregiver to the demands of caring ${ }^{23}$.

Relatively little is known about the impact of YOD on caregivers and whether this differs from LOD. Previous research has shown that YOD caregivers experience high levels of burden and suffer from depressive symptoms ${ }^{13}$. In addition, they appear to experience a considerable number of psychosocial problems related to their younger phase of life, including relational difficulties, family conflict, employment and financial issues ${ }^{13}$. The increasing and time consuming tasks together with other responsibilities such as working and being a parent cause double demands. Several of these issues appear to be age-specific. However, results on the differences in impact between YOD and LOD caregivers were inconclusive ${ }^{13}$. Furthermore, specifically in YOD there is a group of young informal caregivers involved. Children are confronted with a parent with a progressive disease and often assist in caregiving tasks, which has a major impact on their well-being ${ }^{24,25}$. Supporting informal caregivers is important as they play a crucial role in enhancing the wellbeing and care of the person with dementia ${ }^{19}$. Therefore, knowledge on the specific problems and needs that families experience during the different stages of YOD is essential in order to develop adequate support programs. 


\section{Needs and experiences with care}

Services for dementia in general are often specifically designed for the elderly, and might have difficulties in addressing the challenges younger individuals face ${ }^{17,26}$. Because of the specific needs of people with YOD and their caregivers, they might feel like they are marginalized within the existing services. The younger individuals probably need help with the impact of the diagnosis on the whole family and arranging employment and financial issues. In addition, they might have different interests, are more physically fit and sexually active ${ }^{27}$. Furthermore, one of the most pressing issues in YOD, is the difficult diagnostic period ${ }^{28}$. Establishing a diagnosis can take a long time ${ }^{29}$ and this delay causes difficulties and a lot of frustration within the families. They are unable to understand what is happening and consequently postpone arranging appropriate care ${ }^{29}$. Additionally they express negative experiences during the referral trajectory with professional health care as there are too many indistinct pathways to care and not enough information and practical help available ${ }^{30}$. It remains unclear to what extent their needs are met within the available services and access to care.

\section{Aim of the thesis}

The general aim of this thesis is to investigate the specific needs in care and guidance for people with YOD and their caregivers, and to explore the impact of YOD on informal caregivers and other family members during the different stages of the disease.

The following research questions were addressed:

1. What is known from previous research about the needs of people with YOD and their informal caregivers with regard to available services and access to care? (chapter 2)

2. What are the perspectives of caregivers with high and low unmet needs on the impact of YOD? (chapter 3)

3. What are the experiences and needs of children living with a parent with young onset dementia? (chapter 4)

4. What is the psychosocial impact of YOD on caregivers and is this different compared to LOD? (chapter 5)

5. What are determinants of QOL in people with YOD? (chapter 6) 


\section{Outline of the thesis}

In chapter 2, existing literature is reviewed to get more insight into the care needs and experiences with the use of services of people with young onset dementia and their caregivers.

In chapter 3 and $\mathbf{4}$ needs and experiences with care are further explored by means of interviews with both spousal caregivers, as well as children living at home.

In chapter 5 YOD and LOD caregivers were compared with regard to several measurements related to well-being.

In chapter 6 determinants of QOL were identified in people with YOD, and assessed whether there were differences in specific domains for people with FTD and AD.

In chapter 7 the main findings are discussed together with methodological considerations. In addition, implications for people with YOD, their caregivers and healthcare professionals are addressed, as well as recommendations for future research.

Data was mainly used from the Needs in young onset dementia (NeedYD) study ${ }^{31}$. This is a longitudinal study including both people with YOD and their caregivers with measurements every six months for the first two years, and follow up measurements after three, four and six years. For the comparison between YOD and LOD caregivers in chapter 5, data from a historical cohort of people with LOD was added, the MAAstricht Study of BEhaviour in Dementia (MAASBED) ${ }^{32}$. Chapter 2 and 3 are part of the Research to Assess Policies and Strategies for Dementia in the Young (RHAPSODY) project ${ }^{33}$. The findings described in these chapters will provide the basis for the development of an e-health intervention to assist caregivers in coping with YOD. For chapter 6 we used data from both the NeedYD and the Nordic YOD study ${ }^{34}$. 


\section{References}

1 World Health organization. (2012). Dementia: a public health priority. WHO

2 Launer, L., Andersen, K., Dewey, M. et al. (1999). Rates and risk factors for dementia and Alzheimer's disease results from EURODEM pooled analyses. Neurology, 52(1), 78-78.

$3 \quad$ Koopmans, R. \& Rosness, T. (2014). Young onset dementia-what does the name imply? International Psychogeriatrics, 26(12), 1931-1933.

Lambert, M., Bickel, H., Prince, M. et al. (2014). Estimating the burden of early onset dementia; systematic review of disease prevalence. European journal of neurology, 21(4), 563-569.

Koopmans, R. T., van der Steen, J. T., Zuidema, S. U. \& Hobbelen, J. S. M. (2009). De richtlijn Dementie 1.0. Retrieved from: [http://www.netwerkpalliatievezorg.nl/Portals/22/22nov2012/ Landelijke\%20richtlijn\%20 Dementie.pdf]

Alzheimer's Disease International. (2015). World Alzheimer Report. The global impact of dementia. An analysis of prevalence, incidence, cost and trends. Alzheimer's disease International: London.

Rossor, M., Fox, N., Mummery, C., Schott, J. \& Warren, J. (2010). The diagnosis of young-onset dementia. The Lancet Neurology, 9(8), 793-806.

Vieira, R. T., Caixeta, L., Machado, S. et al. (2013). Epidemiology of early-onset dementia: a review of the literature. Clinical Practice \& Epidemiology in Mental Health, 9(1).

Werner, P., Stein-Shvachman, I. \& Korczyn, A. D. (2009). Early onset dementia: clinical and social aspects. International Psychogeriatrics, 21(4), 631-636.

10 Sperlinger, D. \& Furst, M. (1994). The service experiences of people with presenile dementia: a study of caregivers in one London borough. International Journal of Geriatric Psychiatry, 9(1), 47-50. Harris, P. B. \& Keady, J. (2009). Selfhood in younger onset dementia: transitions and testimonies. Aging and Mental Health, 13(3), 437-444.

12 Teng, E., Tassniyom, K. \& Lu, P. H. (2012). Reduced quality-of-life ratings in mild cognitive impairment: analyses of subject and informant responses. The American Journal of Geriatric Psychiatry, 20(12), 1016-1025.

13 van Vliet, D., de Vugt, M. E., Bakker, C., Koopmans, R. T. \& Verhey, F. R. (2010). Impact of early onset dementia on caregivers: a review. Internatioal Journal of Geriatric Psychiatry, 25(11), 1091-1100. Beattie, A., Daker-White, G., Gilliard, J. \& Means, R. (2004). 'How can they tell?'A qualitative study of the views of younger people about their dementia and dementia care services. Health $\&$ social care in the community, 12(4), 359-368.

15 Huber, M., Knottnerus, J. A., Green, L. et al. (2011). How should we define health? British Medical Journal, 343.

Bakker, C., de Vugt, M. E., van Vliet, D. et al. (2013). The use of formal and informal care in early onset dementia: results from the NeedYD study. American journal of geriatric psychiatry, 21(1), 37-45. Bakker, C., de Vugt, M. E., Vernooij-Dassen, M. et al. (2010). Needs in early onset dementia: a qualitative case from the NeedYD study. American journal of Alzheimer's disease and other dementias, 25(8), 634-640. in young-versus late-onset dementia: results from the Needs in Young Onset Dementia (NeedYD) study. Journal of the American Medical Directors Association, 14(4), 248-253. Adelman, R. D., Tmanova, L. L., Delgado, D., Dion, S. \& Lachs, M. S. (2014). Caregiver burden: a clinical review. Jama, 311(10), 1052-1060. 
de Vugt, M. E. \& Verhey, F. R. (2013). The impact of early dementia diagnosis and intervention on informal caregivers. Progress in neurobiology, 110, 54-62.

21 Baumgarten, M., Battista, R. N., Infante-Rivard, C. et al. (1992). The psychological and physical health of family members caring for an elderly person with dementia. Journal of clinical epidemiology, 45(1), 61-70.

22 Zarit, S. H., Reever, K. E. \& Bach-Peterson, J. (1980). Relatives of the impaired elderly: correlates of feelings of burden. The gerontologist, 20(6), 649-655.

23 Verhey, F., De Vugt, M., Aalten, P. et al. (2007). Caregiver outcomes in disease modifying trials. Journal Of Nutrition Health And Aging, 11(4), 342.

24 Svanberg, E., Stott, J. \& Spector, A. (2010). 'Just helping': Children living with a parent with young onset dementia. Aging \& mental health, 14(6), 740-751.

25 Gelman, C. R. \& Greer, C. (2011). Young children in early-onset Alzheimer's disease families: research gaps and emerging service needs. American Journal of Alzheimers Disease and Other Dementias, 26(1), 29-35. Chemali, Z., Schamber, S., Tarbi, E., Acar, D. \& Avila-Urizar, M. (2011). Diagnosing early onset dementia and then what? A frustrating system of aftercare resources. International journal of general medicine, 5, 81-86.

27 Chaston, D. (2011). Between a rock and a hard place: exploring the service needs of younger people with dementia. Contemporary nurse, 39(2), 130-139.

28 Koopmans, R. T. \& Thompson, D. (2013). Services for people with young onset dementia. Designing and Delivering Dementia Services, 33-45. Van Vliet, D., de Vugt, M., Bakker, C. et al. (2013). Time to diagnosis in young-onset dementia as compared with late-onset dementia. Psychological medicine, 43(02), 423-432. Williams, T., Cameron, I. \& Dearden, T. (2001). From pillar to post-a study of younger people with dementia. Psychiatric Bulletin, 25(10), 384-387. van Vliet, D., Bakker, C., Koopmans, R. T. et al. (2010). Research protocol of the NeedYD-study (Needs in Young onset Dementia): a prospective cohort study on the needs and course of early onset dementia. BMC Geriatrics, 10, 13. de Vugt, M. E., Jolles, J., van Osch, L. et al. (2006). Cognitive functioning in spousal caregivers of dementia patients: findings from the prospective MAASBED study. Age and Ageing, 35(2), 160-166. Kurz, A., Bakker, C., Böhm, M. et al. (2016). RHAPSODY-Internet-Based Support For Caregivers of People with Young Onset Dementia: Program Design and Methods of a Pilot Study. International Psychogeriatrics, [epub ahead of print].

34 Hvidsten, L., Engedal, K., Selbaek, G. et al. (2015). Young Onset Dementia study? A Prospective Cohort Study of Quality of Life and Specific Needs in Persons with Young Onset Dementia and their Families. Journal of Clinical Trials, 5(1). 


\section{Chapter}

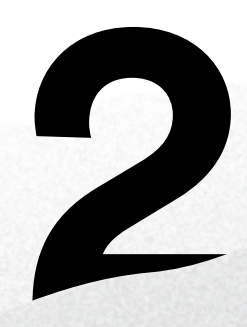

The care needs and experiences with the use of services of people with young onset dementia and their caregivers: a systematic review.

Joany K. Millenaar

Christian Bakker

Raymond T.C.M. Koopmans

Frans R.J. Verhey

Alexander Kurz

Marjolein E. de Vugt 


\section{Abstract}

Objective: In this review the care needs and experiences with the use of available services of individuals with young onset dementia (YOD) and their caregivers were investigated. This knowledge is an important prerequisite for the development of appropriate interventions and personalised care to address their specific needs and problems. Design: A systematic literature search was performed in PubMed, Psycinfo and Cinahl. A quality checklist for observational and qualitative studies was used to appraise the methodological quality of the studies.

Results: Twenty-seven studies were included and a synthesis of the literature revealed six themes. The first theme concerned problems in the diagnostic period. Early recognition and referral was reported as an essential area which required improvement in order to obtain appropriate help in time. The second theme discussed the need for information about YOD and the availability of care throughout the caregiving trajectory. The third theme described barriers in access to care that hindered caregivers in finding the right services. The fourth theme showed the availability of appropriate services and specific unmet needs. The fifth theme illustrated that behavioural and personality changes pose a significant challenge for caregivers and other family members. The last theme showed the profound impact of YOD on caregivers.

Conclusions: The literature indicates that people with YOD and their caregivers face a wide range of difficulties during the disease process. The reviewed studies provide an important foundation for knowledge and awareness about the specific care needs and experiences of people with YOD and their caregivers. 


\section{Introduction}

Dementia does not only affect the elderly. When the onset of the dementia is before the age of 65, the term young onset dementia (YOD) is used, however there is no consensus on this terminology $y^{1}$. In reports the estimations of the proportion of people with YOD varies from $5-9 \%^{2,3}$. The early dementia symptoms occurring at a younger age are often missed due to the lower prevalence of dementia in younger people and large variability in etiologies ${ }^{4}$. YOD may present differently than late onset dementia (LOD) with more non-cognitive neurological features ${ }^{5}$. Compared to LOD, establishing a diagnosis can take a longer time ${ }^{6}$ often leading to frustration for both the person with YOD and their caregivers ${ }^{7}$. Moreover, families of persons with YOD often have negative experiences with professional health care during the referral trajectory, as they feel there too many indistinct pathways to care ${ }^{8}$, or that they are not taken seriously and neglected by their general practitioner $(\mathrm{GP})^{6}$.

After the diagnosis is established, counselling and support for both the person with YOD as well as their caregivers is important as they seem to experience specific problems related to their active phase in life ${ }^{9}$. The functional and cognitive decline adversely affects their daily roles and responsibilities. Dementia symptoms often lead to quitting work early with the accompanying financial consequences ${ }^{10}$, changing social roles ${ }^{9}$ and have an adverse impact on family relationships ${ }^{11}$. Furthermore, YOD caregivers often experience high levels of burden?.

Services for dementia in general are often specifically designed for the elderly and might have difficulties in addressing the needs of younger individuals ${ }^{12,13}$. It is unclear to what extent the needs of people with YOD and their informal caregivers are met, and if they are satisfied with the available services and access to care. This information is an important prerequisite for the development of appropriate interventions and personalised care that addresses their specific needs.

With this literature review we systematically investigate: (1) care needs of both people with YOD and their informal caregivers; (2) experiences with access to service and care; and (3) experiences with the use of these services. The review was carried out as part of the Research to Assess Policies and Strategies for Dementia in the Young (RHAPSODY) project. The findings of this literature review will be used to develop an internet-based, interactive, skill-building intervention to assist caregivers in coping with YOD. 


\section{Methods}

\section{Literature search}

The review complies with the PRISMA statement for systematic reviews ${ }^{14}$. The literature selection included a search of the following electronic databases until November 2015: PubMed, Psychinfo and CINAHL (table 1). The titles and abstracts of all studies were assessed by one reviewer (JM) and excluded if they did not meet the following inclusion criteria: Individuals with dementia onset before the age of 65 or their informal caregivers; focus on care needs or experiences with services; availability of the full text article in English, Dutch, French or German. Articles that focused solely on people with Huntington's disease, or on dementia after acquired brain damage, HIV, alcohol abuse, or Down's syndrome were excluded. Two reviewers (JM and CB) assessed the remaining full text articles for eligibility. Additional papers were retrieved through a search of the references in the reviewed papers and by conducting a survey among YOD experts involved in the RHAPSODY project.

Table 1 Search strategy

\begin{tabular}{ll}
\hline Search terms \\
\hline 1 & Dementia OR Alzheimer OR Frontotemporal (title or abstract) \\
2 & Young onset OR early onset OR presenile OR under 65 (title or abstract) \\
3 & $\begin{array}{l}\text { Patient* OR caregiver* OR caregiver* OR child* OR family OR families OR } \\
\text { relative* OR spouse* OR son* OR daughter* (title or abstract) }^{*} \text { OR }\end{array}$ \\
4 & $\begin{array}{l}\text { support OR services OR care OR facilities (title or abstract) } \\
5\end{array}$ \\
6 & experiences OR satisfaction OR needs OR problems OR access (title or abstract) \\
\hline 1 AND \#2 AND \#3 AND \#4 AND \#5
\end{tabular}

\section{Quality assessment}

To appraise the methodological quality of the included studies a quality checklist for observational studies with twenty-three criteria ${ }^{15}$ and a quality checklist for qualitative studies with twelve criteria ${ }^{16}$ was used. If the criterion was met it was rated with a + , unmet was rated with a - and when the criterion was not completely met it was rated with +/-. If the criterion was not applicable it did not receive a rating. The quality of the included studies was first assessed by one rater (JM). A second rater (CB) independently assessed a random sample of three qualitative and three quantitative articles. Both raters reached full agreement on the methodological quality.

\section{Data extraction}

In addition to their methodological quality all included studies were examined for their characteristics and main outcomes of interest with a standardised data extraction 
form ${ }^{17}$. With the use of this data extraction form a narrative synthesis was carried out by identifying key issues of each study ${ }^{18}$. By using these key issues all study outcomes could be clustered, resulting in several themes to describe the results.

\section{Results}

\section{Study characteristics}

The search resulted in a total of 187 hits, after duplicates were removed. Figure 1 shows a flowchart of the selection process. After assessment of the titles and abstracts, 155 papers were rejected because they did not meet the inclusion criteria. Two reviewers assessed the remaining 28 full text articles for eligibility and reached full agreement. Three articles were excluded. Cross-referencing the reference list of the remaining articles and consulting with YOD experts resulted in four additional articles. After careful consideration only 2 of them fitted the inclusion criteria, resulting in the inclusion of 27 papers. A variety of designs was used, twelve papers used a qualitative approach (one case study and eleven cross-sectional studies); ten papers used a quantitative approach (nine cross-sectional and one longitudinal study) and five papers used both quantitative and qualitative measures in a cross-sectional design. Only one paper included LOD caregivers as well ${ }^{19}$. Eight of the reviewed articles included the person with YOD themselves. The included studies differed on methods, participants and sample sizes, which made pooling of the data impossible. A summary of the extracted data is presented in table 2 .

\section{Methodological aspects}

As shown in table 3 and 4 , the quality rating of the included studies varied. The lower quality rating of some studies was mainly due to the limited description of the sample, methods or results. For the observational studies the total score on the quality checklist ranged from 8 to 18 out of 23 (table 3). Some methodological concerns need to be raised. Participants in several studies were not representative of the population. The articles often included only patients with specific diagnoses such as Alzheimer's disease (AD) or frontotemporal dementia (FTD) or only rare cases, people who did not receive a diagnosis yet or were under consideration for a diagnosis. It was often unclear how the diagnosis was established. Several studies relied on self-report to obtain diagnostic information. The in- and exclusion criteria were not always specified and not every paper explicitly described participant characteristics (e.g. diagnosis, age), making it difficult to evaluate the quality of the sample. Samples were generally small and because participants were recruited through services, people with YOD who do not use, or have no access to specialist facilities were excluded. Some studies included participants who identified themselves as being keen to participate for research purposes creating a bias. 
For the qualitative studies the total score on the checklist ranged from 4 to 11,5 out of 12 (table 4). Most studies scored high except for three ${ }^{7,820}$. These lower quality ratings were mainly caused by the limited description of the sample or the sampling method and the research process which made it difficult to assess their studies properly.
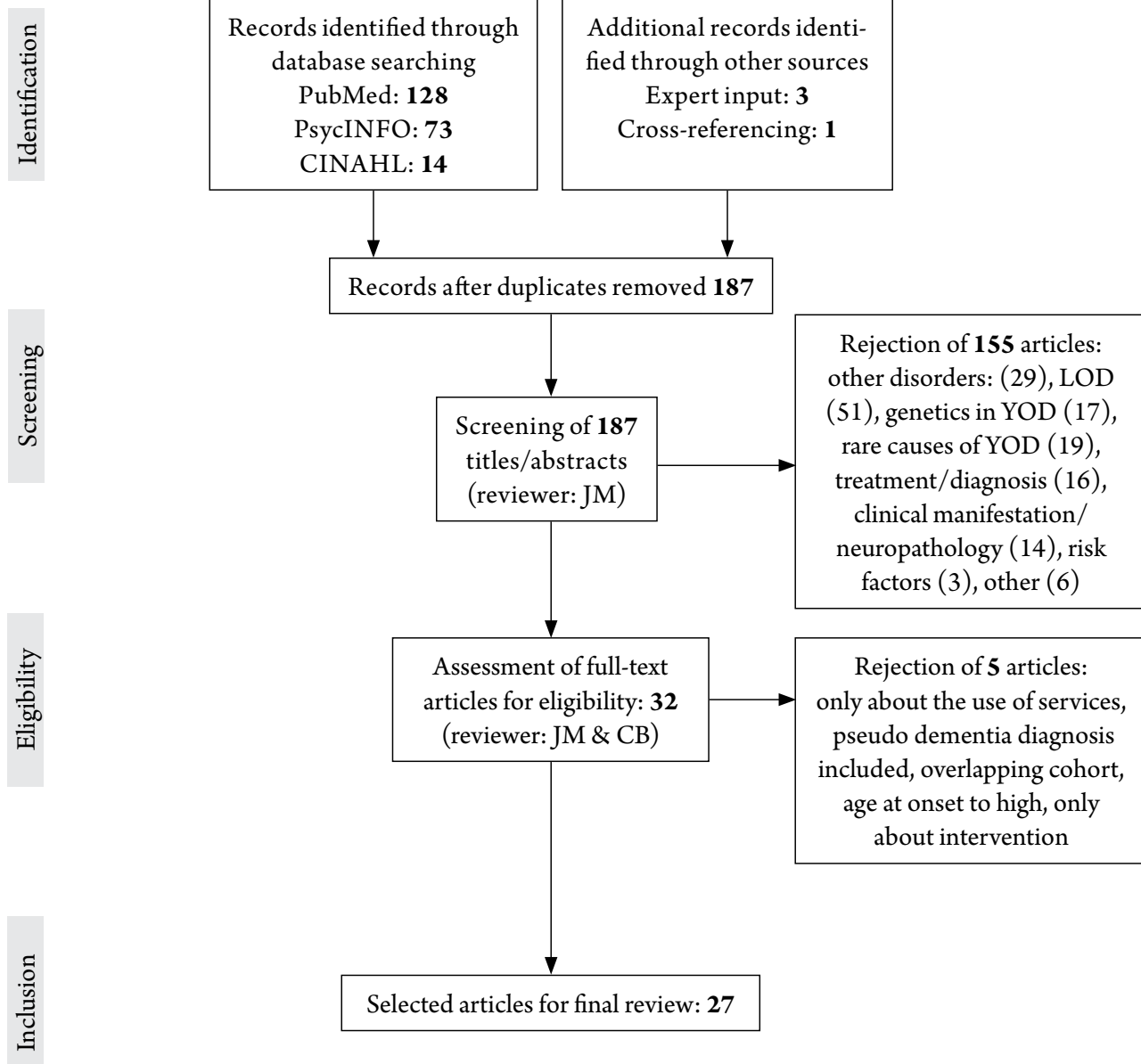

Selected articles for final review: $\mathbf{2 7}$ 
Table 2. Main characteristics of the included studies

\begin{tabular}{|c|c|c|c|c|c|c|}
\hline Author/year & Design & Study Population & Diagnosis PwYOD & Care Setting & Measures & Outcomes of interest \\
\hline $\begin{array}{l}\text { Allen et al. } \\
(2009)\end{array}$ & $\begin{array}{l}\text { Qualitative, } \\
\text { cross-sectional }\end{array}$ & $\begin{array}{l}\text { Children of pwYOD (12): age: } 19 \\
\text { years (13-24), gender: } 7 \text { female, } 5 \\
\text { male. }\end{array}$ & $\begin{array}{l}\text { AD } 4 \\
\text { FTD } 2 \\
\text { Mixed AD/FTD } 3 \\
\text { VD } 3\end{array}$ & $\begin{array}{l}\text { Home } 10 \\
\text { Residential } 2\end{array}$ & Interview & $\begin{array}{l}5 \text { themes: damage of dementia, } \\
\text { changing relationships, caring, strain } \\
\text { and coping. Overarching theme: one } \\
\text { day at a time. }\end{array}$ \\
\hline $\begin{array}{l}\text { Arai et al. } \\
(2007)\end{array}$ & $\begin{array}{l}\text { Quantitative, } \\
\text { cross-sectional, } \\
\text { comparative }\end{array}$ & $\begin{array}{l}\text { YOD CGs (14): age: } 60.5 \text { years } \\
\text { (59-63), gender: } 7 \text { female, } 7 \text { male, } \\
\text { relationship: } 13 \text { spouses, } 1 \text { other. } \\
\text { LOD CGs ( } 54) \text { : age: } 70 \text { years ( } 63- \\
74) \text {, gender: } 44 \text { female, } 10 \text { male, } \\
\text { relationship: } 39 \text { spouses, } 7 \text { children, } \\
8 \text { other. }\end{array}$ & $\begin{array}{l}\text { AD } 10 \\
\text { FTD } 3 \\
\text { VD } 1\end{array}$ & Home & $\begin{array}{l}\text { Subscales GHQ } \\
\text { TBS } \\
\text { J-ZBI }\end{array}$ & $\begin{array}{l}\text { Perceived difficulties caused by NPS } \\
\text { greater in YOD group (trend not } \\
\text { significant; trend significant when OR } \\
\text { adjusted for age, NPI, CDR). ORs } \\
\text { showed no significant differences } \\
\text { between the groups in any of the CG } \\
\text { variables. }\end{array}$ \\
\hline
\end{tabular}

\section{Armari et al.}

(2013)
Quantitative,

cross-sectional
YOD CGs (39): age: 53.13 years, gender: 24 female, 15 male, relationship with PwD: 20 spouse, 8 child, 7 sibling, 4 other pwYOD (18): age: 59.13 years, gender: 10 female, 8 male

\section{$\mathrm{AD} 14$}

FTD 3

No diagnosis 1
Home 17

NS 1

Self-developed Early recognition and referral princiquestionnaire

ple areas of improvement (patients 94.4\%; caregivers 69.2\%; $\mathrm{P}<.0002$ ). PwYOD: diagnosis area of most need (88.9\%) CGs rated treatment (69.2\%) as principle concern.

PwYOD: high levels of unmet needs in daytime activities, social company, intimate relationships, and information. Higher levels of unmet needs related to higher levels of NPS over time

\begin{tabular}{|c|c|c|c|c|c|c|}
\hline $\begin{array}{l}\text { Bakker et al. } \\
(2014 a)\end{array}$ & $\begin{array}{l}\text { Quantitative, } \\
\text { longitudinal }\end{array}$ & $\begin{array}{l}\text { YOD CGs (209): age: } 58.4 \text { years } \\
\text { (20-78), gender: } 125 \text { female, } 84 \text { male, } \\
\text { relationship with PwD: } 191 \text { spouse, } \\
13 \text { child, } 5 \text { other. } \\
\text { pwYOD (209): age: } 61.1(43-74) \text {, } \\
\text { gender: } 95 \text { female, } 114 \text { male }\end{array}$ & $\begin{array}{l}\text { AD } 119 \\
\text { FTD } 41 \\
\text { VD } 24 \\
\text { Mixed } 8 \\
\text { Other } 17\end{array}$ & $\begin{array}{l}\text { Home } 209 \\
\text { Institutionalized } \\
\text { during FU } 71\end{array}$ & $\begin{array}{l}\text { NPI } \\
\text { CANE }\end{array}$ & $\begin{array}{l}\text { PwYOD: high levels of unmet needs } \\
\text { in daytime activities, social company, } \\
\text { intimate relationships, and informa- } \\
\text { tion. Higher levels of unmet needs } \\
\text { related to higher levels of NPS over } \\
\text { time }\end{array}$ \\
\hline
\end{tabular}


Table 2. Main characteristics of the included studies (continued)

\begin{tabular}{lllllll}
\hline Author/year & Design & Study Population & Diagnosis PwYOD & Care Setting & Measures & Outcomes of interest \\
\hline Bakker et al. & Quantitative, & YOD CGs (209) age: 58.4 years & AD 119 & Home 209 & CANE & Unmet needs related to CG HRQL: \\
(2014b) & cross-sectional & (20-78), gender: 125 female, 84 male, & FTD 41 & Institutionalized & RAND-36 & cg less vital and lower levels of general \\
& & relationship with PwD: 191 spouse, & VD 24 & during FU 71 & health, more difficulties in performing \\
& & 13 child, 5 other. & Mixed 8 & daily tasks due to physical problems \\
& & pwYOD (209): age: 61.1 years & Other 17 & & and higher levels of pain.
\end{tabular}

(43-74), gender: 95 female, 114 male

\begin{tabular}{|c|c|c|c|c|c|c|}
\hline $\begin{array}{l}\text { Bakker et al. } \\
(2010)\end{array}$ & $\begin{array}{l}\text { Qualitative, case- } \\
\text { study }\end{array}$ & $\begin{array}{l}\text { YOD CG (1): age: } 55 \text { years, gender: } \\
\text { female, relationship with PwYOD: } \\
\text { spouse }\end{array}$ & $\mathrm{AD} 1$ & Home & $\begin{array}{l}\text { Semi-structured } \\
\text { interview }\end{array}$ & $\begin{array}{l}\text { Themes: prolonged time to diagnosis, } \\
\text { lack of fit between needs and services, } \\
\text { strain of dedication to care and CG's } \\
\text { future perspective, need for responsive } \\
\text { services to changing preferences. }\end{array}$ \\
\hline
\end{tabular}

\begin{tabular}{|c|c|c|c|c|c|c|}
\hline $\begin{array}{l}\text { Barca } \\
(2014)\end{array}$ & $\begin{array}{l}\text { Qualitative, } \\
\text { cross-sectional }\end{array}$ & $\begin{array}{l}\text { Children of pwYOD (14): age: } 20-37 \\
\text { years, gender: } 12 \text { female, } 2 \text { male. }\end{array}$ & $\begin{array}{l}\text { AD } 6 \\
\text { FTD } 4 \\
\text { Mixed } 1 \\
\text { Other } 3\end{array}$ & $\begin{array}{l}\text { Home } 3 \\
\text { Residential } 11\end{array}$ & $\begin{array}{l}\text { Semi-structured } \\
\text { interview }\end{array}$ & $\begin{array}{l}\text { Stressors during disease process in- } \\
\text { crease family conflicts. Living together } \\
\text { longer increased stress and burden. } \\
\text { Need for information and support. }\end{array}$ \\
\hline
\end{tabular}

\begin{tabular}{|c|c|c|c|c|c|c|}
\hline $\begin{array}{l}\text { Beattie } \\
(2004)\end{array}$ & $\begin{array}{l}\text { Qualitative, } \\
\text { cross-sectional }\end{array}$ & $\begin{array}{l}\text { pwYOD (14): age: } 59.4 \text { years }(41-66) \text {, } \\
\text { gender: } 5 \text { female, } 9 \text { male }\end{array}$ & NS & $\begin{array}{l}\text { Home } 13 \\
\text { Residential } 1\end{array}$ & $\begin{array}{l}\text { Semi-structured } \\
\text { interview }\end{array}$ & $\begin{array}{l}\text { Themes: The experience of dementia, } \\
\text { diagnosis, the importance of age, risk } \\
\text { and danger issues }\end{array}$ \\
\hline $\begin{array}{l}\text { Chow et al. } \\
\text { (2011) }\end{array}$ & $\begin{array}{l}\text { Quantitative, } \\
\text { cross-sectional }\end{array}$ & $\begin{array}{l}\text { YOD CGs (79): age: } 58 \text { years ( } 28- \\
78) \text {, gender: } 37 \text { female, } 26 \text { male, } 16 \\
\text { NS, relationship with PwD: NS }\end{array}$ & $\begin{array}{l}\text { FTD } 22 \\
\text { Other } 75 \\
\text { No diagnosis } 14\end{array}$ & NS & $\begin{array}{l}\text { Self-completed } \\
\text { online survey }\end{array}$ & $\begin{array}{l}\text { Troubles of caregiving: diagnostic } \\
\text { issues, feeling inadequate, pwYOD } \\
\text { persistent to drive, separation anxiety, } \\
\text { ineligibility for day program, financial } \\
\text { difficulties. }\end{array}$ \\
\hline
\end{tabular}


Table 2. Main characteristics of the included studies (continued)

\begin{tabular}{|c|c|c|c|c|c|c|}
\hline Author/year & Design & Study Population & Diagnosis PwYOD & Care Setting & Measures & Outcomes of interest \\
\hline Delaney \& & Mixed & YOD CGs (27): age: 60.7 years & $\mathrm{AD} 18$ & Home 19 & IRSS & High degrees of stress in CGs. Caring \\
\hline Rosenvinge & methodology, & (54-64), gender: 14 female, 13 male, & MID 9 & Residential 6 & GHQ & impact on employment in nine CGs. \\
\hline$(1995)$ & cross-sectional & relationship with $\mathrm{PwD}: 21$ spouse, 3 & & Other 2 & Semi-structured & Identified needs: more counseling \\
\hline & & child, 3 NS. & & & interview & $\begin{array}{l}\text { and advise, specific provision for } \\
\text { physically active PwYOD (more age } \\
\text { appropriate). }\end{array}$ \\
\hline
\end{tabular}

\begin{tabular}{|c|c|c|c|c|c|c|}
\hline $\begin{array}{l}\text { Ducharme et al. } \\
\text { (2013) }\end{array}$ & $\begin{array}{l}\text { Qualitative, } \\
\text { cross-sectional }\end{array}$ & $\begin{array}{l}\text { YOD CGs (12) age: } 55 \text { years, gender: } \\
8 \text { female, } 4 \text { male, relationship with } \\
\text { PwD: } 12 \text { spouse. }\end{array}$ & $\begin{array}{l}\text { AD } 9 \\
\text { Pick's disease } 1 \\
\text { Mixed } 2\end{array}$ & NS & $\begin{array}{l}\text { Semi-structured } \\
\text { interview } \\
\text { FCSA }\end{array}$ & $\begin{array}{l}\text { Themes: difficulty managing NPS, } \\
\text { diagnostic issues, denial, grief for loss, } \\
\text { difficulty juggling CG role and daily } \\
\text { life responsibilities, difficulty planning } \\
\text { for future. }\end{array}$ \\
\hline
\end{tabular}

\section{Ducharme et al.}

(2014)

\section{Mixed}

methodology,

cross-sectional

YOD CGs (32): age: 54.28 years,

gender: 24 female, 8 male, relationship

with PwD: 25 spouse, 5 child, 2 other.
AD 19

FTD 8

Other 5
NS
Semi-structured 16 of the 30 needs (from FCSA) interview unmet in $>50 \%$ of the CGs. Most

prominent needs: Need for assistance, need to make life better for PwYOD, need to reduce $\mathrm{CG}$ stress.

Study 1

Home 23

FTD 6

Other 3

$\mathrm{AD} 11$

FTD 2

years, gender: 9 female, 6 male, rela-

tionship with PwD: 12 spouse, 3 child
Study 2

Home 8

Residential 4

Deceased 3
Study 1 Themes: difficulties in obtaining a

Semi structured diagnosis; issues of self-hood and

interviews

self-esteem; changing relations; awareness of changes in self; work/

Study 2

Focus groups financial issues; feelings of social isolation, "off-time" dependency, lack of meaningful occupation. 
Table 2. Main characteristics of the included studies (continued)

\begin{tabular}{lllllll}
\hline Author/year & Design & Study Population & Diagnosis PwYOD & Care Setting & Measures & Outcomes of interest \\
\hline Johannessen \& & Qualitative, & PwYOD (20): age: 62 years (54-67), & NS & Home & Semi-structured Themes: diagnostic process; fighting \\
Möller (2011) & cross-sectional & gender: 8 female, 12 male & & & interview & for dignity. Needs not met properly by \\
& & & & & health personnel and others.
\end{tabular}

\begin{tabular}{|c|c|c|c|c|c|c|}
\hline $\begin{array}{l}\text { Lockeridge \& } \\
\text { Simpson (2013) }\end{array}$ & $\begin{array}{l}\text { Qualitative, } \\
\text { cross-sectional }\end{array}$ & $\begin{array}{l}\text { YOD CGs (6): age: } 52-70 \text { years, } \\
\text { gender: } 3 \text { female, } 3 \text { male, relationship } \\
\text { with PwD: } 4 \text { spouse, } 2 \text { widow }\end{array}$ & NS & $\begin{array}{l}\text { Home } 4 \\
\text { Deceased } 2\end{array}$ & $\begin{array}{l}\text { Semi-structured } \\
\text { interview }\end{array}$ & $\begin{array}{l}\text { Themes: denial as a coping strategy; } \\
\text { stigma in young onset dementia; } \\
\text { struggling to maintain control of events } \\
\text { and emotions; CGs' adaptation to loss. }\end{array}$ \\
\hline
\end{tabular}

Luscombe et al. Quantitative, YOD CGs (102): age: 51.7 years, gen-

(1998)

cross-sectional

der: 77 female, 25 male, relationship

$\mathrm{AD}$

HD

NS

with PwD: 69 spouses, 12 children, 13 OD

parents, 8 other.
Self-completed Caregivers reported diagnostic

survey problems (71\%), frustration $(81 \%)$, grief (73\%), work problems (59\%) financial problems (89\%). Adverse psychological effects higher in female and younger caregivers.

Home

AD 5 Home

FTD 4

VD 1

NOS 1 years (15-27), gender: 8 female, 6 male.

\section{NS}

59 female, 50 male, relationship with PwD: 88 spouses, 18 children, 3 siblings.

PwYOD (109) age: 64.1 years (51-

71), gender: 61 female, 48 male

$\begin{array}{lll}\text { Newens et al. } & \text { Quantitative, } & \text { YOD CGs (102): age: NS, gender: } \\ \text { (1995) } & \text { cross-sectional } & 59 \text { female, } 50 \text { male, relationship } \\ & & \text { with PwD: } 88 \text { spouses, } 18 \text { children, } \\ & \text { siblings. } \\ & \text { PwYOD (109) age: } 64.1 \text { years (51- } \\ & 71) \text {, gender: } 61 \text { female, } 48 \text { male }\end{array}$

\begin{tabular}{|c|c|c|}
\hline $\begin{array}{l}\text { Home } 54 \\
\text { Residential } 23\end{array}$ & $\begin{array}{l}\text { Structured } \\
\text { questionnaire }\end{array}$ & $\begin{array}{l}21 \% \text { of PwYOD: more advanced age } \\
\text { of other participants distressing at day- }\end{array}$ \\
\hline Long term hospi- & $\mathrm{ADL}$ & care. $31 \%$ no offer of respite care. $12 \%$ \\
\hline tal care 32 & BDS & support from community nurses. $12 \%$ \\
\hline
\end{tabular}

Semi-structured Themes: impact of dementia on daily interview life, coping with the disease, need for care and support. 
Table 2. Main characteristics of the included studies (continued)

\begin{tabular}{|c|c|c|c|c|c|c|}
\hline Author/year & Design & Study Population & Diagnosis PwYOD & Care Setting & Measures & Outcomes of interest \\
\hline $\begin{array}{l}\text { Nichols et al. } \\
(2013)\end{array}$ & $\begin{array}{l}\text { Qualitative, } \\
\text { cross-sectional }\end{array}$ & $\begin{array}{l}\text { YOD CGs (14) age: } 14.3 \text { years ( } 11- \\
\text { 18), gender: } 10 \text { female, } 4 \text { male, rela- } \\
\text { tionship: } 10 \text { children, } 2 \text { stepchildren, } 2 \\
\text { grandchildren. }\end{array}$ & FTD & NS & Focus groups & $\begin{array}{l}\text { Themes: emotional impact, } \\
\text { caregiving, coping, symptoms, diag- } \\
\text { nosis, relationships, support. Request } \\
\text { for assistance in overcoming stigma. }\end{array}$ \\
\hline $\begin{array}{l}\text { Riedijk et al. } \\
\text { (2009) }\end{array}$ & $\begin{array}{l}\text { Quantitative, } \\
\text { cross-sectional }\end{array}$ & $\begin{array}{l}\text { YOD CGs ( } 46) \text { age: } 59.1 \text { ( } 32-79) \text {, } \\
\text { gender: } 26 \text { female, } 20 \text { male, relation- } \\
\text { ship: } 36 \text { spouses, } 8 \text { children, } 2 \text { other. } \\
\text { PwYOD ( } 46) \text { : age: } 61.4 \text { years ( } 43- \\
76 \text { ), gender: } 28 \text { female, } 18 \text { male }\end{array}$ & FTD & $\begin{array}{l}\text { Home } 8 \\
\text { Nursing home } 24 \\
\text { Deceased } 13 \\
\text { Unknown } 1\end{array}$ & $\begin{array}{l}\text { SCQ } \\
\text { NPI } \\
\text { SCL-90 } \\
\text { SF-36 }\end{array}$ & $\begin{array}{l}\text { Few negative emotions towards } \\
\text { PwYOD. CG conscious of heavy } \\
\text { responsibility of caring. Sacrificing } \\
\text { personal life associated with more } \\
\text { psychological complaints and a worse } \\
\text { QoL. }\end{array}$ \\
\hline
\end{tabular}

$\begin{array}{lll}\begin{array}{l}\text { Roach \& Drum- } \\ \text { mond (2014) }\end{array} & \begin{array}{l}\text { Qualitative, } \\ \text { cross-sectional }\end{array} & \text { YOD familymembers (11): age: } 22-68 \\ & & \text { years, gender: } 11 \text { female, relationship: } \\ & 9 \text { spouses, } 2 \text { children. } \\ & & \text { PwYOD }(9): \text { age: } 58-68 \text { years, gender: } \\ & 9 \text { male }\end{array}$

AD 7

Mixed 1

PCA 1

PCA

9 male

\begin{tabular}{|c|c|c|c|c|c|c|}
\hline $\begin{array}{l}\text { Rosness et al. } \\
(2012)\end{array}$ & $\begin{array}{l}\text { Quantitative, } \\
\text { cross-sectional }\end{array}$ & $\begin{array}{l}\text { YOD CGs (45): age: } 59.1 \text { (32-79), } \\
\text { gender: } 31 \text { female, } 14 \text { male, rela- } \\
\text { tionship with PwD: } 36 \text { spouses, } 8 \\
\text { children, } 2 \text { other. }\end{array}$ & $\begin{array}{l}\text { AD } 27 \\
\text { FTD } 10 \\
\text { VD } 3 \\
\text { Other } 5\end{array}$ & NS & $\begin{array}{l}\text { Care-EOD } \\
\text { GHQ-28 }\end{array}$ & $\begin{array}{l}\text { Concerns: not receiving help from } \\
\text { beginning }(49 \%) \text {; worrying about } \\
\text { course of illness ( } 68 \%) \text {; being scared } \\
\text { of the pwYOD not recognizing them } \\
(61 \%) \text {; responsibility of arranging } \\
\text { care (58\%); workproblems ( } 59 \%) \text {; } \\
\text { benefit from personal assistants } \\
(63 \%) \text {; need of respite }(56 \%) \text {; no } \\
\text { adequate nursing home }(51 \%) \text {. }\end{array}$ \\
\hline
\end{tabular}

Semi-structured Main theme: Meaningful activity interview

Two subthemes: the traumatic cessation of work, the need for purposeful activity. adequate nursing home (51\%). 
Table 2. Main characteristics of the included studies (continued)

\begin{tabular}{|c|c|c|c|c|c|c|}
\hline Author/year & Design & Study Population & Diagnosis PwYOD & Care Setting & Measures & Outcomes of interest \\
\hline Rosness et al. & Quantitative, & PwYOD (60): age: 59.8 years, gender: & AD: 37 & FTD: Home 13 & Structured & pwFTD more frequently offered stays \\
\hline \multirow{3}{*}{ (2008) } & cross-sectional, & 33 female, 27 male, principal caregiv- & FTD: 23 & Residential 10 & questionnaire & in nursing homes $(\mathrm{p}=.04)$. CG of pw- \\
\hline & comparative & er: 29 spouses, 15 children, 6 other. & & AD: Home 29 & (interview) & FTD less satisfied with information \\
\hline & & & & Residential 8 & & $(\mathrm{p}=.05)$ and counselling $(\mathrm{p}=.05)$. \\
\hline
\end{tabular}

\begin{tabular}{|c|c|c|c|c|c|c|}
\hline $\begin{array}{l}\text { Sperlinger \& } \\
\text { Furst (1994) }\end{array}$ & $\begin{array}{l}\text { Mixed } \\
\text { methodology, } \\
\text { cross-sectional }\end{array}$ & $\begin{array}{l}\text { YOD CGs (15): age: NS, gender: } 7 \text { fe- } \\
\text { male, } 8 \text { male, relationship with PwD: } \\
13 \text { spouses, } 2 \text { children. }\end{array}$ & NS & $\begin{array}{l}\text { Home } 6 \\
\text { Residential } 9\end{array}$ & $\begin{array}{l}\text { Semi-structured } \\
\text { interview } \\
\text { RSS }\end{array}$ & $\begin{array}{l}\text { CG generally satisfied with help. More } \\
\text { support necessary around diagnosis. } \\
\text { Process of admission distressing. High }\end{array}$ \\
\hline
\end{tabular}

\begin{tabular}{|c|c|c|c|c|c|c|}
\hline $\begin{array}{l}\text { van Vliet et al. } \\
\text { (2011) }\end{array}$ & $\begin{array}{l}\text { Qualitative, } \\
\text { cross-sectional }\end{array}$ & $\begin{array}{l}\text { YOD CGs (92): age: } 59.3 \text { years } \\
\text { (25-78), gender: } 48 \text { female, } 44 \text { male, } \\
\text { relationship with PwD: } 88 \text { spouse, } 1 \\
\text { sibling, } 3 \text { child. } \\
\text { PwYOD (92): age: } 60.6 \text { years ( } 43- \\
68 \text { ), gender: } 47 \text { female } 45 \text { male. }\end{array}$ & $\begin{array}{l}\text { AD } 62 \\
\text { FTD } 16 \\
\text { VD/ Mixed } 9 \\
\text { Other } 5\end{array}$ & Home & $\begin{array}{l}\text { Semi-structured } \\
\text { interview }\end{array}$ & $\begin{array}{l}\text { Themes: Cognitive and behavioural } \\
\text { changes, disrupted family life, misat- } \\
\text { tribution, denial and refusal to seek } \\
\text { advice, lack of confirmation from } \\
\text { social context, non-responsiveness of } \\
\text { GP, misdiagnosis. }\end{array}$ \\
\hline
\end{tabular}

\begin{tabular}{|c|c|c|c|c|c|c|}
\hline $\begin{array}{l}\text { Wain et al. } \\
\text { (2009) }\end{array}$ & $\begin{array}{l}\text { Mixed } \\
\text { methodology, } \\
\text { cross-sectional }\end{array}$ & $\begin{array}{l}\text { YO-AD siblings ( } 24) \text { age: } 56.8 \text { years } \\
(37-83) \text { gender: } 15 \text { female, } 9 \text { male }\end{array}$ & $\mathrm{AD} 24$ & NS & $\begin{array}{l}\text { Questionnaires } \\
\text { Semi-structured } \\
\text { interviews }\end{array}$ & $\begin{array}{l}\text { Genetics in }(62.5 \%) \text { perceived risk } \\
\text { factor. } 54 \% \text { changes behavior to } \\
\text { reduce risk. Wide range in perceived } \\
\text { personal risk }(0-100 \%) \text {, higher risk } \\
\text { associated with worry about } \mathrm{AD}(\mathrm{p}<.01) \text {. }\end{array}$ \\
\hline $\begin{array}{l}\text { Williams et al. } \\
\text { (2001) }\end{array}$ & $\begin{array}{l}\text { Mixed method- } \\
\text { ology, cross-sec- } \\
\text { tional }\end{array}$ & $\begin{array}{l}\text { YOD CGs (49) age: NS, gender: NS, } \\
\text { relationship with PwD: NS. } \\
\text { PwYOD (112): age: NS, gender: NS. }\end{array}$ & $\begin{array}{l}\text { AD } 41 \\
\text { VD } 16 \\
\text { Alcohol } 19 \\
\text { Other } 36\end{array}$ & NS & $\begin{array}{l}\text { Postal survey } \\
\text { Semi- structured } \\
\text { interview }\end{array}$ & $\begin{array}{l}4 \text { main gateways for specialist investi- } \\
\text { gation and care and } 38 \text { referral path- } \\
\text { ways. Difficult to access information } \\
\text { and services. }\end{array}$ \\
\hline
\end{tabular}


Table 2. Main characteristics of the included studies (continued)

Notes: Pw, person with;YO,Young onset; EOD, early onset dementia; CG, caregiver; GP, general practitioner; NA, Not applicable; NS, Not stated; AD, Alzheimer's disease;VD,

Vascular dementia; PPA, Primary progressive aphasia; PCA, posterior cortical atrophy; FTD, Frontotemporal dementia; HD, Huntington's disease; OD, other dementias; PD,

Parkinson's disease; MID, multi infarct dementia; NOS, Not otherwise specified; NPS, neuropsychological symptoms; M, Male; F, Female; RSS, Relatives Stress Scale;

ZBI, Zarit Burden Interview; BDI, Becks Depression Inventory; CDR, Clinical Dementia Rating Scale; GHQ, General Health Questionnaire;TBS, Troublesome Behavior

Scale; NPI, Neuropsychiatric Inventory; CANE, Camberwell assessment of Needs; FCSA, Family CGs Support Agreement; SCQ, Sense of Competence Questionnaire ; BDS,

Blessed Dementia Scale; SF-36, Short Form 36, GHQ-28 General Health Questionnaire 28; BDI, HRQoL, health related quality of life; ADL, activities of daily living;

OR, odds ratio. 


\begin{tabular}{|c|c|c|c|c|c|c|c|c|c|c|c|c|}
\hline & \multicolumn{12}{|c|}{ Author (year) } \\
\hline & $\begin{array}{c}\text { Arai } \\
\text { et al. } \\
(2007)\end{array}$ & $\begin{array}{l}\text { Armari } \\
\text { et al. } \\
(2013)\end{array}$ & $\begin{array}{l}\text { Bakker } \\
\text { et al. } \\
(2013)\end{array}$ & $\begin{array}{l}\text { Bakker } \\
\text { et al. } \\
(2014)\end{array}$ & $\begin{array}{l}\text { Chow } \\
\text { et al. } \\
(2011)\end{array}$ & $\begin{array}{c}\text { Delany \& } \\
\text { Rosenvinge } \\
\text { (1995) }\end{array}$ & $\begin{array}{c}\text { Luscombe } \\
\text { et al. } \\
(1998)\end{array}$ & $\begin{array}{c}\text { Newens } \\
\text { et al. } \\
(1995)\end{array}$ & $\begin{array}{l}\text { Riedijk } \\
\text { et al. } \\
(2009)\end{array}$ & $\begin{array}{l}\text { Rosness } \\
\text { et al. } \\
(2012)\end{array}$ & $\begin{array}{l}\text { Rosness } \\
\text { et al. } \\
(2008)\end{array}$ & $\begin{array}{c}\text { Sperlinger } \\
\text { \& Furst } \\
(1994)\end{array}$ \\
\hline $\begin{array}{l}\text { Accurate and appropriate } \\
\text { outcome measures }\end{array}$ & + & $+/-$ & + & + & $+/-$ & + & $+/-$ & $+/-$ & + & + & $+/-$ & + \\
\hline Adjustment for confounding & + & na & + & + & - & - & + & - & + & - & - & - \\
\hline Appropriate case/control & + & na & na & na & na & na & na & na & na & na & na & na \\
\hline Appropriate statistical tests & + & + & + & + & + & - & + & + & + & + & + & na \\
\hline Pt representative of population & - & - & + & + & - & $+/-$ & $+/-$ & $+/-$ & $+/-$ & $+/-$ & $+/-$ & $+/-$ \\
\hline Confounders described & + & na & + & + & + & - & + & + & + & - & - & - \\
\hline Recruitment of case/control & + & na & na & na & na & na & na & na & na & na & na & na \\
\hline Pt characteristics described & + & + & + & + & $+/-$ & + & + & + & + & + & + & $+/-$ \\
\hline $\begin{array}{l}\text { Numerical description of } \\
\text { important outcomes given }\end{array}$ & + & + & + & + & + & + & + & + & + & + & + & + \\
\hline Outcomes clearly described & + & + & + & + & $+/-$ & + & + & + & + & + & + & + \\
\hline (non)response rate described & + & - & + & + & + & $+/-$ & $+/-$ & + & + & $+/-$ & $+/-$ & + \\
\hline Clear case/control definition & + & na & na & na & na & na & na & na & na & na & na & na \\
\hline Power calculation used & - & na & - & - & na & - & - & - & - & - & - & - \\
\hline Losses and completers described & $+/-$ & na & + & + & $+/-$ & - & na & + & + & na & na & $+/-$ \\
\hline Reliable assessment disease & + & - & + & + & - & + & - & + & + & + & + & $+/-$ \\
\hline Clear inclusion/exclusion criteria & $+/-$ & + & + & + & $+/-$ & $+/-$ & $+/-$ & + & $+/-$ & $+/-$ & $+/-$ & $+/-$ \\
\hline Clear hypothesis & - & - & + & + & - & - & - & - & - & - & - & - \\
\hline $\begin{array}{l}\text { Reported probability } \\
\text { characteristics }\end{array}$ & + & $+/-$ & + & + & na & na & + & + & + & + & + & na \\
\hline Type of study stated & - & - & + & + & - & - & + & - & - & - & - & - \\
\hline
\end{tabular}


Table 3. Quality assessment of observational studies (continued)

\begin{tabular}{ccccccccccccc}
\hline \multicolumn{10}{c}{ Author (year) } \\
\hline Arai et & Armari & Bakker & Bakker & Chow & Delany \& & Luscombe & Newens & Riedijk & Rosness & Rosness & Sperlinger \\
al. & et al. & et al. & et al. & et al. & Rosenvinge & et al. & et al. & et al. & et al. & et al. & \& Furst \\
$(2007)$ & $(2013)$ & $(2013)$ & $(2014)$ & $(2011)$ & $(1995)$ & $(1998)$ & $(1995)$ & $(2009)$ & $(2012)$ & $(2008)$ & $(1994)$
\end{tabular}

\begin{tabular}{|c|c|c|c|c|c|c|c|c|c|c|c|c|}
\hline Disclosure of funding source & + & + & + & + & - & - & - & - & + & + & + & - \\
\hline Conclusions supported by findings & + & $+/-$ & + & + & $+/-$ & + & + & + & + & + & + & + \\
\hline Statistical tests of heterogeneity & na & na & na & na & na & na & na & na & na & na & na & na \\
\hline Total score & 17 & 8 & 18 & 18 & 8 & 8.5 & 12 & 13 & 15 & 11.5 & 11 & 8.5 \\
\hline
\end{tabular}

Notes: $+=$ criterion met, $+/-=$ criterion partly met, $-=$ criterion unmet, na $=$ not applicable 


\begin{tabular}{cccccccc}
\multicolumn{7}{c}{ Author (year) } \\
Allen & Bakker & Barca & Beattie & Ducharme & Ducharme & Harris \& & Johannessen \\
et al. & et al. & $(2014)$ & $(2004)$ & et al. & et al. & Keady & \& Möller \\
$(2009)$ & $(2010)$ & & & $(2013)$ & $(2014)$ & $(2004)$ & $(2013)$
\end{tabular}

Clear statement of, and rationale for, research question/aims/purposes Study thoroughly contextualized by existing literature

Method/design apparent, and consistent with research intent

Data collection strategy apparent and appropriate

Sample and sampling method appropriate

Analytic approach appropriate

Context described and taken account of in interpretation

Clear audit trail given

Data used to support interpretation

Researcher reflexivity demonstrated

Demonstration of sensitivity to ethical concerns

Relevance and transferability evident

Total score

\begin{tabular}{|c|c|c|c|c|c|c|c|}
\hline+ & + & + & + & $+/-$ & + & + & + \\
\hline+ & + & + & + & + & $+/-$ & + & + \\
\hline+ & + & $+/-$ & + & + & + & + & $+1-$ \\
\hline+ & + & + & + & + & + & + & $+/-$ \\
\hline$+/-$ & + & $+/-$ & - & + & + & $+/-$ & $+/-$ \\
\hline+ & + & + & + & + & + & $+/-$ & + \\
\hline+ & + & + & + & + & + & - & $+/-$ \\
\hline+ & + & + & + & + & + & $+/-$ & + \\
\hline+ & + & + & + & + & + & + & + \\
\hline+ & $+/-$ & $+/-$ & + & - & - & - & $+/-$ \\
\hline+ & - & + & + & + & + & - & + \\
\hline+ & + & + & + & + & + & $+/-$ & + \\
\hline 11.5 & 10.5 & 10 & 11 & 10.5 & 10.5 & 7 & 9.5 \\
\hline
\end{tabular}




\begin{tabular}{lcccccc}
\multicolumn{7}{c}{ Author (year) } \\
Lockeridge & Millenaar & Nichols & Roach \& & van Vliet & Wain & Williams \\
\& Simpson & et al. & et al. & Drummond & et al. & et al. & et al. \\
$(2013)$ & $(2013)$ & $(2013)$ & $(2014)$ & $(2011)$ & $(2009)$ & $(2001)$
\end{tabular}

Clear statement of, and rationale for, research question/aims/purposes

Study thoroughly contextualized by existing literature

Method/design apparent, and consistent with research intent

Data collection strategy apparent and appropriate

Sample and sampling method appropriate

Analytic approach appropriate

Context described and taken account of in interpretation

Clear audit trail given

Data used to support interpretation

Researcher reflexivity demonstrated

Demonstration of sensitivity to ethical concerns

Relevance and transferability evident

Total score

$\begin{array}{ll}+ & + \\ + & + \\ + & + \\ +/- & + \\ - & +\end{array}$

+
+
+
+
+

Notes: $+=$ criterion met,$+/-=$ criterion partly met, $-=$ criterion unmet, $\mathrm{na}=$ not applicable 


\section{Findings}

\section{Problems around the diagnosis}

A timely diagnosis was perceived as an important marking point to explain the difficulties encountered during the period before the diagnosis ${ }^{13,21}$ and considered a prerequisite for obtaining appropriate care in time ${ }^{13,22}$. Unfortunately the diagnostic process for someone with YOD was often challenging ${ }^{10,13,21-28}$ and early recognition and referral was reported as a principle area which required improvement ${ }^{26}$. The diagnostic process was considered problematic by $71 \%$ of caregivers ${ }^{23}$. The study of van Vliet et al. ${ }^{24}$ described several factors that contributed to a delay in diagnosis including: misattribution of symptoms; denial by the person with YOD and refusal to seek help; lack of confirmation from the environment; unresponsiveness of the general practitioner (GP) and misdiagnosis.

\section{Need for information}

After receiving the diagnosis, specific information was needed to provide a better understanding of the disease. This could help with care planning and offer some relief of tension within the family ${ }^{22}$. The diagnosis was often a source of uncertainty as people struggled to find any explanations within the health care system ${ }^{21}$. This elicited feelings of anxiety and helplessness and as a consequence caregivers often searched for information themselves ${ }^{21}$. Caregivers would have liked to receive information on the type of help available ${ }^{29}$, especially in the period right after the diagnosis. In addition, they wanted to learn more about the disease and treatment options and to talk about practical issues such as adapting your home, how to provide specific care, who to contact in case of emergencies and were to get help with financial issues ${ }^{29}$. In the study of Sperlinger and Furst ${ }^{10}$ approximately half of all caregivers felt that they were given appropriate information about the diagnosis and the prognosis. However, $80 \%$ of the caregivers would have liked additional advice about how to plan care for the future. Caregivers worried about the course of the illness ${ }^{30}$ and the possibility of an upcoming institutionalization ${ }^{11}$. Caregivers of someone with FTD were significantly less satisfied with the information provided about the diagnosis, the counselling and follow-up advice compared to caregivers of someone with young-onset $\mathrm{AD}^{31}$. Several children mentioned the specific need for practical information to deal with their parent with YOD more effectively ${ }^{11}$. Siblings of someone with YOD want to learn more about heredity aspects ${ }^{20,29}$. However, instead of alleviating levels of stress and strain by providing more information, more knowledge could also lead to further distress ${ }^{11,22}$. Several caregivers did not want any further information or details about the disease ${ }^{10}$ possibly as a protective mechanism ${ }^{22}$. The people who searched for information by themselves reported that all the information available could be quite overwhelming and did not always fit a particular diagnosis ${ }^{11}$. 


\section{Barriers in access to care}

The literature showed several factors that were particularly prominent in YOD caregivers, which hindered them in finding the right and appropriate care. First of all, given the delay in establishing the dementia diagnosis there was a subsequential delay in the initiation of appropriate support such as day-care or support groups ${ }^{13}$. Secondly, a reoccurring theme in the literature was the experienced stigma around YOD. As dementia is very uncommon at such a young age, people with YOD, their caregivers or other family members did not always feel comfortable sharing the diagnosis with others ${ }^{21,22}$. Caregivers described embarrassment and fear as a cause for gradually losing contact with friends $\mathrm{s}^{32}$. In addition, others often overestimated the abilities of the person with YOD because of the mismatch between their physically strong appearance and their declining cognitive skills. This caused an underestimation of the challenges the caregivers faced which made them feel unappreciated ${ }^{32}$. When the diagnosis and the accompanying problems were kept hidden for a longer period of time it contributed to the isolation of people with YOD and their caregivers and increased reluctance to seek help ${ }^{21}$. A third important issue that influenced the ability of the YOD caregivers to allow others to care for their significant other was the lack of fit between the needs of the person with YOD and available services $^{13}$. This made it difficult to accept further support. The fourth major barrier in the access to care was the denial and refusal of people with YOD themselves to seek help ${ }^{24}$.

\section{Availability of appropriate services and unmet needs}

A specific area in which people with YOD reported unmet needs, were daytime activities $^{7,33}$. They felt a lack of meaningful activity and a loss of sense of purpose in their day-to-day lives because of their reduced functioning 7,34 . Other frequently experienced unmet needs were social company, intimate relationships and information about the dementia and services available ${ }^{33}$. Furthermore, some people with YOD reported that their caregivers were too focused on risk and danger issues. This caused tension as the person with dementia had a desire to maintain independent and felt that their worries were unnecessary ${ }^{28}$. The availability of appropriate services for the person with YOD and reducing unmet care needs was also important for the caregiver as alleviating caregivers distress enabled them to care for the person with YOD at home for a longer period of time ${ }^{35}$. Examples of these services are support groups specifically for caregivers of people with YOD, support and assistance with the management of behavioural problems, and intermittent stays at nursing homes as a form of respite care ${ }^{13}$. These services facilitate the development of problem-focused coping strategies to help caregivers to change their situation and overcome obstacles ${ }^{32}$. However, sometimes it might be difficult to find the right services that fit the needs of people with YOD. For instance, the advanced age of individuals attending mainstream day care facilities can be very distressing and cause reluctance to attend ${ }^{10,36,37}$. Since people with YOD are still in an active life phase, the need 
for stimulating activities and social contact are high ${ }^{29,37}$. People with YOD reported that specialist day care services represented a place to meet new friends and socialize and engage in meaningful activities ${ }^{28}$. Developing new skills and ordinary activities, such as going to the pub, were seen as very valuable ${ }^{28}$. Finding appropriate care for their significant other was often experienced as very stressful by YOD caregivers ${ }^{8,10,30}$. Another issue for the caregivers was the difficulty in maintaining a balance between the care situation and their own life $\mathrm{e}^{13,21,32,38,39}$. The role of caregiving occupied a lot of time in their lives, adversely affecting other roles and responsibilities ${ }^{29,38}$. In order to remain able to care for the person with YOD it was important that the needs of caregivers themselves were met and that they were allowed to take a break from caring ${ }^{13}$, stressing the importance of respite services. However, YOD caregivers appeared to have difficulties in accessing such services ${ }^{8,36}$.

\section{The consequences of behavioural changes}

Apart from cognitive changes people with YOD also frequently present with behavioural and personality changes posing a significant challenge for caregivers and other family members. It was suggested that caregivers of people with YOD perceive greater difficulties due to these behavioural disturbances compared to LOD caregivers ${ }^{19}$. The person with YOD did not respond anymore when help or comfort was needed ${ }^{11,22}$. The behavioural problems could also cause conflicts with outsiders who did not understand the illness and the accompanying symptoms ${ }^{40}$. In addition, dealing with aggressive behaviour could eventually make it impossible to safely care for the person with YOD ${ }^{32}$. Dealing with these changes could cause irritability and frustration within the family ${ }^{11}$. Some children with a parent with YOD described how coping with hallucinations and aggressiveness of their parent was frightening ${ }^{22}$ and it was not always clear how to react to behavioural problems. Children found it difficult to know to what extent they had to confront their parent about their problematic behaviour or whether they should avoid the confrontation ${ }^{11}$.

\section{Impact on the caregivers and changing relationships within the family}

People with YOD usually still have multiple roles in the family and the dementia diagnosis affects the relationships within the family structure ${ }^{7}$. For the partner, the reciprocity in the relationship gradually diminishes and it is difficult to keep involving the person with YOD in major life decisions concerning work, finances and the household ${ }^{13,21}$. Caregivers grieve the loss of the relationship that existed prior to the disease and exchange their role as spouse for a caregiver role ${ }^{21}$. This adaptation is continuous as the abilities of the person with YOD further deteriorate and causes necessary adjustments for future plans ${ }^{32}$. Being a caregiver can cause high levels of stress ${ }^{10,29,37}$, psychological complaints $^{23,38}$, poor emotional well-being ${ }^{8}$ and low (health related) quality of life ${ }^{38,39}$. 
Living with someone with YOD also has an impact on the children since they start to feel responsible for the well-being of their parent and gradually become a caregiver instead of receiving parental care $\mathrm{e}^{11,22,41}$. In addition the children find it difficult to witness the strain in their healthy parent ${ }^{11}$.

\section{Discussion}

In this review we provide a systematic overview of the literature describing the care needs and experiences with the use of services of people with YOD and their caregivers. The main themes concerned problems around the diagnosis, need for information, barriers in access to care, availability of appropriate services and several specific unmet needs, consequences of behavioural changes and impact on the caregiver and changing relationships within the family.

Early recognition and referral was reported as an essential area which required improvement ${ }^{23,26}$. This emphasizes the need for better support from health care professionals to obtain appropriate and tailored help in time ${ }^{24}$. After the diagnosis is established, acceptance appears to be difficult due to the felt stigma around YOD ${ }^{21,22,32}$. Hiding the diagnosis and accompanying problems cause feelings of isolation and increase reluctance to seek help ${ }^{21}$. Therefore, help with the disclosure of the diagnosis and its consequences to other people might increase understanding of the impact and difficulties of dementia at a younger age. Another area for improvement concerns the provision of information about YOD and available care throughout the caregiving trajectory. The reviewed literature indicates that especially early in the process people want to learn more about YOD and what getting diagnosed with dementia entails. The caregivers have to deal with cognitive, emotional and behavioural changes in their significant other and wonder about the implications of the disease on several aspects of their life. As these caregivers are young they still have many years ahead of them and facing an uncertain future can cause feelings of helplessness ${ }^{21}$. When the cognitive abilities and behaviour of the person with YOD deteriorates it might cause avoidant ways of coping ${ }^{32}$, which could be a risk factor for psychological dysfunction if continuously applied ${ }^{42}$. Knowing more about the possible ways of treatment, practical issues and the type of help that is available might help in the development of more problem focused ways of coping.

In the more advanced stages of the dementia it might be more important to focus on supporting the caregivers because of the increasing demands in caregiving tasks. The caregiver's competence in caring for the person with dementia is an important predictor for institutionalization ${ }^{43}$. Providing the caregiver with support to deal with behavioural changes may increase their feeling of competence ${ }^{43}$. In addition, finding 
practical solutions, such as alarm devises that are triggered when someone leaves, could help caregivers to cope with the behavioural problems ${ }^{32}$.

Compared to the general Dutch population, caregivers of individuals with YOD report lower health related quality of life scores, mostly because of experienced role limitations due to both emotional and physical problems ${ }^{39}$. This shows the difficulties in balancing their role as a caregiver and maintaining their own life ${ }^{13,21,38}$. Caregivers with more unmet needs such as psychological support and respite care seem more at risk for feelings of depression and anxiety ${ }^{39}$. For this reason it might be important for the caregivers to be able to hand over some of the care from time to time for example with day-care or intermittent stays at the nursing homes and proper respite care. To make this possible the caregiver should trust that the available services fit the needs of the person with YOD and that they feel comfortable to go there ${ }^{13}$. However, finding appropriate care for their significant other was often experienced as very stressful by YOD caregivers ${ }^{8,10,30}$. For such profound care decisions YOD caregivers would benefit from support in the decision making process from health care professionals ${ }^{13,32}$. Although consulting health care professionals more often could support the decision making process, in YOD the rate of consultations with the GP appeared to be very low and very infrequent ${ }^{36}$. Individuals with YOD reported unmet needs concerning social company and intimate relationships ${ }^{33}$, which are important contributors to a higher quality of life ${ }^{44}$. However, more research is necessary into the specific unmet needs of people with YOD as the findings indicate that there seems to be a lack of data representing the voices of the person with YOD themselves. Previous research has shown that people with young onset Alzheimer's disease have high awareness, especially in the earlier stages of the disease ${ }^{45}$. Therefore they may have the ability to take a more proactive role in making decisions about their care process and future ${ }^{45}$ and their view about their needs probably differs from their caregivers ${ }^{26,28}$.

The reviewed studies laid an important foundation for knowledge and awareness about the specific care needs and experiences of people with YOD and their caregivers. It is important to note that several articles were published more than ten years ago $\mathrm{a}^{7,8,10,23,36,37}$, however, recent studies still report specific problems and unmet needs consistent with the finding of these older articles. Future research should build on these findings with longitudinal cohort studies to investigate them in larger samples during different stages of the disease. The needs of the caregivers as well as the needs of the person with YOD themselves change during the disease process and this information is essential for the development of specific interventions, tailored to their particular needs. To further tailor the interventions, it is necessary to distinguish between the different diagnoses. Rosness et al., ${ }^{31}$ found that caregivers of individuals with FTD were less satisfied with 
the provision of information and counselling and advice compared to caregivers of people with early onset Alzheimer's disease. However, not many articles compare the needs between different diagnostic groups. In addition, none of the reviewed articles addressed diversity in pathways to diagnosis, treatment and care for people with different socioeconomic and cultural backgrounds. It would be interesting to learn more about the differences in national health and social systems and the organization of health care in different countries. The above-mentioned methodological issues and the finding that several current studies lacked methodological quality concerning their sample and sampling methods decrease the validity of the results with regard to the variability of perceived needs and service availability. Future studies should take into account the different dementia subtypes, disease stages and care settings. Some of the main themes found in this article might be relevant for LOD as well. Therefore, further recommendations for future research is to compare the experiences and needs of people with LOD and YOD, as there are hardly any studies that compare their needs directly which makes it difficult to say anything about the specific aspects for people with YOD.

In conclusion, the literature indicates that there is still a lot to be gained in the care for this group as the people with YOD and their caregivers encounter a wide range of difficulties during the disease process specifically related to their younger age. 


\section{References}

1. Koopmans, R. \& Rosness, T. (2014). Young onset dementia-what does the name imply? International Psychogeriatrics, 26(12), 1931-1933.

2. World Health organization. (2012). Dementia: a public healt priority. WHO

3. Prince, M., Knapp, M., Guerchet, M. et al. (2014). Dementia UK: Update. Alzheimer's Society.

4. Mendez, M. F. (2006). The accurate diagnosis of early-onset dementia. The International Journal of Psychiatry in Medicine, 36(4), 401-412.

5. Kelley, B. J., Boeve, B. F. \& Josephs, K. A. (2009). Cognitive and noncognitive neurological features of young-onset dementia. Dementia and geriatric cognitive disorders, 27(6), 564.

6. Van Vliet, D., de Vugt, M., Bakker, C. et al. (2013). Time to diagnosis in young-onset dementia as compared with late-onset dementia. Psychological medicine, 43(02), 423-432.

7. Harris, P. B. \& Keady, J. (2004). Living With Early Onset Dementia: Exploring the Experience and Developing Evidence-based Guidelines for Practice. Alzheimer's Care Today, 5(2), 111-122.

8. Williams, T., Cameron, I. \& Dearden, T. (2001). From pillar to post-a study of younger people with dementia. Psychiatric Bulletin, 25(10), 384-387.

9. van Vliet, D., de Vugt, M. E., Bakker, C., Koopmans, R. T. \& Verhey, F. R. (2010). Impact of early onset dementia on caregivers: a review. International Journal Geriatric Psychiatry, 25(11), 1091-1100.

10. Sperlinger, D. \& Furst, M. (1994). The service experiences of people with presenile dementia: a study of caregivers in one London borough. International Journal of Geriatric Psychiatry, 9(1), 47-50.

11. Millenaar, J. K., van Vliet, D., Bakker, C. et al. (2013). The experiences and needs of children living with a parent with young onset dementia: results from the NeedYD study. International Psychogeriatrics, 1-10.

12. Chemali, Z., Schamber, S., Tarbi, E., Acar, D. \& Avila-Urizar, M. (2011). Diagnosing early onset dementia and then what? A frustrating system of aftercare resources. International journal of general medicine, 5, 81-86.

13. Bakker, C., de Vugt, M. E., Vernooij-Dassen, M. et al. (2010). Needs in early onset dementia: a qualitative case from the NeedYD study. American journal of Alzheimer's disease and other dementias, 25(8), 634-640.

14. Moher, D., Liberati, A., Tetzlaff, J. \& Altman, D. G. (2009). Preferred reporting items for systematic reviews and meta-analyses: the PRISMA statement. Annals of Internal Medicine, 151(4), 264-269.

15. Mallen, C., Peat, G. \& Croft, P. (2006). Quality assessment of observational studies is not commonplace in systematic reviews. Journal of Clinical Epidemiology, 59(8), 765-769.

16. Walsh, D. \& Downe, S. (2006). Appraising the quality of qualitative research. Midwifery, 22(2), 108-119.

17. Higgins, J. P. \& Green, S. (2008). Cochrane handbook for systematic reviews of interventions. Wiley Online Library.

18. Popay, J., Roberts, H., Sowden, A. et al. (2006). Guidance on the conduct of narrative synthesis in systematic reviews. ESRC methods programme, 15(1), 047-071.

19. Arai, A., Matsumoto, T., Ikeda, M. \& Arai, Y. (2007). Do family caregivers perceive more difficulty when they look after patients with early onset dementia compared to those with late 
onset dementia? International Journal of Geriatric Psychiatry, 22(12), 1255-1261.

Wain, K. E., Uhlmann, W. R., Heidebrink, J. \& Roberts, J. S. (2009). Living at risk: the sibling's perspective of early-onset Alzheimer's disease. Journal of Genetic Counseling, 18(3), 239-251.

21 Ducharme, F., Kergoat, M.-J., Antoine, P., Pasquier, F. \& Coulombe, R. (2013). The Unique Experience of Spouses in Early-Onset Dementia. American journal of Alzheimer's disease and other dementias, 28(6), 634-641.

Allen, J., Oyebode, J. R. \& Allen, J. (2009). Having a father with young onset dementia The impact on well-being of young people. Dementia, 8(4), 455-480

23 Luscombe, G., Brodaty, H. \& Freeth, S. (1998). Younger people with dementia: diagnostic issues, effects on caregivers and use of services. International Journal of Geriatric Psychiatry, 13(5), 323-330.

24 van Vliet, D., de Vugt, M. E., Bakker, C. et al. (2011). Caregivers' perspectives on the pre-diagnostic period

in early onset dementia: a long and winding road. International Psychogeriatrics, 23(9), 1393-1404.

25 Johannessen, A. \& Möller, A. (2013). Experiences of persons with early-onset dementia in everyday life: a qualitative study. Dementia, 12(4), 410-424. Armari, E., Jarmolowicz, A. \& Panegyres, P. K. (2013). The needs of patients with early onset dementia. American Journal of Alzheimers Disease and other Dementias, 28(1), 42-46. Chow, T. W., Pio, F. J. \& Rockwood, K. (2011). An international needs assessment of caregivers for frontotemporal dementia. The Canadian Journal of Neurological Sciences. 38(5), 753-757. Beattie, A., Daker-White, G., Gilliard, J. \& Means, R. (2004). 'How can they tell?’ A qualitative study of the views of younger people about their dementia and dementia care services. Health \& social care in the community, 12(4), 359-368.

29 Ducharme, F., Kergoat, M. J., Coulombe, R. et al. (2014). Unmet support needs of early-onset dementia family caregivers: a mixed-design study. BMC Nursing, 13(1), 49.

Rosness, T. A., Haugen, P. K., Gausdal, M., Gjøra, L. \& Engedal, K. (2012). Caregivers of patients with early-onset dementia, their burden and needs: a pilot study using a new questionnaire Care-EOD. International Journal of Geriatric Psychiatry, 27(10), 1095-1097. Rosness, T. A., Haugen, P. K. \& Engedal, K. (2008). Support to family caregivers of patients with frontotemporal dementia. Aging \& Mental Health, 12(4), 462-466.

32 Lockeridge, S. \& Simpson, J. (2013). The experience of caring for a partner with young onset dementia: How younger caregivers cope. Dementia, 12(5), 635-651.

Bakker, C., de Vugt, M. E., van Vliet, D. et al. (2014). The relationship between unmet care needs in young-onset dementia and the course of neuropsychiatric symptoms: a two-year follow-up study. International Psychogeriatrics, 26(12), 1991-2000. Roach, P. \& Drummond, N. (2014). 'It's nice to have something to do': early-onset dementia and maintaining purposeful activity. Journal of Psychiatric and Mental Health Nursing, 21(10), 889-895

35 Etters, L., Goodall, D. \& Harrison, B. E. (2008). Caregiver burden among dementia patient caregivers: a review of the literature. Journal of the American Academy of Nurse Practitioners, 20(8), 423-428. 
Alzheimer's disease. The British Journal of Psychiatry, 166(6), 777-782.

37 Delany, N. \& Rosenvinge, H. (1995). Presenile dementia: sufferers, caregivers and services. International Journal of Geriatric Psychiatry, 10(7), 597-601.

38 Riedijk, S., Duivenvoorden, H., Van Swieten, J., Niermeijer, M. \& Tibben, A. (2009). Sense of competence in a Dutch sample of informal caregivers of frontotemporal dementia patients. Dementia and Geriatric Cognitive Disorders, 27(4), 337-343.

39 Bakker, C., de Vugt, M. E., van Vliet, D. et al. (2014). Unmet needs and health-related quality of life in young-onset dementia. The American Journal of Geriatric Psychiatry, 22(11), 1121-1130.

40 Nichols, K. R., Fam, D., Cook, C. et al. (2013). When dementia is in the house: needs assessment survey for young caregivers. The Canadian journal of neurological sciences. 40(1), 21-28.

41 Barca, M. L., Thorsen, K., Engedal, K., Haugen, P. K. \& Johannessen, A. (2014). Nobody asked me how I felt: Experiences of adult children of persons with young-onset dementia. International Psychogeriatrics, 26(12), 1935-1944.

42 Moos, R. H. \& Schaefer, J. A. (1984) Coping with physical illness, Springer, 3-25.

43 Bakker, C., de Vugt, M. E., van Vliet, D. et al. (2013). Predictors of the time to institutionalization in young- versus late-onset dementia: results from the Needs in Young Onset Dementia (NeedYD) study. Journal of the American Medical Directors Association, 14(4), 248-253.

44 Ettema, T. P., Dröes, R.-M., de Lange, J. et al. (2005). The concept of quality of life in dementia in the different stages of the disease. International Psychogeriatrics, 17(03), 353-370.

45 van Vliet, D., de Vugt, M. E., Köhler, S. et al. (2013). Awareness and its association with affective symptoms in young-onset and late-onset Alzheimer disease: a prospective Alzheimer Disease \& Associated Disorders, 27(3), 265-271. 


\section{Chapter}

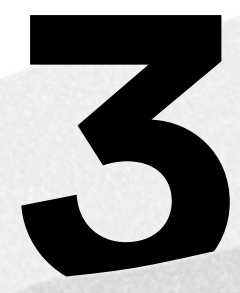

Exploring perspectives of young onset dementia caregivers with high versus low unmet needs

Joany K. Millenaar

Christian Bakker

Deliane van Vliet

Raymond T.C.M. Koopmans

Alexander Kurz

Frans R.J. Verhey

Marjolein E. de Vugt 


\section{Abstract}

Background: This study is part of the Research to Assess Policies and Strategies for Dementia in the Young (RHAPSODY) project. Information about specific needs in young onset dementia (YOD) will provide the basis for the development of an e-health intervention to assist caregivers in coping with YOD in several European countries.

Objective: The aim is to investigate the issues caregivers of people with YOD face and whether there are differences between caregivers with high and low unmet needs.

Methods: A qualitative content analysis method was used to analyse interviews with YOD caregivers. Quantitative data of the NeedYD study was used to select caregivers based on a ranking of unmet needs, to capture differences and similarities between caregivers that experienced high levels of unmet needs versus those with low levels of unmet needs. Needs were assessed with the Camberwell Assessment of Needs in the Elderly

Results: Findings revealed the following themes: (1) acceptance of the diagnosis (2) perception of the relationship (3) role adaptation (4) availability of services and tailored care (5) support system and communication, and (6) awareness in the person with dementia and acceptance of help. Several factors were more apparent in the caregivers who experienced few unmet needs opposed to the caregivers who experienced more unmet needs.

Conclusion: The current study provides an in depth perspective on the caregivers experiences and emphasizes specific themes that could be addressed in future interventions. This might contribute to a caring situation in which the caregiver experiences less unmet needs. 


\section{Introduction}

Young onset dementia (YOD), defined as dementia with an onset before the age of 65 , causes specific challenges related to the earlier phase of life. The symptoms of YOD are diverse and include cognitive, neurological, behavioral and psychiatric symptoms ${ }^{1}$. YOD includes a variety of differential diagnoses and causes, and its prevalence is lower than late onset dementia (LOD), making it a diagnostic challenge ${ }^{2}$. Since the symptoms occur at a relatively young age they can cause specific problems related to this earlier phase of life. The person with YOD is more likely to be working and the disease affects their ability to function properly and remain employed. This often has financial consequences as well as a negative impact on their self-esteem and sense of efficacy ${ }^{3}$. In addition, they still might be raising children and making plans for their future. The cognitive and functional decline and the changes in personality will make it difficult to carry out former roles and responsibilities ${ }^{4}$. Therefore, the person with dementia often experiences a loss of autonomy and increased social isolation ${ }^{5}$ and this adversely affects their wellbeing ${ }^{4}$.

YOD caregivers experience high levels of physical and psychological complaints and a low sense of competence in caring for their significant other, affecting their ability to fulfill their roles and responsibilities in daily living ${ }^{6}$. Life phase specific issues may cause particular needs and requirements for support and services for both the individuals with YOD and their caregivers. Meeting these needs is important as unmet needs are associated with lower (health related) quality of life $\mathrm{fe}^{7,8}$, neuropsychiatric symptoms $\mathrm{s}^{7}$, and earlier nursing home placement ${ }^{9}$. However, it is not known whether specific challenges add to lower unmet needs of people with YOD and their informal caregivers, and to what extent their needs are met. Previous research has shown that in late onset dementia several factors are related to unmet needs such as a the presence of problem behavior and high anxiety in caregivers ${ }^{8}$. Furthermore, the limited availability of social networks and low levels of social support were negatively associated with overall needs ${ }^{8,10}$.

The aim of this study is to investigate the specific issues caregivers of people with young onset dementia face and whether there are differences between caregivers with high and low unmet needs. This work is part of the Research to Assess Policies and Strategies for Dementia in the Young (RHAPSODY) project ${ }^{11}$ for which insight in the specific needs in YOD is an important first step. The findings of the present study, together with the results of an earlier conducted literature review $w^{12}$ and focus groups with caregivers in several European countries will provide the basis for the development of an e-health intervention to assist caregivers in coping with YOD. 


\section{Methods}

\section{Participants}

To explore the experiences of YOD caregivers, qualitative interviews were used which were conducted as part of the Needs in Young Onset Dementia (NeedYD) study in the Netherlands ${ }^{13}$. The participants of this study were recruited trough memory clinics at the Maastricht University Medical Center (MUMC) and the VU University Medical Center (VUMC) in the Netherlands, regional hospitals, regional mental health services, and specialized day care services. Inclusion criteria were: contact with the person with YOD at least twice a week, symptom onset before the age of 65 and a dementia diagnosis according to the criteria from the 4th edition of the Diagnostic and Statistical Manual of Mental Disorders American Psychiatric ${ }^{14}$ based on clinical, neuropsychological and neuroimaging data and the Dutch consensus guidelines ${ }^{15}$. Participants were excluded if there was no informed consent, if the person with dementia was living in a nursing home, or when the dementia was caused by something other than a neurodegenerative or vascular disorder (i.e., Human Immuno-deficiency Virus (HIV), traumatic brain injury, Down's syndrome, Huntington's chorea or dementia related to substance use). All 209 caregivers were assessed with the Camberwell Assessment of Needs in the Elderly (CANE) ${ }^{16}$. This semi-structured interview covers 24 domains to assess social, physical, psychological and environmental needs of the person with dementia. For each item it is noted whether there is a need and if this need is met, according to the caregiver. For the current study, 20 caregivers were selected on the basis of their ranking of unmet needs. A random selection of the highest (95th) percentile (more than 8 unmet needs) and the lowest (5th) percentile (no unmet needs) was made in order to capture differences and similarities between caregivers indicating high numbers of unmet needs versus those indicating no unmet needs.

\section{Data collection}

The Medical Ethics Committee of the Maastricht University Medical Centre in the Netherlands approved the study protocol of the NeedYD study. Prior to participation in the study written informed consent of all participants was obtained. An interview guide (appendix I) was composed from topics derived from relevant literature and clinical practice. All interviews were conducted at the caregivers' homes and audiotaped. The semi-structured interview contained questions about the period prior to the diagnosis, the diagnostic process, the way the dementia diagnosis changed caregivers lives, the problems they experienced in daily live and their experiences with (access to) care. Each topic started with open questions and specific sub questions. In addition to the qualitative interview, caregiver characteristics were inventoried, such as age, gender, level of education and relationship to the person with dementia. Characteristics of the 
person with YOD were also gathered, including type of dementia, disease duration from symptom onset to study inclusion and dementia severity which was assessed with the Global deterioration scale (GDS), which was divided in low (GDS 1-4), middle (GDS 5) and high (GDS 6-7) ${ }^{17}$.

\section{Data analysis}

An inductive content analysis ${ }^{18}$ was used in order to thoroughly explore the caregivers care needs and experiences with health care services. With a content analysis, data is distilled into content-related categories. The deductive approach is used to form categories based on the narratives of the caregivers, moving from specific data to general findings. The audiotapes of all individual interviews were transcribed verbatim and independently analyzed by two researchers (JM and CB). Both researchers thoroughly read the interview transcripts and assigned open codes to depict all aspects of the content ${ }^{19}$. Through the use of inductive reasoning these codes were grouped into higher-order themes. The assigned codes and the content of the themes was thoroughly discussed. The last step of the analyses was the comparison between caregivers who indicated no unmet needs for their relative and those indicating high numbers of unmet needs based on the quantitative scores on the CANE. To illustrate the results, quotations were used from the interviews. Each quotation is marked with a number indicating the specific caregiver and whether this caregiver experienced high levels of unmet needs $(\mathrm{H})$ or no unmet needs (L).

\section{Results}

\section{Participants}

After analyzing 18 transcripts no new information emerged, indicating data saturation ${ }^{20}$. Therefore, eighteen face-to-face interviews with caregivers of younger people with dementia were included. This sample included fourteen spouses, two children and two friends, with an age range of 41 to 69 years with a mean caring history of seven years. Participants in the group with high levels of unmet needs scored eight to thirteen items on the CANE as unmet. Table 1 shows the baseline characteristics of the two groups. The group with low unmet needs consisted only of spouses while in the high unmet needs group half of the caregivers were spouses and the rest were friends or children. There were no significant differences in the other characteristics between the two groups. 
Table 1. Characteristics of the caregivers

\begin{tabular}{|c|c|c|c|c|}
\hline & $\begin{array}{l}\text { Total } \\
(\mathrm{N}=18)\end{array}$ & $\begin{array}{l}\text { Low unmet needs } \\
\qquad(\mathrm{N}=10)\end{array}$ & $\begin{array}{l}\text { High unmet needs } \\
\qquad(\mathrm{N}=8)\end{array}$ & Test-value \\
\hline Age, mean (SD) & $58.7(8.4)$ & $59.9(6.9)$ & $57.06(10.35)$ & $t(16)=.7$ \\
\hline Female, n (\%) & $9(50)$ & $4(40)$ & $5(62)$ & $\chi^{2}(1)=.9$ \\
\hline \multicolumn{5}{|l|}{ Education, $\mathrm{n}(\%)$} \\
\hline - low & $8(44.4)$ & $4(40)$ & $4(50)$ & \multirow[t]{3}{*}{$\chi^{2}(2)=.3$} \\
\hline - medium & $6(33.3)$ & $4(40)$ & $3(38)$ & \\
\hline - high & $3(16.7)$ & $2(20)$ & $1(12)$ & \\
\hline \multicolumn{5}{|l|}{ Diagnosis pwYOD, n (\%) } \\
\hline$-\mathrm{AD}$ & $8(44.4)$ & $5(50)$ & $3(38)$ & \multirow[t]{5}{*}{$\chi^{2}(4)=3.0$} \\
\hline - FTD & $3(16.7)$ & $2(20)$ & $1(12)$ & \\
\hline$-\mathrm{VD}$ & $3(16.7)$ & $2(20)$ & $1(12)$ & \\
\hline - Lewy body & $2(11.1)$ & $0(0)$ & $2(25)$ & \\
\hline - Mixed dementia (AD, VD) & $2(11.1)$ & $1(10)$ & $1(12)$ & \\
\hline $\begin{array}{l}\text { Disease duration in years, } \\
\text { mean }(S D)\end{array}$ & $7.0(3.6)$ & $7.5(2.4)$ & $6.4(4.9)$ & $t(16)=.6$ \\
\hline \multicolumn{5}{|l|}{ GDS, $\mathrm{n}(\%)$} \\
\hline - mild & $9(50)$ & $6(60)$ & $3(38)$ & \multirow[t]{3}{*}{$\chi^{2}(2)=2.6$} \\
\hline - moderate & $4(22.2)$ & $3(30)$ & $1(12)$ & \\
\hline - severe & $4(22.2)$ & $1(10)$ & $3(38)$ & \\
\hline \multicolumn{5}{|l|}{ Relationship, n\% } \\
\hline - partner & $14(77.8)$ & $10(100)$ & $4(50)$ & \multirow[t]{3}{*}{$\chi^{2}(2)=6.4^{*}$} \\
\hline - child & $2(11.1)$ & $0(0)$ & $2(25)$ & \\
\hline - friend & $2(11.1)$ & $0(0)$ & $2(25)$ & \\
\hline
\end{tabular}

Notes: n: number of subjects, $\mathrm{SD}$ : standard deviation, $\mathrm{AD}$ : Alzheimer's disease, FTD: frontotemporal dementia, VD: vascular dementia, GDS: global deterioration scale. ${ }^{*}$ indicates p-value $<.05$

Figure 1. Schematic representation of the factors related to experienced needs

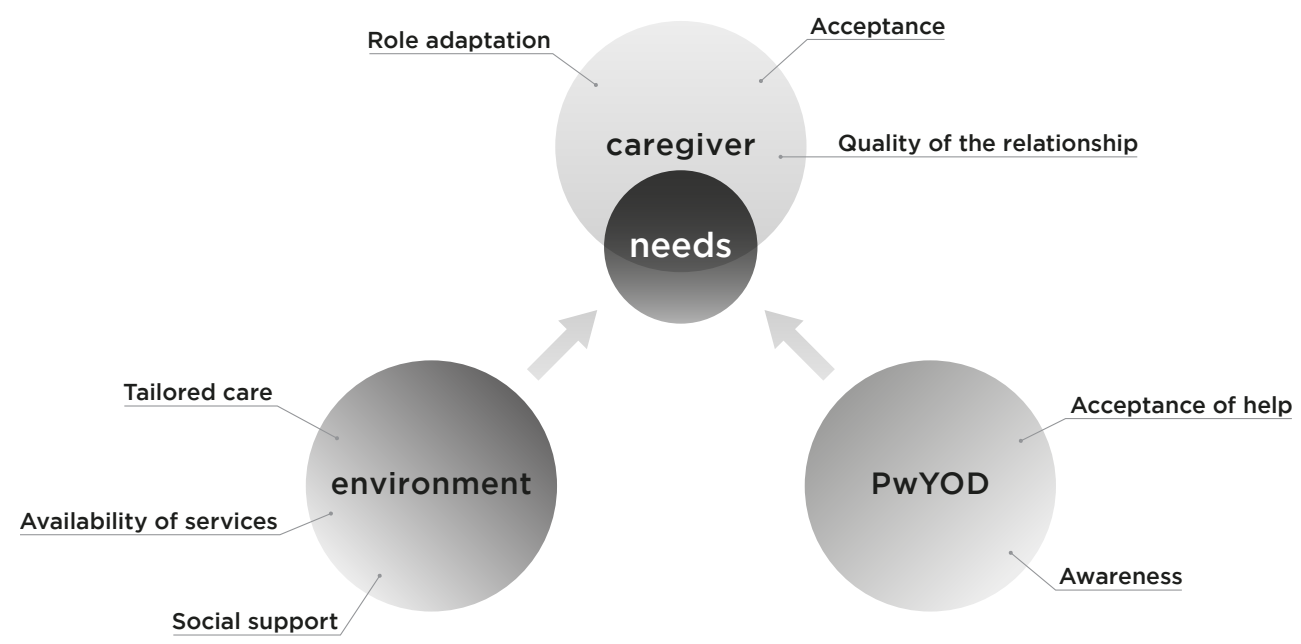




\section{Interviews}

The analysis resulted in six major themes: (1) acceptance of the diagnosis (2) perception of the relationship (3) role adaptation (4) availability of services and tailored care (5) support system and communication, and (6) awareness in the person with dementia and acceptance of help. Figure 1 shows a schematic representation of the specific issues that were discussed in the interviews. The themes will be further illustrated with quotes from the caregivers.

\section{Acceptance of the diagnosis}

The process of accepting the diagnosis and its consequences was a reoccurring theme in several interviews. First of all, the diagnosis was an important first step to give clarity about the encountered problems and uncertainties. Some caregivers explained that they perceived the diagnosis as a relief because the issues they experienced were acknowledged and explained. This was explicitly stated by almost all caregivers who expressed no unmet needs.

"If they would not have found anything, then there was no hope for me to continue the way we were going, because it was unbearable at the moment. The diagnosis was the final missing piece of the puzzle" (caregiver $7, L$ ).

After receiving the diagnosis caregivers also reacted differently to the changes. The group that experienced no unmet needs seemed to be more able to accept these changes.

"Your whole life changes, for example you never expected to quit work so early. It's just that everything is different. When we go on holiday it's a different kind of holiday than before because we always have to go to the same place. But that does not mean it's not good. I see the pleasant side of it." (caregiver $1, L$ )

Other caregivers had more difficulties with accepting the diagnosis and its severity. One caregiver explained how she could not believe that it was dementia, and kept doubting if there was really something wrong.

"You start to doubt if the diagnosis is correct until you are confronted with specific problems that confirm something is wrong. But than you ask yourself if you are to focused on mistakes and you start doubting again." (caregiver $2, \mathrm{H}$ )

Next to difficulties with accepting the diagnosis, some caregivers in the high unmet needs group also struggled with accepting the consequences. 
"I was still thinking about looking for another job, or doing a second study, or starting something new (....) we are in the life phase that we could go travel, we have the time and the means, but now we can't because it is to complicated" (caregiver 4, H).

\section{Perception of the relationship}

The dementia causes changes in the relationship between the caregiver and the person with dementia. Caregivers talked about missing their comrade, decreasing intimacy and reciprocity and changes in the original role division.

"It is a constant battle; you are not on the same level anymore. It feels like you are taking care of a child, a child who is very stubborn" (caregiver $2, H$ ).

Particularly in the high unmet needs group the caregivers seemed more focused on the things they had lost in their relationship and found it difficult to handle these changes and worried that it would get even worse.

"I realise more and more often that nothing fun ever happens anymore. Some days there is only conflict and anger and we never laugh (... ) I start to realise that we've had 25 good years but that there are bad years ahead of us" (caregiver $4, H$ )

In the no unmet needs group, caregivers were more often able to find a new balance within the relationship and to adjust their expectations.

"We try to go on in the way we always have, of course you have to adjust to issues if they come in your path but for now we don't experience many problems." (caregiver 14, L)

\section{Role adaptation}

The attitude towards the caregiving situation differed between the caregivers.

Especially the caregivers without unmet needs focused on the aspects in their life that were still possible and believed it was better to live in the present in stead of worrying about the future. They accepted that their lives had changed and adjusted accordingly with a realistic view.

"You have to stay positive, there are so many things that can still be nice. We are not able to do the thing we used to so now we do different things but it can be just as good. If you start to think in a negative way you have nothing to live for anymore." (caregiver 6, L)

On the contrary many of the caregivers in the high unmet needs group were very worried about the future and avoided difficult situations. 
"I don't want to disturb his daily rhythm because it upsets him. If we have visitors he can be terribly irritated. In the end I just think never mind... it's too much of a hassle." (caregiver $2, H$ )

In most caregivers, the person with YOD was their absolute priority and they adapted a big part of their life to the person with dementia's needs. Almost everyone in both groups, expressed the desire to take care of the person with YOD by themselves for as long as possible. Many caregivers had difficulties delegating the care for different reasons such as distrust in the available services, feelings of shame or guilt, or resistance of the person with YOD to accept care from others. The difference between the two groups was the way the caregivers dealt with the situation. In the group without unmet needs the caregivers were better in determining their boundaries for example with respite care and realising that they had to hand over the care eventually. In addition, they more often felt competent in dealing with the caregiving situation and finding their way within the care system. The caregivers from the high unmet needs group seemed to have more difficulties in balancing the care with their own lives, and asking for help when necessary.

"At one point it is just too much, then I just have to get out. The problem is when I'm home, he just wants to go with me." (caregiver 11, H)

"My children try to support me, but when they go home they are done. Of course I don't want to bother them too much because they have their own life and they are young. So I just let them be, they are busy as it is." (caregiver 12, $\mathrm{H}$ )

\section{Availability of appropriate services}

There was a lot of variability in the amount of help the participants received during the course of the disease and their experiences with the services available. Particularly caregivers with high levels of unmet needs were not satisfied with the help they received and mentioned how they struggled to find the right services and how to establish what care was necessary and how it could be arranged.

"I think that the biggest problem for all of us is to find our way. There is no instruction manual." (caregiver 4, $H$ )

Especially around the time of diagnosis they experienced a lack of information and guidance. They sometimes felt that health care professionals were inconsiderate, did not take them seriously or did not offer the support they needed. This led to a general distrust of health care professionals and the postponement of the use of professional 
services and support.

"They don't listen to me. They think they know best, because they work in health care. But I know better, because I have been caring for him for the past six years, 24 hours a day." (caregiver $8, H$ )

On the contrary, caregivers without unmet needs, generally reported that they were satisfied with the amount and quality of information and guidance received. They described how the care and support were generally directed by a health care professional and tailored to their specific needs. These caregivers also reported that they knew were to ask for help when needed, even though they did not need help right now.

"I know help is there when I need it, if it is to much they said she can be admitted for a week so I can go away by myself. It is possible but I don't need it (... ) it is good to know you have a safety net if something goes wrong." (caregiver $13, L$ )

\section{Social support}

Many caregivers expressed the importance of open communication with people around them about the diagnosis and the difficulties they perceived. In this way others knew what was going on and were able to provide a helping hand when needed. Particularly in the no unmet needs group many caregivers reported that they had friends or family around them who they could turn to when needed.

"We talk very openly about the disease within the family, it should not be something that has to be difficult. It is not like us to hold anything back." (caregiver 17, L)

In the high unmet needs there were several caregivers who mentioned that they did not receive a lot of support from their friends and family, and felt like they were on their own.

"I asked my sister if it would be possible if the family could meet us some times. Because I knew he would like that. But nobody ever comes, maybe his sister once or twice." (caregiver $8, H$ )

From the total sample, half of all the caregivers noticed that their social life diminished because they lost a lot of friends.

\section{Awareness in the person with dementia and acceptance of help}

When the person with dementia did not accept the diagnosis or was not aware of the difficulties the caregiver was facing, it was very difficult to arrange appropriate care. 
Specifically, the caregivers in the high unmet needs group described how the person with dementia was in denial. They tried to hide their problems and consequently refused help.

"He tries to prove himself when he is with others, ten times a day he says 'you see I don't have Alzheimer's." (caregiver 2, $\mathrm{H}$ )

If the person with dementia did not want to go to day care it cost a lot of energy for the caregiver to convince them to go or they felt guilty for sending their significant other away against their will.

"She does not like day care. Sometimes she was standing next to the taxi screaming she didn't want to go. It breaks your heart to see her like that, it's horrible, so then I just let her stay with me." (caregiver $3, H$ )

The reluctance to accept help from others or to go to day care was often caused by insecurities experienced by the person with dementia. When they felt more comfortable to go somewhere because they liked spending time with others or being active it was much easier for the caregiver to allow others to take over some of the care.

\section{Discussion}

This study investigated the specific issues caregivers of people with young onset dementia face and how these relate to unmet care needs in the person with YOD. Six themes were identified: acceptance of the diagnosis; perception of the relationship; role adaptation; availability of services and tailored care; support system and communication, and awareness in the person with dementia and acceptance of help. The results showed that there are several factors that are more apparent in the caregivers reporting no unmet care needs opposed to the caregivers who reported a high amount of unmet needs.

Especially acceptance of the diagnosis was a reoccurring theme in the interviews with the caregivers who did not express any unmet needs. Accepting the diagnosis and the accompanying changes allowed them to adjust their expectations and to adapt to their role as caregiver. This finding is in accordance with a previous study that emphasizes that caregivers and their significant others who understand and accept the diagnosis better have less difficulties in adjusting to changes ${ }^{21}$. This allows them to focus more on the positive in stead of on the experienced losses and the things that are not possible anymore $^{22}$. In order to do so, adequate information about the diagnosis is necessary ${ }^{21-23}$. Unfortunately, not all caregivers received appropriate help in the beginning. Particularly in the high unmet needs group the caregivers experienced a lack of information and 
guidance. This might explain why they seemed more focused on the things they had lost and found it difficult to handle the changes.

The positive effect of focusing on the things that were still possible and adjusting expectations was also apparent in the theme that described the caregivers' perspective on their relationship with the person with YOD. Almost all caregivers talked about the difficult changes in the relationship and the burden they experienced. However, the caregivers that did not express any unmet needs were more often able to find a new balance within the relationship and to adjust their expectations. Previous research has shown that a closer relationship between the caregiver and the care recipient has multiple beneficial effects on well-being ${ }^{24}$, behavioral symptoms ${ }^{25}$ and decline in the person with dementia ${ }^{26}$. Therefore it is essential to reinforce the positive perceptions of the relationship in the caregivers who struggle to adapt to their new role. Our results show that in the group that experienced high unmet needs there were more children and friends compared to the low unmet needs group that consisted of spousal caregivers only. This might influence the caregiving experience as well, as spouses often view their role as caregiver as part of their marital duties ${ }^{27}$ while others might have different feelings of responsibility. Furthermore, even though child caregivers often spend less time providing care, they seem to experience more burden than spousal caregivers ${ }^{28}$.

It is important to note that not all caregivers in the low unmet needs group received formal support or were content with the amount of guidance they received. This is in line with previous research showing that just the total number of services used is not indicative of unmet needs $s^{8}$. The difference between the two groups was that caregivers who did not express unmet needs had other ways to deal with their caregiving tasks despite the absence of (good) formal care. They often had more social support and thought it was important to openly communicate about the disease and the difficulties they were facing. In addition, they were better in determining their boundaries and realized that it was important to ask for help in their environment when necessary or use respite care. A recent study ${ }^{29}$ shows that open communication is an important step in acquiring support from the environment, as there is often a mismatch between the support someone would like to receive and the support that is given. Caregivers are hesitant to ask for help because they are afraid they are burdening others or assume that people from the social environment are reluctant to help. However, people around them are actually often willing to provide support but do not know how they can contribute or are afraid to violate their privacy or stigmatize the situation. Therefore, it is important that caregivers express their needs and experiences, so others will be able to help. Previous research has also shown that the availability of social networks is associated with less unmet need ${ }^{8}$. Other factors that were more apparent in the caregivers that experienced less unmet 
needs were related to the person with dementia. Arranging the right care was easier when the person with dementia was either aware of the diagnosis or accepted the changes that it caused. However, it appears that younger caregivers not always share knowledge about the diagnoses or discuss it with the person with dementia ${ }^{30}$. One of the reasons to do this is wanting to protect the person with YOD and this was also mentioned by caregivers in our study. However, the use of denial as a coping strategy might also have negative consequences on their relationship because it can lead to conflict and loss of trust ${ }^{30}$. In this study, openly communicating about the disease seemed beneficial for arranging the right care because the person with dementia had more insight into his or her limitations and could be more involved in the necessary adaptations in life without resisting.

Limitations of the study is that in a qualitative analysis the sample size is too small to be a representative sample of caregivers of people with YOD, which limits the generalizability. In addition, our results are based on proxy ratings while it is known that the evaluation of unmet needs might differ from the perspective of the person with dementia. There is fair agreement about the areas in which needs occur, but caregivers seem to report more needs than the person with dementia themselves ${ }^{7}$. However, since the goal of this study is to provide input for the development of an educative intervention for caregivers, the use of proxy rated measurements seemed suitable.

The current study provides an in depth perspective on the caregivers experiences and emphasizes specific themes that could be addressed in future interventions. It seems that several factors described above, are connected to a caring situation in which the caregiver experiences less unmet needs. Nevertheless, there are a lot of differences between caregivers in the amount of help they need and how they handle the caring situation. Therefore, listening to their individual situation and letting them express their problems and wishes will help tailoring the care to their specific needs. Interventions should focus on accepting the changes, adjusting expectations and focusing on the positive aspects of their lives rather than the experienced losses. In addition, it is important to encourage open communication within the social environment to allow others to provide support. These findings might be similar in people caring for someone with dementia at older ages as well, however, specifically when the dementia starts at a younger age, themes addressing acceptance and the experienced losses might carry additional weight. These younger individuals still have expectations for the future and might be more focused on what could have been. Because dementia at a young age is less common than late onset dementia, caregivers might not have been prepared for their role as caregiver. This emphasizes the importance of support early on, to facilitate the acceptance process in the caregivers as well as the person with dementia. 


\section{References}

1 Sampson, E., Warren, J. \& Rossor, M. (2004). Young onset dementia. Postgraduate medical journal, 80(941), 125-139.

2 van Vliet, D., de Vugt, M. E., Bakker, C. et al. (2011). Caregivers' perspectives on the pre-diagnostic period in early onset dementia: a long and winding road. International Psychogeriatrics, 23(9), 1393-1404.

Alzheimers Association (2006). Early Onset Dementia, A National Challenge, a Future Crisis. Washington, DC.

4 Harris, P. B. \& Keady, J. (2004). Living With Early Onset Dementia: Exploring the Experience and Developing Evidence-based Guidelines for Practice. Alzheimer's Care Today, 5(2), 111-122. Beattie, A., Daker-White, G., Gilliard, J. \& Means, R. (2004). 'How can they tell?'A qualitative study of the views of younger people about their dementia and dementia care services. Health of social care in the community, 12(4), 359-368.

Millenaar, J. K., de Vugt, M. E., Bakker, C. et al. (2016). The impact of young onset dementia on informal caregivers compared to late onset dementia: Results from the NeedYD study. The American Journal of Geriatric Psychiatry, 24(6), 467-474.

Bakker, C., de Vugt, M. E., van Vliet, D. et al. (2014). The relationship between unmet care needs in young-onset dementia and the course of neuropsychiatric symptoms: a two-year follow-up study. International Psychogeriatrics, 26(12), 1991-2000. Miranda-Castillo, C., Woods, B., Galboda, K. et al. (2010). Unmet needs, quality of life and support networks of people with dementia living at home. Health and quality of life outcomes, $8(1), 1$.

9 Gaugler, J. E., Kane, R. L., Kane, R. A. \& Newcomer, R. (2005). Unmet care needs and key outcomes in dementia. Journal of the American Geriatrics Society, 53(12), 2098-2105. Wilcox, J. (1995). Identifying the support needs of people with dementia and older people with mental illness on a Joint Community Team: A preliminary report. Journal of mental health, 4(2), 157-164.

11 Kurz, A., Bakker, C., Böhm, M. et al. (2016). RHAPSODY-Internet-Based Support For Caregivers of People with Young Onset Dementia: Program Design and Methods of a Pilot Study. International Psychogeriatrics, epub ahead of print.

12 Millenaar, J. K., Bakker, C., Koopmans, R. T. et al. (2016). The care needs and experiences with the use of services of people with young-onset dementia and their caregivers: a systematic review. International journal of geriatric psychiatry, epub ahead of print.

13 van Vliet, D., Bakker, C., Koopmans, R. T. et al. (2010). Research protocol of the NeedYD-study (Needs in Young onset Dementia): a prospective cohort study on the needs and course of early onset dementia. BMC Geriatrics, 10, 13. American Psychiatric Association(2000). Diagnostic and statistical manual of mental disorders DSM-IV-TR (Text Revision) American Psychiatric Association. Washington, DC.

15 CBO (2005). Guideline diagnosis and pharmacological treatment of dementia. Alphen aan den Rijn: Van Zuiden Communications B.V.

16 Reynolds, T., Thornicroft, G., Abas, M. et al. (2000). Camberwell Assessment of Need for the Elderly (CANE) Development, validity and reliability. The British Journal of Psychiatry, 176(5), 444-452.

17 Reisberg, B., Ferris, S. H., de Leon, M.J. \& Crook, T. (1982). The Global Deterioration Scale for 
assessment of primary degenerative dementia. The American journal of psychiatry, 139(9), $1136-1139$.

Elo, S. \& Kyngäs, H. (2008). The qualitative content analysis process. Journal of advanced nursing, 62(1), 107-115.

Hsieh, H.-F. \& Shannon, S. E. (2005). Three approaches to qualitative content analysis. Qualitative health research, 15(9), 1277-1288.

20 Guest, G., Bunce, A. \& Johnson, L. (2006). How many interviews are enough? An experiment with data saturation and variability. Field methods, 18(1), 59-82.

21 Banerjee, S., Willis, R., Matthews, D. et al. (2007). Improving the quality of care for mild to moderate dementia: an evaluation of the Croydon Memory Service Model. International journal of geriatric psychiatry, 22(8), 782-788.

22 Boots, L. M., Wolfs, C. A., Verhey, F. R., Kempen, G. I. \& de Vugt, M. E. (2015). Qualitative study on needs and wishes of early-stage dementia caregivers: the paradox between needing and accepting help. International Psychogeriatrics, 27(06), 927-936.

23 Quinn, C., Clare, L., Pearce, A. \& van Dijkhuizen, M. (2008). The experience of providing care in the early stages of dementia: An interpretative phenomenological analysis. Aging and Mental Health, 12(6), 769-778.

24 Burgener, S. \& Twigg, P. (2002). Relationships among caregiver factors and quality of life in care recipients with irreversible dementia. Alzheimer Disease \& Associated Disorders, 16(2), 88-102.

25 Perren, S., Schmid, R., Herrmann, S. \& Wettstein, A. (2007). The impact of attachment on dementia-related problem behavior and spousal caregivers' well-being. Attachment \& human development, 9(2), 163-178.

26 Norton, M. C., Piercy, K. W., Rabins, P. V. et al. (2009). Caregiver-recipient closeness and symptom progression in alzheimer disease. The Cache county dementia progression study. The Journals of Gerontology Series B: Psychological Sciences and Social Sciences, 64(5), 560-568.

27 Conde-Sala, J., Garre-Olmo, J., Turró-Garriga, O., Vilalta-Franch, J. \& López-Pousa, S. (2010). Quality of life of patients with Alzheimer's disease: differential perceptions between spouse and adult child caregivers. Dementia and geriatric cognitive disorders, 29(2), 97-108.

28 Reed, C., Belger, M., Dell'Agnello, G. et al. (2014). Caregiver burden in Alzheimer's disease: differential associations in adult-child and spousal caregivers in the GERAS observational study. Dementia and geriatric cognitive disorders extra, 4(1), 51-64.

29. Dam, A. E. H., Boots, L. M. M., van Boxtel, M. P. J., Verhey, F. R. J. \& de Vugt, M. E. A mismatch between supply and demand of social support in dementia care: a qualitative study on the perspectives of spousal caregivers and their social network members, submitted.

30. Lockeridge, S. \& Simpson, J. (2013). The experience of caring for a partner with young onset dementia: How younger caregivers cope. Dementia, 12(5), 635-651. 


\section{Appendix}

\section{Interview}

\section{Period before diagnosis}

1. When did you first notice that something was going on?

- What did you notice?

2. How was the period before the diagnosis?

- What did you think that was the matter?

- What problems did you experience? (What problems did the children experience?)

- When did you seek help? Where did you seek help?

- How did they help you?

The diagnosis

1. When was the diagnosis determined?

2. What was your reaction to the diagnosis?

- What did it mean to you and your children?

- How did you handle it? (How did your children handle it?)

- Did you tell other people about the diagnosis? Who did you tell?

- What were the reactions?

- How did you handle it?

- If the caregiver has children: Did your children tell other people? What were the reactions? How did your children handle that?

3. What kind of help did you receive after the diagnosis?

- What do you think about the help that you received?

- Was the information/support/treatment that you received sufficient?

\section{After diagnosis}

4. Did the dementia change your relationship? In what way?

- Communication?

- Intimacy?

5. What else did change for you?

- Family?

- Social?

- Work?

- Financially? 
If the caregiver has children: How did the relationship between your significant other and your children change? Did the relationship between you and your children change? What else did change for your children?

6. What do you miss the most?

7. How do you try to manage the disease?

- How do you try to manage the problems, such as changes in behavior?

- (How do the children manage?)

- Do you talk about the dementia with each other? How do you talk about it?

- (How do your children react to that?)

Care

8. What do you think is most important in your care for your spouse?

9. What do you miss the most?

10. What are your needs?

- What kind of support do you need for yourself?

- What care do you want for your spouse?

- Do you experience problems in communication with care professionals?

\section{Future}

11. What do you think about the future?

- What do you think about day-care in the future?

- What do you think about nursing home admission in the future? (Time, place, reason? 


\section{Chapter}

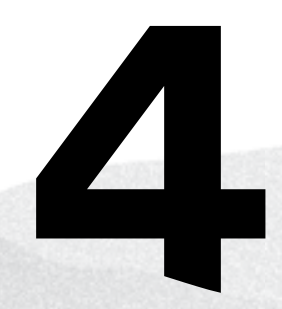

The experiences and needs of children living with a parent with young onset dementia

Joany K. Millenaar

Deliane van Vliet

Christian Bakker

Myrra J.F.J. Vernooij-Dassen

Raymond T.C.M. Koopmans

Frans R.J. Verhey

Marjolein E. de Vugt 


\section{Abstract}

Background: Children of individuals with young onset dementia are confronted with a parent who has a progressive disease that causes changes in personality, behavior, and cognition. They often assist in caregiving tasks, which may have an enormous impact on their lives. This The objective of the present study is to explore the experiences of children living with a young parent with dementia with a specific focus on their needs. Methods: Semi-structured interviews with 14 adolescent children between the ages of 15 and 27 years of individuals with YOD were analyzed using inductive content analysis. Themes were identified based on the established codes.

Results: The emerging categories were divided into three themes that demonstrated the impact of dementia on daily life, different ways of coping with the disease, and children's need for care and support. The children had difficulties managing all of the responsibilities and showed concerns about their future. To deal with these problems, they demonstrated various coping styles, such as avoidant or adaptive coping. Although most children were initially reluctant to seek professional care, several of them expressed the need for practical guidance to address the changing behavior of their parent. The children felt more comfortable talking to someone who was familiar with their situation and who had specific knowledge of YOD and the available services.

Conclusion: In addition to practical information, more accessible and specific information about the diagnosis and the course of YOD is needed to provide a better understanding of the disease for the children. These findings underline the need for a personal, family-centered approach. 


\section{Introduction}

Dementia is often associated with older age. Although young onset dementia (YOD) is not as prevalent as late onset dementia (LOD) ${ }^{1}$, approximately $6-9 \%$ of all people with dementia develop symptoms of the disease before the age of $65^{2}$. YOD causes specific social and medical problems for the person with dementia themselves and their families ${ }^{3}$.YOD caregivers experience high levels of psychological suffering and problems related to their phase in life, including relational difficulties, family conflict, and employment and financial issues ${ }^{4}$.

Children of individuals with YOD are confronted with a parent who has a progressive disease that causes changes in personality, behavior, and cognition. These changes usually take place at a younger developmental stage; the children may be in their teens or even younger, which is a crucial time in their development ${ }^{5}$. Because young caregivers often assist in caregiving tasks, they risk to prematurely fulfill parental roles before they are emotionally or developmentally able to manage these adult responsibilities ${ }^{6}$. In the long run, this situation may impede normal development ${ }^{7}$ and may lead to insecure attachment ${ }^{8}$ due to the lack of availability of both parents and the responsibility for care. Furthermore, caring at a young age may increase the risk of social, behavioral, and emotional difficulties because of continuous demands for support from the family'. Children may have difficulties achieving emotional and financial independence ${ }^{9}$, restrictions on peer relationship ${ }^{10}$, and difficulties with educational achievement ${ }^{11}$.

Previous research on the experiences and needs of young caregivers in general has revealed that this population has not received appropriate attention ${ }^{12}$ and many families receive no external support ${ }^{11}$. These young caregivers were defined as younger individuals who provide a substantial amount of care on a regular basis to others ${ }^{13}$. Healthcare services rarely concentrate on the needs of the entire family and are not fully aware of the challenges these young people face ${ }^{12}$. Furthermore, it is shown that young people wish to avoid drawing attention to their situation ${ }^{14}$ due to embarrassment about their responsibilities or fear of portraying their parent as inadequate ${ }^{15}$.

Research on the impact of a parent with YOD is scarce ${ }^{4,5}$. The few existing studies indicate that caring for a parent with YOD may be a significant stressor ${ }^{5,9,16}$. One study showed that a third of children in this situation suffered from mood disorders and more than half of the children scored above the cut off for high burden levels ${ }^{16}$. Dementia appeared to have a major impact on well-being of the children. "One day at a time" was an overarching theme, reflecting a way of seeing life and coping with the fear of severe threats in the future ${ }^{9}$. These studies have investigated the consequences of the disease and the way 
children address these consequences, and have recommended that children of people with YOD require adequate support. However, not all studies have specifically focused on the needs of children of people with YOD, which is essential for developing adequate support programs and guidelines for clinical practice. Therefore, attention to YOD caregivers is needed. The aim of the present study is to explore the experiences of children living with a young parent with dementia with a specific focus on the children's needs.

\section{Methods}

\section{Subjects}

The present study is part of the Needs in Young onset Dementia (NeedYD) study. The aims and design of this two-year follow-up study are extensively described elsewhere ${ }^{17}$. The NeedYD study recruited 215 individuals with YOD and their families through memory clinics at the Maastricht University Medical Center+ (MUMC+) and the VU University Medical Center (VUMC) in the Netherlands, regional hospitals, regional mental health services, and specialized day care services. For this study, baseline qualitative interviews were used to explore the children's experiences and needs. Children were recruited through their parents and were approached if they were still living at home at the time of inclusion. For ethical reasons, inclusion was restricted to children older than 14 years. There was a total of 35 eligible children living in 29 families. Fifteen children agreed to participate in the study. Several children did not live at home permanently or were not available at the time of inclusion. Furthermore, some children refused because their parents were afraid it would be to demanding.

\section{Data collection}

Written informed consent was obtained prior to participation in the study. A semistructured interview (appendix) with topics derived from clinical practice and the relevant literature was conducted and audiotaped at the children's homes. The interview included topics such as the children's reactions to the diagnosis, the help they received after the diagnosis, and the resulting changes in their lives. The interview consisted of various sections with open questions and specific sub-questions. The children were encouraged to describe their thoughts and feelings about the issues that emerged. When necessary, the interviewer asked the children to elaborate or to clarify their answers. In addition to the qualitative interview, the children were asked how many hours of contact they had with their parent, how many hours per week they spent caring for their parent with dementia, and what type of care they provided. Furthermore, information about age, gender and education was collected. Additional information from the NeedYD study about the parent was used, including gender, age, type of dementia, and disease duration from symptom onset to study inclusion. The severity of the dementia was 
assessed with the Global Deterioration Scale (GDS) ${ }^{18}$. The GDS is a seven point scale (1-7) ranging from "no cognitive decline" (1) to "very severe cognitive decline" (7). The GDS is a widely used instrument that has been validated for behavioral, neuro-anatomic, and neurophysiologic measures, for which significant correlations have been found ${ }^{18}$.

\section{Data analysis}

We used a qualitative analysis method to thoroughly explore the experiences and needs of the children. This method allowed us to study complex and interacting topics in the interviews ${ }^{19}$. The audiotapes of all interviews were transcribed verbatim and analyzed independently by two researchers (DvV and JM) using ATLAS.ti 7 software ${ }^{20}$. Both researchers applied an inductive content analysis ${ }^{21}$, in which themes and categories emerge from the data through the use of inductive reasoning as a result of the researchers' careful examination and continual comparison. The process includes open coding in which codes are written in the margin of the text to describe all aspects of the content of the transcribed material ${ }^{22}$. Following this open coding, codes referring to the same phenomenon are grouped into categories, and these categories are grouped into higher-order themes. The purpose of creating these categories and themes is to combine particular observed instances into general statements to describe the phenomenon. After analyzing all 14 interviews, we established that saturation of the data occurred because no important new information was obtained in the last interviews ${ }^{23}$. The content of the various categories and the relationships between them were developed and refined over the course of the analytical process. After thorough discussion between the researchers, consensus was reached regarding the categories and themes.

\section{Results}

\section{Subjects}

The group of children consisted of six males and eight females, with an average age of 21.0 years (SD 3.6, range 15-27), drawn from eleven families. Participant 1 and 2 belong to the same family as well as participant 4 and 5 and participant 11 and 12 . In three cases, the mother had dementia. The mean age of the parent was 53.6 years (SD 4.5, range 4762). Five of the parents had Alzheimer's disease, four had frontotemporal dementia (two with the behavioral variant and two with primary progressive aphasia), one had vascular dementia, and one had dementia not otherwise specified. Most of the parents with YOD were mildly or moderately demented (GDS score range 3-6). The mean duration from symptom onset to inclusion was 6.0 years (SD 3.1, range 2-11). The mean duration of the disease from diagnosis to inclusion was 2.1 years (SD .33, range 1 month to 4 years). The type of care the children provided for their parent included housekeeping tasks, such as cooking, cleaning, or grocery shopping, supervision, and social contact (table 1). 
Table 1. Caring tasks

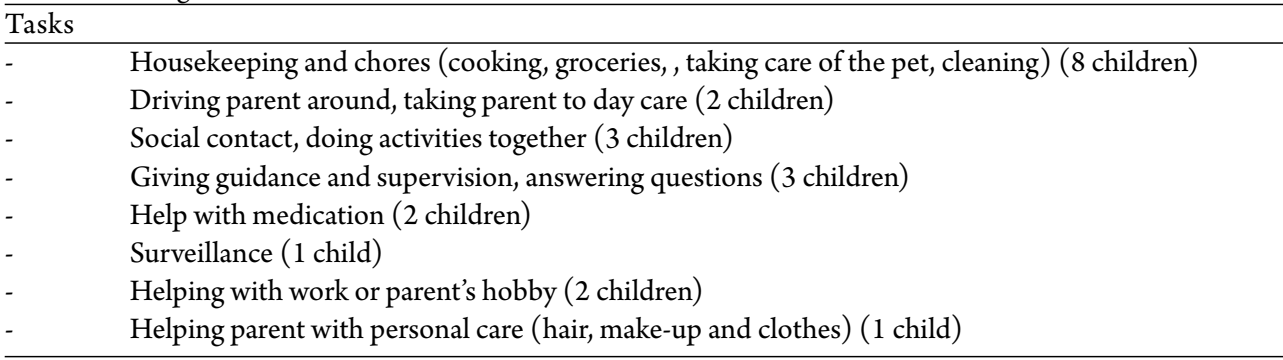

\section{Interviews}

The analysis of the qualitative data resulted in three major themes: (1) the impact of dementia on daily life, (2) coping with the disease, and (3) the need for care and support. An overview of the categories and themes is provided in table 2 .

Table 2. Overview of categories and major themes

\begin{tabular}{ll}
\hline Themes & Categories \\
\hline Impact of dementia on daily life & $\begin{array}{l}\text { Changing relationships } \\
\text { Managing responsibilities versus maintaining own life } \\
\text { Concerns about future perspectives }\end{array}$ \\
Coping with the disease & $\begin{array}{l}\text { Process of acceptance } \\
\text { Avoidance } \\
\text { Relief of the situation } \\
\text { Dealing with changes }\end{array}$ \\
& Timing of care \\
Need for care and support & Understanding of dementia \\
& Value of communication and social support \\
& Desire for practical guidance \\
\hline
\end{tabular}

\section{Impact of dementia on daily life}

For eleven children, the diagnosis of dementia was unexpected; they did not notice many changes in their parent at first, nor did they consider the first symptoms abnormal.

"At that moment, I did not think anything was wrong. I just thought he was in a bad mood, which happens to anyone at times"

(participant 11, female, age 19, father with YOD).

When these changes became evident, they affected not only the children's relationships with the parent with dementia but also with the other parent and with their siblings. 
Six of the children felt that the child-parent bond was inverted as their parent became increasingly dependent.

"You miss them being a parent. Normally you are father and child, but now we are on the same level because he does not think like an adult anymore"

(participant 4, female, age 19, father with YOD).

In addition, several children mentioned that there was more tension at home due to the stress of the caring process and the changes in their parent with dementia.

"I notice it in all of us, that we are more stressed, which is mainly caused by my father's problems"

(participant 7, male, age 27, father with YOD).

The children witnessed the strain on their healthy parent, they had difficulties adjusting to the behavioral, cognitive, and personality changes in the parent with dementia, and they had to contribute more to the household, which sometimes caused friction. One child stated that she sometimes felt like a prison guard in her own house because of the constant supervision that her parent required. In contrast, five children indicated that the other family members were closer than before because of the shared problems.

"My mom and I have to take over more chores in the household since my father can not do everything anymore, which causes some friction sometimes" (participant 1, male, age 19, father with YOD).

Furthermore, it was evident that many children felt that they were needed and were concerned about their parent with dementia but also about their healthy parent. This had a big impact on their lives since they witnessed the strain in their healthy parent who often had difficulties accepting the diagnosis and the accompanying changes in their spouse and who had to deal with the additional responsibility of taking care of the other family members. To cope with these problems the children tried to support them emotionally and practically as much as they could.

"I try to comfort and to support my mother when my father is being difficult.

He used to be the one comforting her but now he does not see when she needs him, therefore it is my job now"

(participant 7, male, age 27, father with YOD).

This dedication to providing care often clashed with their own wishes and future 
perspectives because they prioritized the needs of their parents above their own needs. Consequently, three children did not feel comfortable leaving home and postponed their plans to move out.

"I planned to move out a while ago, but now I feel like I cannot leave anymore since my mother will be alone with him. I did not tell her that because I do not want her to feel guilty" (participant 7, male, age 27, father YOD).

Maintaining the self-esteem of their parent with dementia and avoiding negative emotions seemed to be essential. The aspects of care they described as most important were treating their parent as normally as possible, allowing their parent do things by themselves, protecting their parent from harmful comments from others, and helping their parent do the things he/she wanted to do. This sense of responsibility caused concerns about the future. The children worried about when their parent would be institutionalized and what impact that would have on both parents. Therefore, it was considered important to manage the care for their parent with dementia together with their healthy parent for as long as possible.

"We will always try to take care of him, unless it is really not possible any more. We try to do as much as we can as long as we are able to do so" (participant 1, male, age 19, father with YOD).

The children soon realized that admission to a nursing home would eventually become inevitable. Furthermore, almost all of the children stated that the most difficult part of the future was not knowing what would happen and the sense of uncertainty about the progression of the disease.

"I worry about where we will end up. People around me ask me how we will continue and how it will end. I tell them we just have to wait and see and that only time can tell"

(participant 3, male, age 26, father with YOD).

\section{Coping with the disease}

From the interviews, it became apparent that the children used different strategies during the disease process to manage the consequences. These ways of coping were connected to their ability to process what was happening around them and the impact the disease had on their lives. Especially in the beginning several children showed 
avoidant ways of coping because they did not know how to address the disease and the changes occurring around them. Coping appeared to be challenging since they were not able to fully understand what was happening or they were frightened by the information they found.

"My sister tells me my mother could pass away and than I think: I do not want to know! Things have to remain pleasant around here so we don't have to talk about it" (participant 10, female, age 23, mother with YOD).

Also, later on in the disease process when difficulties were encountered at home, some children would leave to avoid confrontations and discussions. Even the children who were comfortable and who did not feel the need to escape their home situation, occasionally felt the need to withdraw and to give themselves a time out.

"Most of the time when something happens, I just want to go outside so I will not have to think about it. Usually I call some friends or I go to my girlfriend, and then it just disappears"

(participant 5, male, age 17, father with YOD).

Sometimes the children felt it was better to avoid confrontation with their parent. However, at other times they tried to correct the inappropriate behavior or openly expressed their frustrations even though they knew this was not helping. These ways of coping were not always successful and caused tension. Always avoiding confrontations was not possible and correcting their parent was difficult because they did not understand what they were doing wrong. In addition, expressing their frustrations sometimes led to unintentional spiteful comments. Talking about the disease and their frustrations appeared to be difficult and therefore several children chose to hide their feelings from time to time because talking about it made them feel even worse; they preferred to focus on other aspects of their life as a distraction. The problems were not always dealt with by means of avoidance. More children attempted to address the changes through adaptive coping, in which they adjusted to their parent's needs and supported their parent when necessary. They felt that it was important to stay positive and to be patient.

"You try to pay attention to your parent's needs as much as possible, what ever is happening you try to adapt your life to his needs"

(participant 3, male, age 26, father with YOD).

Eight children stated that it was important to rest and to attempt to live their lives as normally as possible to reduce the strain of caring and the emotional problems and worries. 
"You try to continue with your life as normal as possible without it influencing you" (participant 4, female, age 19, father with YOD).

When there were problems at home, they tried to avoid feeling frustrated, and they stressed the importance of open communication. However, not all families communicated openly about the disease at home. Many found it difficult to talk about the disease, especially in front of their parent with dementia, or they did not want to talk about it. Immediately after the diagnosis, some of the children were open about the diagnosis only with a select group of people, which subsequently expanded.

"Not everyone has to know. Maybe if it gets very bad I might tell them because I most likely have to be at home more often or I might need help. However, for now, it is fine as it is. Only my boyfriend knows" (participant 10, female, age 23, mother with YOD).

In contrast, some of the children were glad that other people knew so they could talk about it and people would understand if there were any problems. The interviewees mentioned that it was sometimes easier to confide in someone other than their healthy parent to avoid burdening them.

\section{Need for care and support}

This theme relates to the care needs of the children. One important issue was the timing of care. It seemed to be important that the care was offered at the pace of the children because they needed time to adjust to the idea that their parent had dementia. When the children received help immediately after the diagnosis, this was often perceived as unnecessary, whereas later on, they needed more support.

"In the beginning, the symptoms were not that obvious since he received the diagnosis quite early, so it did not bother me that much. However, because of the deterioration, I find it more and more difficult to accept the diagnosis" (participant 11, female, age 19, father with YOD).

Later in the disease process, time was needed to become accustomed to the changes in the family and the changing needs of the parents and children. Ten of the children did not feel that they were in need of professional help yet, but five of them could imagine needing some type of help in the future.

\footnotetext{
"For now I do not need help, but I think if it deteriorates we will need it. We will need guidance to see how to continue so we can prepare for when it gets worse"
} 
(participant 6, female, age 24, father with YOD).

Two children were offered the opportunity to talk to a psychologist at the memory clinic, who also provided their parents with support. They went once for information and found it reassuring to have the opportunity to go there again whenever they had the need.

Another issue was the need for more information about the diagnosis. Not all of the children were included in conversations with the health care professionals after the diagnosis. Consequently, five children talked about how they searched for information independently on the Internet or in folders.

"When they came home and I asked them how it went, they told me it was

Alzheimer's. I had no clue what it was, so I went looking for information"

(participant 2, male, age 20, father with YOD).

All of this information was sometimes overwhelming or was not specific to young onset dementia or their parent's particular diagnosis.

"I went looking for information on the Internet, and it was frightening to read what could happen"

(participant 8, female, age 26, father with YOD).

Seven children mentioned the specific need for practical information to help them with the problems they faced when dealing with their parent. For instance, they wondered about the extent to which they should confront their parent about his/her behavior or whether they should allow their parent to perform tasks with the risk of making errors.

"Especially in the beginning, you do not know how to handle certain situations. How do you react if he is really stubborn? You can get mad, you can walk away or try to solve the problem, but my mom and I had to find our own ways.

Some guidance would have been welcome"

(participant 3, male, age 26, father with YOD).

Some children mentioned their own irritability and frustration as a result of their parent's behavior. In one family, the individual family members used different care management strategies, which caused tension between them. Moreover, there was an overall need to talk to people with specific knowledge about dementia because these people could understand the issues that the children faced and could provide practical solutions. 
"It would be nice to talk to someone who knows what we can expect so that we'll know what we can do for my father to make it easier for him and, at the same time, more bearable for us"

(participant 11, female, age 19, father with YOD).

For some of the children, it was important that the person who provided help was familiar with their parent and with the situation at home. One child described how every week a social worker came to visit, and the child got to know her very well. She felt comfortable talking to the social worker about her daily life, whereas talking to other healthcare professionals made her feel very irritated due to what she perceived as an impersonal approach.

"At the psychologist, we only talked about my problems; there was no room to talk about nice things, and I felt really uncomfortable discussing everything with someone I don't know. All of a sudden you have to talk about your problems, and then you can go home again. I don't like that at all" (participant 12, female, age 19, father with YOD).

This need to talk to someone familiar was also illustrated by the fact that three of the children particularly valued the help and advice they received from friends or acquaintances who had experience with dementia in their own family or who were professionally involved in the care of people with dementia.

"Fortunately, I have a friend who works with elderly people with dementia who I can talk to. She can also give me advice, which helped me a lot" (participant 1, male, age 19, father with YOD).

There was only one child who mentioned the need for peer contact. She stated that she would like to know how other people handled the disease and what to expect in the future because she did not know anyone who had experience with dementia.

\section{Discussion}

The goal of this study was to explore the experiences and needs of children living with their young parent with dementia, with a specific focus on the children's needs. The analysis of the interviews revealed three major themes. The first theme indicated the impact of dementia on daily life, which included the changing relationships within the family, the children's difficulties managing all responsibilities while maintaining a life of their own, and the children's concerns about their future. The second theme reflected 
the different ways the children coped with the disease, including the process of acceptance, avoidance, searching for relief from the situation, and actively dealing with the changes. The third theme revealed the need for care and support. Many children wanted to know more about dementia but received little information after the diagnosis from either their parents or health care professionals. In addition, they wanted practical guidance in dealing with their parent. It seemed that most of the children valued communication and social support, which was sometimes lacking.

Our findings suggest that most children were more focused on the needs of their parents as opposed to their own. They often felt responsible for the well-being of their parent, and they worried about the strain on their healthy parent caused by the caring process. Consequently, many children provided not only instrumental care, such as cooking, cleaning, or grocery shopping, but also emotional care because they often had to comfort their healthy parent, mediate conflicts, and protect and support their family members. According to Jurkovic et al. ${ }^{24}$, it is important for children to receive support and recognition for their part in caretaking; otherwise, the demand for this adult-like behavior may become harmful. Emotional parentification, in which the child feels responsible for the emotional well-being of their parents, is difficult to identify. Consequently, it is perceived as more detrimental than instrumental parentification, which involves the child completing physical tasks that would normally be provided by a parent ${ }^{24}$. Therefore, specific attention is needed for the potentially overwhelming demands that are placed on these children. These demands may be harmful over a long period of time and may be associated with a range of psychological difficulties, such as depression, anxiety, shame, and social isolation ${ }^{25}$, if they are not addressed properly. Feelings of abandonment or loneliness are not always expressed because of children's fear of alienating or offending their parents ${ }^{25}$.

It appears that managing the stress and emotions that result from the caring process and the changes in the parent with dementia was a frequent part of the children's lives. According to Greenberg et al. ${ }^{26}$, the provision of information and advice and participation in social activities is important because social support is an essential part of coping. Most children received support and sympathy in their environment, but not all of the children were able to confide in others, or they did not want to talk about their problems and feelings. Therefore, not all of the children may have received the social support they needed to be able to cope with the disease.

In addition, several children tended to apply avoidant coping strategies when faced with stressors. The use of avoidant strategies indicates that the child fails to attempt to alter the situation and uses denial or wishful thinking to avoid the situation ${ }^{27}$. Better adjust- 
ment is associated with less reliance on avoidant coping ${ }^{28}$. Furthermore, research has indicated that the continuous use of avoidant coping strategies can be a risk factor for psychological dysfunction if the crisis at hand is not directly confronted ${ }^{29}$. The interviews suggest that the avoidance displayed by some of the children may be partly explained by ignorance about the disease. The children did not want to think about the possible consequences of the disease because it made them feel worse. On the other hand not all children precisely knew what it meant to have dementia at a young age since searching for the information themselves could be very confronting, therefore they chose to avoid learning more about the disease. Providing these children with more information may assist them in dealing with the disease. The provision of information may be especially important after the diagnosis because several of the children in our study had to search for information independently and found it ti be nonspecific or overly confrontational. Likewise, it may be helpful to educate these children about the course of the disease and the challenges they may face in the future so that they are better prepared for what they might encounter. Many children were concerned about the uncertain future and avoided thinking about upcoming events. In addition to information about the disease itself, there is a need for practical information to help them with the everyday problems they face when dealing with their parents.

There was a remarkable duality in the reported needs. Although several children mentioned the need for practical help and information for a better understanding of the disease, when explicitly asked, most children were quite resistant to professional help. This finding is in line with findings of Dearden and Becker ${ }^{11}$, which showed that services were sometimes refused in families with young caregivers. Aldrigde and Becker ${ }^{30}$ found that parents of young caregivers were not always aware of their child's needs, possibly explaining why they were less likely to ask for support. In addition, professionals who were in contact with families often failed to identify the children as providers of informal care because they did not ask about their caring role ${ }^{31}$. Furthermore, young caregivers may be reluctant to discuss their caregiving tasks. Several studies have shown that young people wish to avoid drawing attention to their situation ${ }^{14,15}$. For example, embarrassment about their responsibilities might be a reason for them to avoid talking about their caring role ${ }^{15}$. There might also be the fear of portraying their parent as inadequate ${ }^{15}$ which could raise concerns about the capability of their parents to remain at home. Moreover, the currently offered services may not suit the needs of these children. Several of the interviewees stated that they preferred to talk with someone familiar rather than sporadically visiting health care professionals, which felt too impersonal.

The research in this study was exploratory in nature and was restricted to the availability of the children in the sample of the NeedYD study, which provided only 
a limited amount of interviews. However, because no important new codes emerged in the last interviews, sufficient information was available for saturation of the data to occur $^{23}$. In addition, because of the high rate of refusals the sample may be biased. This could have caused an underestimation of the needs since it is likely that the children that were not included found it to demanding or did not want to talk about their experiences. Another limitation of the study was that only children older than 14 were included, and the mean age in our sample was relatively high. To investigate the caretaking role in the development of these children, more information is required from children of younger age groups. Therefore, further research is needed to investigate the impact of having a parent with young onset dementia on children's development to illustrate possible future consequences.

\section{Conclusion}

This study illustrates the impact of having a parent with YOD and the specific needs of the children involved. Although most children are initially reluctant to seek professional care, several of them expressed the need for practical guidance to address the changing behavior of their parent. In addition to this practical information, specific attention should be directed toward providing these children with more specific information about YOD after their parent receives the diagnosis. This information will provide a better understanding of the disease and may prevent avoidant coping styles. Not all children communicate openly about the disease with their parents or know where to find specific information, suggesting the need for more accessible information. A more family-centered approach in which service providers focus on the needs of the entire family is preferred because children are mainly concerned about the needs of their parents as opposed to their own and may be reluctant to search help. Furthermore, the children feel more comfortable talking to someone who is familiar with their situation and who has specific knowledge on YOD and available services. Therefore, the children may benefit from a more personal approach with a case manager, for example, who can gradually establish a relationship of trust and who is familiar with their home situation. A case manager can evaluate the needs of the whole family and help with the organization of specific care. This will relieve some of the strain in the healthy parent which is important to reduce the pressure on the children. 


\section{References}

1 Harvey, R., Roques, P. K., Fox, N. C. \& Rossor, M. N. (1998). CANDID-Counselling and Diagnosis in Dementia: a national telemedicine service supporting the care of younger patients with dementia. International journal of geriatric psychiatry, 13(6), 381-388. World Health organization. (2012). Dementia: a public health priority. WHO. Retrieved from: [http://www.who.int/mental_health/publications/dementia_report_2012/en/] Sampson, E., Warren, J. \& Rossor, M. (2004). Young onset dementia. Postgraduate medical journal, 80(941), 125-139. van Vliet, D., de Vugt, M. E., Bakker, C., Koopmans, R. T. \& Verhey, F. R. (2010). Impact of early onset dementia on caregivers: a review. International Journal of Geriatric Psychiatry, 25(11), 1091-1100. Gelman, C. R. \& Greer, C. (2011). Young children in early-onset Alzheimer's disease families: research gaps and emerging service needs. American Journal of Alzheimers Disease and Other Demenentias, 26(1), 29-35.

Valleau, M. P., Bergner, R. M. \& Horton, C. B. (1995). Parentification and caretaker syndrome: An empirical investigation. Family Therapy; 22(3), 157-164. Barnett, B. \& Parker, G. (1998). The parentified child: early competence or childhood deprivation? Child Psychology and Psychiatry Review, 3(04), 146-155. Bowlby, J. (1973)Attachment and Loss: Volume II: Separation, Anxiety and Anger 1-429. London: The Hogarth Press and the Institute of Psycho-Analysis.

9
Allen, J., Oyebode, J. R. \& Allen, J. (2009). Having a father with young onset dementia The impact on well-being of young people. Dementia, 8(4), 455-480.

10 Aldridge, J. \& Becker, S. (1993). Children who care: Inside the world of young caregivers. Retrieved from: [https://dspace.lboro.ac.uk/2134/619]

11 Dearden, C. \& Becker, S. (2004). Young caregivers in the UK: the 2004 report.

12 Underdown, A. (2002). 'I'm growing up too fast': messages from young caregivers. Children \& Society, 16(1), 57-60.

13 Walker, A. (1996). Young caregivers and their families: A survey carried out by the social survey division of ONS on behalf of the Department of Health. Stationery Office London. Frank, J., Tatum, C. \& Tucker, S. (1999). On small shoulders. Learning from the experiences of former young caregivers. Children's Society: London. Frank, J. (1995). Couldn't Care More: A Study of Young Caregivers and their Needs. Children's Society: London. Svanberg, E., Stott, J. \& Spector, A. (2010). 'Just helping': Children living with a parent with young onset dementia. Aging \& mental health, 14(6), 740-751. van Vliet, D., Bakker, C., Koopmans, R. T. et al. (2010). Research protocol of the NeedYD-study (Needs in Young onset Dementia): a prospective cohort study on the needs and course of early onset dementia. BMC Geriatric, 10, 13.

18 Reisberg, B., Ferris, S. H., de Leon, M.J. \& Crook, T. (1982). The Global Deterioration Scale for assessment of primary degenerative dementia. The American journal of psychiatry, 139(9), 1136-1139. com/uploads/media/atlasti_v7_manual_02.pdf (accessed October 23, 2012), 2012)]. 
21 Elo, S. \& Kyngäs, H. (2008). The qualitative content analysis process. Journal of advanced nursing, 62(1), 107-115.

22 Hsieh, H.-F. \& Shannon, S.E. (2005). Three approaches to qualitative content analysis. Qualitative health research, 15(9), 1277-1288.

23 Guest, G., Bunce, A. \& Johnson, L. (2006). How many interviews are enough? An experiment with data saturation and variability. Field methods, 18(1), 59-82.

24 Jurkovic, G. J., Jessee, E. H. \& Goglia, L. R. (1991). Treatment of parental children and their families: Conceptual and technical issues. American Journal of Family Therapy, 19(4), 302-314.

25 DiCaccavo, A. (2006). Working with parentification: Implications for clients and counselling psychologists. Psychology and Psychotherapy: Theory, Research and Practice, 79(3), 469-478.

26 Greenberg, J. S., Seltzer, M. M., Krauss, M. W. \& Kim, H.-W. (1997). The differential effects of social support on the psychological well-being of aging mothers of adults with mental illness or mental retardation. Family Relations, 46 (4), 383-394.

27 Pakenham, K. I., Chiu, J., Bursnall, S. \& Cannon, T. (2007). Relations between social support, appraisal and coping and both positive and negative outcomes in young caregivers. Journal of Health Psychology, 12(1), 89-102.

28 Thomsen, A. H. (2000). Responses to stress in adolescence: Measurement of coping and involuntary stress responses. Journal of consulting and clinical psychology, 68(6), 976-992.

29 Moos, R. H. \& Schaefer, J. A. (1984) Coping with physical illness: Springer. p3-25.

30 Aldridge, J. \& Becker, S. (1994). My child, my caregiver: the parents' perspective. Jo Aldridge and Saul Becker.

31 Aldridge, J. \& Becker, S. (1993). Punishing children for caring: the hidden cost of young caregivers. Children \& society, 7(4), 376-387. 


\section{Appendix}

\section{Interview}

1. How did you react when you heard about the dementia diagnosis?

- What did this mean to you?

- How did you cope with it at that moment?

- Did you tell others about it? Who did and who didn't you tell?

- How did people react?

2. Did you receive any help in the period thereafter?

- What kind of help did you receive? Who provided you with help?

- What did you think about the help you received?

- Did they provide you with enough information and support?

3. What are the things that changed in the relationship between you and your father/mother?

- Did anything change regarding communication?

- What is the thing you miss most in the relationship?

4. What are the things that changed in the relationship between you and your other parent and brothers or sisters?

- Did anything change in the contact you have with them?

- Did roles change within the family?

5. What else has changed for you?

- At home?

- Friends?

- School/studies/work?

- Financial situation?

6. How do you try to cope with the dementia?

- How do you try to cope with problems you encounter, like behavioral problems?

- Does your family speak about the dementia? In what way?

- How do you feel about that?

7. What is the most important aspect of the care you give to your parent? 
8. Do you receive any support or help at this moment?

- In what way do they support or help you?

- Are you satisfied with the way they support/help you?

9. What kind of help do you need? (for yourself, for your family member)

- Did you encounter any problems in the contact with health care professionals?

10. How did you feel when your father/mother first received day care?

- How did the transition go?

- Did you experience any problems during this transition?

- What did you need at that moment?

11. What is your view of the future?

- How do you feel about the start of day care/ admittance to a nursing home in the future? 


\section{Chapter}

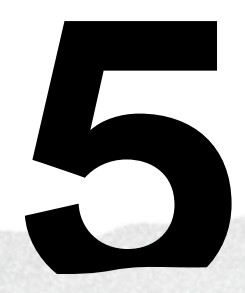

The impact of young onset dementia on informal caregivers compared to late onset dementia

Joany K. Millenaar

Marjolein E. de Vugt

Christian Bakker

Deliane van Vliet

Yolande A.L. Pijnenburg

Raymond T.C.M. Koopmans

Frans R.J. Verhey 


\section{Abstract}

Objectives: The impact of the dementia might be more severe for caregivers of people with young onset dementia (YOD) compared to those who care for someone with late onset dementia (LOD) as a young age among caregivers has been identified as a predictor of increased burden. The present study compares wellbeing between LOD and YOD caregivers longitudinally since this knowledge is essential in order to develop adequate support programs.

Design, setting and participants: 220 YOD and 108 LOD person with dementiacaregiver dyads were included from two prospective cohorts with a two-year follow up. To assess wellbeing we used the Short Sense of Competence Questionnaire, the RAND36, the Symptom Checklist 90 and the Montgomery Asberg Depression Rating Scale. The severity and the course of the different measures used to describe caregiver burden were analyzed with linear mixed models.

Results: Caregivers in both groups experienced high levels of physical and psychological complaints, mild depressive symptoms, poor health related quality of life (HRQoL) and decreased feelings of competence. The severity and the course of most measures were similar in both groups. However, HRQoL on both the physical and the mental domain, was lower for the YOD caregivers.

Conclusion: The amount of actual psychological and physical complaints does not differ between YOD and LOD caregivers. However, YOD caregivers have greater perceived difficulties in daily life due to these complaints. 


\section{Introduction}

Numerous studies have shown that caregiving in dementia can have an adverse effect on the well-being of the caregiver and result in adverse physical and psychological outcomes such as a high risk for depression, illness and decreased quality of life $\mathrm{fe}^{1,2}$. Relatively little is known about caregivers of people with young onset dementia, which is characterized by the development of dementia symptoms before the age of $65^{3}$. The impact of dementia might be more severe for these caregivers compared to late onset dementia (LOD) caregivers, as a younger age has been found to be associated with increased caregiver burden ${ }^{4}$. It is known that young onset dementia (YOD) caregivers experience high levels of psychological suffering and problems related to their younger life phase including relational difficulties, family conflict and employment and financial issues ${ }^{3}$. The increasing and time consuming care demands affect the ability to carry out their professional work ${ }^{5}$. Furthermore, there may be parenting roles that need to be fulfilled. These double demands increase the risk of social isolation ${ }^{6}$. Although it is difficult to find a balance between caregiving and other responsibilities, YOD caregivers are dedicated to care for their significant others by themselves for as long as possible and experience difficulties in accepting help from others ${ }^{7}$. Together with the lack of specialized dementia services this may cause a delay in the use of formal services ${ }^{8}$ which might be reinforced because of the stigma attached to dementia?.

The stress that caregivers experience is a multidimensional and dynamic process in which different stressors and resources interact and influence outcomes ${ }^{10}$. The expression of stress may differ between caregivers. Chronic stress could lead to physical complaints in one caregiver while others may experience more depressive feelings ${ }^{11}$. When investigating caregiver well-being it is important to include multiple distress related outcomes to capture the broad impact caregiving can have on the caregiver's life. Few researchers directly compared the difference in well-being between caregivers of persons with YOD and $\mathrm{LOD}^{12,13}$ and the results remain inconclusive ${ }^{3}$. Freyne et al..$^{13}$ showed an increase in burden with the decrease of the person with dementia's age. Arai et al. ${ }^{12} \mathrm{did}$ not find any significant differences between caregivers of persons with YOD or LOD, but their findings did suggest that YOD caregivers experience greater difficulties in dealing with behavioral problems. However, these prior studies were based on cross-sectional data using small sample sizes. In addition, the heterogeneity in design and sample characteristics do not allow for fair comparisons between the different studies. Therefore, a large-scale longitudinal study was conducted to investigate the course of well-being in YOD caregivers compared to LOD caregivers. We hypothesized that YOD caregivers experience lower levels of well-being. 


\section{Methods}

\section{Subjects}

This study is part of a Dutch national prospective cohort study, the NeedYD-study (Needs in Young onset Dementia). The aims and design of this two-year follow-up study are described elsewhere in more detail ${ }^{14}$. Two hundred and fifteen person with dementia-caregiver dyads were recruited from university medical centers, regional hospitals, regional community mental health services, and from YOD specialized day care facilities. From the original sample, 209 person with dementia-caregiver dyads were included. Six caregivers refused to participate because of high levels of subjective burden. Inclusion criteria were symptom onset before the age of 65 , the availability of an informant who has regular contact with the person with dementia and a dementia diagnosis. The dementia diagnosis was established according to the criteria from the 4 th edition of the Diagnostic and Statistical Manual of Mental Disorders ${ }^{15}$ on the basis of clinical, neuropsychological and neuroimaging data and the Dutch consensus guidelines ${ }^{16}$. Exclusion criteria were an absent informed consent, living in a nursing home, or dementia caused by human immuno-deficiency virus (HIV), traumatic brain injury, Down's syndrome, Huntington's chorea or alcohol related dementia. A comparison group of $108 \mathrm{LOD}$ caregivers was selected from another cohort, the MAASBED study (MAAstricht Study of Behavior in Dementia) ${ }^{17}$. This study had a similar design, assessment measures and diagnostic criteria as the NeedYD-study. Participants from the MAASBED study were consecutively enrolled from the memory clinic of the Maastricht University Medical Center or the Community Mental Health Care Team (RIAGG) in Maastricht. Participants with a symptom onset before $65(n=11)$ were added to the YOD sample of the NeedYD study (total $n=220$ ).

\section{Data collection}

The study consisted of a baseline measurement and four follow-ups. The follow-ups occurred every six months over the course of two years. The assessments at baseline, after one year and after two years were more extensive than the measurements in between.

\section{Ethics}

The Medical Ethics Committee of the Maastricht University Medical Center approved the study protocol. Written informed consent of all Person with dementia or their legal representatives was obtained prior to the investigation.

\section{Primary outcomes}

The Short Sense of Competence Questionnaire (SSCQ $)^{18}$ was used to measure subjective competence of the caregiver. The SSCQ is derived from the family crisis model ${ }^{19}$ 
and Burden interview of Zarit ${ }^{2}$. It denotes the caregiver's feeling of being capable of caring for someone with dementia. The questionnaire consists of 7 items, which are rated on a 5-point Likert scale ( $1=$ agree very strongly; $5=$ disagree very strongly). A high total score denotes a low sense of competence. Three domains are distinguished: satisfaction with the person with dementia as a recipient of care; satisfaction with one's own performance as a caregiver; and consequences of involvement in care for the personal life of the caregiver. The SSCQ is reported to have satisfactory reliability and validity ${ }^{18}$. Psychological and physical complaints were measured with the Symptom Checklist 90 (SCL-90). The SCL-90 is a 90 item multidimensional questionnaire designed to screen for a broad range of psychological and physical problems ${ }^{20}$. Each of the 90 items is rated on a 5-point Likert scale of distress ( $0=$ no distress at all; $4=$ extreme distress). The answers are combined in 9 symptom dimensions: somatization, obsessive-compulsive, interpersonal sensitivity, depression, anxiety, anger-hostility, phobic anxiety, paranoid ideation and psychoticism. The checklist has a satisfactory reliability and construct validity ${ }^{21}$

Depressive symptoms were assessed with the Montgomery Asberg Depression Rating Scale (MADRS). The MADRS is a 10-item observer-rated scale with a 7-point scale ranging from 0 to 6 indicating the severity of current depressive symptoms ${ }^{22}$. The total score varies from 0 to 60 with a higher score indicating more severe depressive symptoms. The scale has adequate inter-rater reliability and expresses construct and concurrent validity ${ }^{23}$.

Health related quality of life (HRQoL) was measured with the Dutch translation of the RAND-36 $6^{24}$. It refers to how health impacts an individual's ability to function and the perceived well-being in physical, mental and social domains of life. The RAND-36 evaluates general health in three physical and five mental domains including: role limitations caused by physical as well as mental problems, social and physical functioning, emotional well-being, vitality, general health perception and pain. These domains can be summarized in a physical (PCS) and a mental (MCS) summary score ranging from $0-100$, with higher scores indicating higher quality of life.

The Dutch version of the RAND-36 is a reliable and sensitive measure for general health ${ }^{25}$. The SCL-90 and SSCQ were used during all five measurements and the MADRS and RAND-36 were only used during the first, third and fifth measurement.

\section{Secondary outcomes}

Dementia severity was assessed with the Global Deterioration Scale (GDS) ${ }^{26}$. The GDS is a seven-point scale (1-7) ranging from "no cognitive decline" (1) to "very severe cognitive decline" (7). The GDS is a widely used instrument that has been validated for 
behavioral, neuro-anatomic, and neurophysiologic measures, for which significant correlations have been found ${ }^{26}$. In addition, demographic information was collected from the primary caregivers: age (at onset and at baseline), gender, level of education (1-8), and disease duration in years from symptom onset to study entry.

\section{Data analysis}

All statistical analyses were performed using the Statistical Package for the Social Sciences (SPSS) version 20.0. Before analysis, data was checked for missing values, outliers, and normality. Non-parametric tests were used when necessary in case of non-normality after data transformation. Differences between the YOD and LOD group in baseline characteristics were tested with $\mathrm{t}$-tests for continuous and $\chi^{2}$-tests for categorical variables. All tests of significance were two tailed, with $\alpha$ set at 0.05 . The severity and the course of the different measures used to describe caregiver well-being were analyzed with linear mixed models. This analysis models individual growth curves that take into account within-subject correlation between repeated measures. The analysis allows use of all data without requiring imputation of missing data ${ }^{27}$. Therefore, all participants that were originally enrolled in the study, irrespective of them completing all five assessments, were included. A normalizing transformation did not affect the non-normally distributed dependent variables used in these analyses. However, regression analysis has been found to be reasonably robust to some degree of non-normality ${ }^{28}$.

The design was a repeated measures with group (YOD vs. LOD) as a between subject factor and time as a within subject factor. The dependent variable was the total score of the SSCQ SCL-90, MADRS or the RAND-36 (MCS as well as the PCS). Adjustments were made for possible confounders to obtain the adjusted group effect. To establish which variables were confounders, separate models were fitted with one confounder and one of the dependent variables over time. In order to ensure that all possible confounding baseline characteristics were included, we added all variables in the analysis that differed between the YOD and LOD sample at baseline with a p-value below 0.1 . The initial model was reduced to improve parsimony and interpretability. Each test of significance consisted of a likelihood ratio ( $\mathrm{LR}$ ) test with $\mathrm{df}=\mathrm{k}$, with $\mathrm{k}$ being the difference in parameters between the two models being compared. If the time variable could be considered as a linear function, no dummy variables for the different time points were added and the time point in the middle was used to calculate the mean scores in both groups over the two year course of the study. 


\section{Results}

\section{Subjects}

Of the 328 caregivers who were included in the study, 220 cared for someone with YOD (mean age at baseline was 59.0 years, SD 9.3) and 108 (mean age at baseline was 64.3 years, SD 12.4) cared for someone with LOD. During the 2 -year period, 28 caregivers were lost during follow-up (17 YOD, 11 LOD) and 44 persons with dementia died (19 YOD, 25 LOD). The completers did not differ from non-completers in terms of relationship $\left(\chi^{2}(2)=.615, \mathrm{p}=.735\right)$, diagnosis of the person with dementia $\left(\chi^{2}(2)=7.261\right.$, $\mathrm{p}=.064)$, education of caregiver or person with dementia $\left(\chi^{2}(2)=.688, p=.876 ; \chi^{2}\right.$ $(2)=1.152, p=.765$; respectively) or disease duration $(U=7739.0, p=.069)$. However, the person with dementia and the caregivers in the non-completer group were older $(\mathrm{U}=7094.0, \mathrm{p}=.003 ; \mathrm{U}=7172.5, \mathrm{p}=.004)$ and the persons with dementia had higher GDS scores indicating a more advanced dementia $\left(\chi^{2}(2)=6.6, p=.037\right)$. In addition to a younger age, the YOD group consisted of less female persons with dementia, the mean disease duration was longer and they lived in the same household more often. The diagnoses were distributed differently between the two groups. Furthermore, the caregivers in the YOD group were more often partners while in the LOD group they were mostly children (table 1).

\section{Sense of Competence}

The mean SSCQ score during the two years was 21.9 (SD .829) in the YOD caregivers and 21.8 (SD .804) in the LOD caregivers. No decrease in caregiver's feelings of competence over time was seen in overall SSCQ scores in both groups $(b=.17, t(896.5)=9.36$, $\mathrm{p}=.057)$. Changes in SSCQ scores over the two-year course of the study did not differ between the two groups $(b=-0.11, t(1010.4)=-.527, p=.598)$. The following confounders were included in the model based on identification in separate analyses: gender of the person with dementia, diagnosis, relationship, hours of contact, living in the same household and dementia severity.

\section{Physical and psychological complaints}

The mean scores on the SCL-90 in our sample during the two years were 134 and 140 for the YOD and LOD group, respectively. There was no significant change over time in physical or psychological complaints as measured with the SCL-90 (b=.01, $\mathrm{t}(869.2)=.033, \mathrm{p}=.974)$. There was no overall difference in SCL-90 scores between the two groups $(b=-6.29, \mathrm{t}(303.49)=-1.39, \mathrm{p}=.167)$ nor a difference in change over time $(b=-1.13, t(878.9)=-1.25, p=.212)$. Only the gender of the person with dementia was included as a possible confounder for this model. 
Table 1: Baseline characteristics of the YOD and LOD group

\begin{tabular}{|c|c|c|c|c|}
\hline & $\begin{array}{c}\mathrm{YOD} \\
(\mathrm{N}=220)\end{array}$ & $\begin{array}{c}\text { LOD } \\
(\mathrm{N}=108)\end{array}$ & Test-value & P-value \\
\hline \multicolumn{5}{|l|}{ Person with dementia } \\
\hline Age. mean (SD) & $61.6(5.3)$ & $80.2(6.5)$ & $\mathrm{U}=289.5$ & $<.001$ \\
\hline $\begin{array}{l}\text { Disease duration in years, } \\
\text { mean }(S D)\end{array}$ & $7.0(3.8)$ & $3.4(2.5)$ & $\mathrm{U}=4479.0$ & $<.001$ \\
\hline Female, $\mathrm{n}(\%)$ & $100(45.5)$ & $65(60.2)$ & $\chi^{2}(1)=6.3$ & .012 \\
\hline \multicolumn{5}{|l|}{ Education, n (\%) } \\
\hline - low & $90(40.9)$ & $38(35.2)$ & $\chi^{2}(2)=2.6$ & .457 \\
\hline - medium & $78(35.5)$ & $46(42.6)$ & & \\
\hline - high & $49(22.3)$ & $23(21.3)$ & & \\
\hline \multicolumn{5}{|l|}{ Diagnosis, $\mathrm{n}(\%)$} \\
\hline$-\mathrm{AD}$ & $132(60)$ & $79(73.1)$ & $\chi^{2}(3)=20.6$ & $<.001$ \\
\hline - FTD & $28(12.7)$ & $2(1.9)$ & & \\
\hline$-\mathrm{VD}$ & $23(10.5)$ & $20(18.5)$ & & \\
\hline - Other & $37(16.8)$ & $7(6.5)$ & & \\
\hline \multicolumn{5}{|l|}{ GDS, $\mathrm{n}(\%)$} \\
\hline - mild & $119(54.1)$ & $78(72.2)$ & $\chi^{2}(2)=18.4$ & $<.001$ \\
\hline - moderate & $56(25.5)$ & $29(26.9)$ & & \\
\hline - severe & $35(15.9)$ & $1(0.9)$ & & \\
\hline \multicolumn{5}{|l|}{ Caregiver } \\
\hline Age, mean (SD) & $59.02(9.3)$ & $64.3(12.4)$ & $\mathrm{U}=9213.5$ & .001 \\
\hline Female, $\mathrm{n}(\%)$ & $131(59.5)$ & $71(65.7)$ & $\chi^{2}(1)=1.2$ & .278 \\
\hline $\begin{array}{l}\text { Contact intensity, } \\
\text { mean (SD) }\end{array}$ & $127.9(39.6)$ & $90.9(70.9)$ & $\mathrm{U}=10172.0$ & .079 \\
\hline Same household, n (\%) & $200(90.9)$ & $59(54.6)$ & $\chi^{2}(1)=76.5$ & $<.001$ \\
\hline \multicolumn{5}{|l|}{ Relationship } \\
\hline - partner & $201(91.4)$ & $54(50)$ & $\chi^{2}(2)=72.7$ & $<.001$ \\
\hline - child & $14(6.3)$ & $46(42.6)$ & & \\
\hline - other & $5(2.3)$ & $8(7.4)$ & & \\
\hline \multicolumn{5}{|l|}{ Education, $\mathrm{n}(\%)$} \\
\hline - low & $65(29.5)$ & $38(35.2)$ & $\chi^{2}(2)=2.2$ & .528 \\
\hline - medium & $95(43.0)$ & $46(42.6)$ & & \\
\hline - high & $58(26.4)$ & $24(22.2)$ & & \\
\hline
\end{tabular}

Notes: PwD: person with dementia,YOD: young onset dementia, LOD: late onset dementia,

SD: standard deviation, AD: Alzheimer's disease, FTD: frontotemporal dementia,VD: vascular dementia.

\section{Depressive symptoms}

The mean MADRS scores were 8.8 in the YOD group and 9.2 in the LOD group during the two-year course of the study. The depressive symptoms significantly decreased over time $(b=-.59, t(222.0)=-2.18, \mathrm{p}=.007)$ with no difference between YOD and LOD caregivers concerning the overall mean score $(b=-.35, t(300.24)=-.357, p=.722)$ nor the course of the depressive symptoms over time $(b=1.06, t(194.9)=1.89, p=.060)$. Possible confounders included in the model were gender of the person with dementia, dementia severity and duration of the disease. 


\section{Health related Quality of Life}

The mean physical score on the RAND-36 was 41.0 in the YOD and 46.9 in the LOD group. The mean mental score was 39.4 in the YOD and 42.2 in the LOD group. No change over time was found for the MCS $(b=0.35, t(243.7)=1.54, p=.125)$ nor the PCS $(b=-0.07, t(668.1)=-.60, p=.546)$. There was a significant overall difference between the YOD and LOD groups with lower scores in caregivers of the YOD group. This indicates poorer perceived well-being in physical $(b=-5.90, t(321.7)=-7.65, \mathrm{p}<.001)$ and mental $(b=-2.74, t(330.8)=-.59, p<.001)$ domains of life for the YOD group compared to the caregivers of the LOD group. When comparing changes in the MCS over time, we found a different course between the two groups $(b=2.10, t(402.3)=-3.48, p=.001)$. Caregivers in the LOD group first show a decrease in the perceived well-being of the mental domain before it increases again, while in the YOD group well-being increased first before it decreased again. However, these changes in MCS scores were very minor. The course of the PCS over time was the same in both groups $(b=-1.00, t(565.6)=-.88$, $\mathrm{p}=.381$ ) (figure 1). Post-hoc analyses of the different subscales showed that the groups differed on social functioning $(b=26.8, S E=2.06, p=.000)$, mental health $(b=5.18$, $\mathrm{SE}=1.63, \mathrm{p}=.002)$, vitality $(\mathrm{b}=9.74, \mathrm{SE}=1.74, \mathrm{p}=.000)$, pain $(\mathrm{b}=48.05, \mathrm{SE}=3.92, \mathrm{p}=.000)$ and general health $(b=9.06, S E=2.08, p=.000)$. The diagnosis of the person with dementia and age of the caregivers were identified and included in the model as possible confounders for the mental domain of the RAND-36. Duration of the disease, disease severity and relationship were included as possible confounders for the physical domain of the RAND-36. An overview of the mean differences in the main outcome measures between the YOD and the LOD caregivers is shown in table 2 .

Figure 1. Two year course of the mean physical (PCS) and mental scores (MCS) of the RAND-36

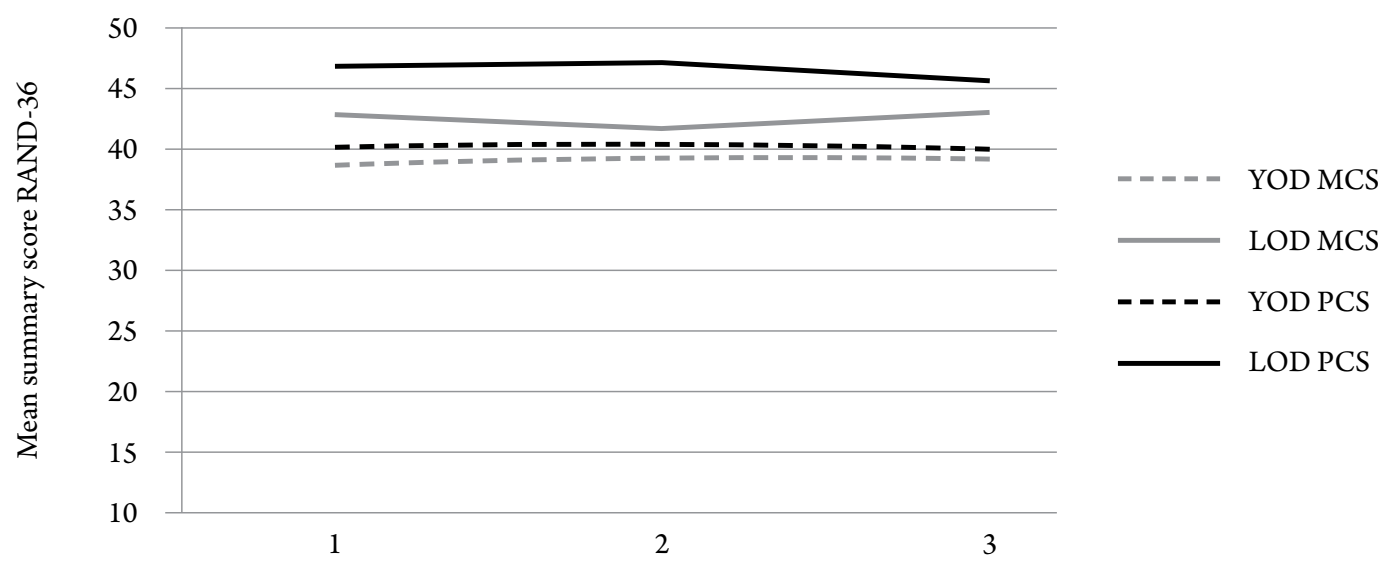

Measurement 
Table 2. Pairwise comparisons of the main outcomes between the YOD and LOD caregivers

\begin{tabular}{lcccc}
\hline & YOD & LOD & P-value & df \\
\hline RAND mean (SD) & & & & \\
Mental & $38.9(0.37)$ & $42.1(0.60)$ & $<.001$ & 319 \\
Physical & $40.9(0.68)$ & $47.2(0.86)$ & $<.001$ & 424 \\
MADRS mean (SD) & $9.5(0.71)$ & $9.3(0.78)$ & .788 & 338 \\
SCL-90 mean (SD) & $133.7(2.48)$ & $140.3(3.80)$ & .145 & 305 \\
SSCQ mean (SD) & $21.9(0.83)$ & $21.8(0.81)$ & .835 & 391 \\
\hline
\end{tabular}

Notes:YOD: young onset dementia, LOD: late onset dementia, SD: standard deviation, SSCQ: Short Sense of Competence Questionnaire, SCL-90: Symptom Checklist 90, MADRS: Montgomery Asberg Depression Rating Scale.

\section{Discussion}

In this longitudinal study we investigated the course of several variables related to caregiver well-being in a unique sample of YOD and LOD caregivers from two large scale cohort studies. When the groups were directly compared, the presence and the course of most outcome measures were similar in both groups. However, we did find a difference in HRQoL on both the physical and mental domain.The results show that both LOD and YOD caregivers experience a low sense of competence in their ability to care for someone with dementia. In addition, all caregivers scored between 113 to 123 on the SCL-90, which implies high levels of physical and psychological complaints compared to scores in the general population ${ }^{29}$. They reported mild depressive symptoms, as cut-offs of the MADRS described in the literature vary between seven ${ }^{30}$ and $10^{31}$. Mean scores on the HRQoL in both groups are lower than the reported mean scores in the general population aged 18-74 which are 49.7 for the PCS and 52.1 for the $\mathrm{MCS}^{32}$.

These findings indicate that the amount of actual psychological and physical complaints does not differ between YOD and LOD caregivers. However, the impact of these complaints on the daily lives of caregivers, as reflected by the RAND-36, appeared to be higher in the YOD group. This difference is not only statistically significant but also clinically relevant. The minimally clinically important difference (MCID) is the smallest difference in a score that is considered to be of clinical importance and in the literature of the RAND this is typically proposed to be between 3 and 5 points ${ }^{33}$. The mean difference between the two groups in the present study was 6.4 points on the PCS and 3.2 points on the MCS over the two year course of the study indicating that these results should be interpreted as clinically meaningful.

The RAND-36, used to measure HRQoL, assesses health complaints, how health impacts the ability to function and how well-being in the physical, mental and social 
domains of life is perceived. Specific items of the RAND-36 focus on the adjustment of what someone wishes to accomplish in life, the restrictions in social and other daily activities and the experience of their general health compared to other people in the same age group. To explain these lower HRQoL scores in the YOD group, some important differences in the caregiver's relationship with the person with dementia should be considered. Although the children in the LOD group and the partners in the YOD group are in a similar stage of life, the YOD caregivers are affected more directly in their daily lives as it concerns the spousal relationship. The impact on their daily lives might be higher for YOD caregivers than for spousal caregivers in the LOD group as expectations about life will be higher as they are still in a more active life phase with more expectations for the future. YOD caregivers are less likely to be prepared for their role as primary caregiver as dementia is rare in younger persons and seldom considered as a possibility. This might explain while they feel more limited in daily life than others around them. The results show they feel less vital, more exhausted and have more complaints related to pain and have more problems with their mental health such as feeling nervous or depressed. They also feel limited in their social functioning and social activities. This might be related to the fact that many younger caregivers have a hard time accepting the diagnosis or feel uncomfortable sharing the dementia diagnosis with others and start to avoid social situations ${ }^{34}$.

Another explanation might be the differences in the use of formal care. Previous research indicates that not living in the same household is associated with an increased use of formal care ${ }^{35}$ and earlier placement in residential care ${ }^{36}$. Therefore, the children who care for their parent with LOD might be more inclined to appeal for care services. Furthermore, the caregivers in the YOD group are more likely to use their own resources since there are less age-appropriate services available specifically for $\mathrm{YOD}^{37}$. This group also tends to postpone service use until it is inevitable resulting in a need to combine more tasks in daily life ${ }^{8}$. More research is needed to investigate the service use in this specific group and the effect it has on their well-being.

The strength of the current study is that information was collected and compared in a relatively large sample of both YOD and LOD caregivers. The longitudinal follow up was highly structured with regular intervals, which gave us a detailed overview of the changes in caregiver well-being. There are also some limitations that need to be considered. The two groups differed in some aspects. First of all, even though essentially the same design was used in both cohorts, slightly different recruitment strategies were used which may have influenced the results. In the LOD group, persons with dementia were mostly included shortly after receiving the diagnoses. In the YOD group, they were also included long after receiving the diagnosis. This might influence the presence of 
symptoms of caregiver well-being since the YOD group is a more heterogeneous group concerning disease severity and ADL disability. However, we aimed to reduce this bias by including disease duration and severity as a covariate. In addition, an important aspect that should be considered is that most caregivers in the YOD group were partners. In the LOD group there were not only partners but also children who cared for their parent with dementia. Therefore, we controlled for the possibility that the relationship between the caregiver and the person with dementia might be a possible confounder in our analyses. In addition, a sensitivity analysis with only the spousal caregivers (data not shown here) showed the same results.

\section{Conclusion}

Caregivers in both groups experience high levels of physical and psychological complaints, a low sense of competence and poor HRQoL. The caregivers in the YOD group experienced more perceived difficulties in daily functioning due to these complaints, which requests appropriate assistance with their daily challenges. Therefore, future studies focused on caregivers of YOD should include HRQoL as an outcome measure. Interventions should specifically target the YOD caregiver's ability to combine the demanding caregiving tasks with their other roles and responsibilities in daily living. Furthermore, as caregiver burden is associated with earlier nursing home placement of persons with dementia ${ }^{38}$, alleviating some of the distress in caregivers also has important economic and social implications for reducing the high costs of long-term care ${ }^{39}$. In order to accomplish this, further research is needed to gain more insight into the predictors of poor HRQoL such as behavioral problems, coping strategies, fear for a possible genetic predisposition and support systems. This research could eventually lead to the development of specific interventions. 


\section{References}

1 Baumgarten, M., Battista, R. N., Infante-Rivard, C. et al. (1992). The psychological and physical health of family members caring for an elderly person with dementia. Journal of clinical epidemiology, 45(1), 61-70.

2 Zarit, S. H., Reever, K. E. \& Bach-Peterson, J. (1980). Relatives of the impaired elderly: correlates of feelings of burden. The gerontologist, 20(6), 649-655. van Vliet, D., de Vugt, M. E., Bakker, C., Koopmans, R. T. \& Verhey, F. R. (2010). Impact of early onset dementia on caregivers: a review. International journal of geriatric psychiatry, 25(11), 1091-1100.

4 Schneider, J., Murray, J., Banerjee, S. \& Mann, A. (1999). EUROCARE: a cross-national study of co-resident spouse caregivers for people with Alzheimer's disease: factors associated with caregiver burden. International journal of geriatric psychiatry, 14(8), 651-661.

5 Sperlinger, D. \& Furst, M. (1994). The service experiences of people with presenile dementia: a study of caregivers in one London borough. International Journal of Geriatric Psychiatry, 9(1), 47-50.

Beattie, A. M., Daker-White, G., Gilliard, J. \& Means, R. (2002). Younger people in dementia care: a review of service needs, service provision and models of good practice. Aging \& mental health, 6(3), 205-212.

7 Bakker, C., de Vugt, M. E., Vernooij-Dassen, M. et al. (2010). Needs in early onset dementia: a qualitative case from the NeedYD study. American journal of Alzheimer's disease and other dementias, 25(8), 634-640.

8 Bakker, C., de Vugt, M. E., van Vliet, D. et al. (2013). The use of formal and informal care in early onset dementia: results from the NeedYD study. The American Journal of Geriatric Psychiatry, 21(1), 37-45.

9 Roelands, M., Van Oost, P. \& Depoorter, A. (2008). Service use in family caregivers of persons with dementia in Belgium: psychological and social factors. Health o social care in the community, 16(1), 42-53.

Pearlin, L. I., Mullan, J. T., Semple, S. J. \& Skaff, M. M. (1990). Caregiving and the stress process: An overview of concepts and their measures. The gerontologist, 30(5), 583-594.

11 Zarit, S. H., Femia, E. E., Kim, K. \& Whitlatch, C. J. (2010). The structure of risk factors and outcomes for family caregivers: implications for assessment and treatment. Aging of mental health, 14(2), 220-231.

12 Arai, A., Matsumoto, T., Ikeda, M. \& Arai, Y. (2007). Do family caregivers perceive more difficulty when they look after patients with early onset dementia compared to those with late onset dementia? International journal of geriatric psychiatry, 22(12), 1255-1261.

Freyne, A., Kidd, N., Coen, R. \& Lawlor, B. A. (1999). Burden in caregivers of dementia patients: higher levels in caregivers of younger sufferers. International Journal of Geriatric Psychiatry, 14(9), 784-788.

14 Van Vliet, D., Bakker, C., Koopmans, R. T. et al. (2010). Research protocol of the NeedYD-study (Needs in Young onset Dementia): a prospective cohort study on the needs and course of early onset dementia. BMC geriatrics, 10(1), 13. American Psychiatric Association (2000). Diagnostic and statistical manual of mental disorders DSM-IV-TR (Text Revision) American Psychiatric Association. Washington, DC. 
Rijn: Van Zuiden Communications B.V.

de Vugt, M. E., Jolles, J., van Osch, L. et al. (2006). Cognitive functioning in spousal caregivers of dementia patients: findings from the prospective MAASBED study. Age and Ageing, 35(2), 160-166.

18 Vernooij-Dassen, M., Felling, A., Brummelkamp, E. et al. (1999). Assessment of caregiver's competence in dealing with the burden of caregiving for a dementia patient: a Short Sense of Competence Questionnaire (SSCQ) suitable for clinical practice. Journal of the American Geriatrics Society, 47(2), 256-257.

19 Bengtson, V. L. \& Kuypers, J. (1985). The family support cycle: Psychosocial issues in the aging family. Life-span and change in a gerontological perspective, 257-273.

20 Derogatis, L. R. (1977). The SCL-90 Manual I: Scoring, administration and procedures for the SCL-90. Baltimore: Johns Hopkins University School of Medicine, Clinical Psychometrics Unit.

21 Arrindell, W. A. \& Ettema, J. (1986). SCL-90: Handleiding bij een multidimensionele psychopathologie-indicator. Swets Test Publishers.

22 Montgomery, S. A. \& Asberg, M. (1979). A new depression scale designed to be sensitive to change. The British journal of psychiatry, 134(4), 382-389.

23 Davidson, J., Turnbull, C. D., Strickland, R., Miller, R. \& Graves, K. (1986). The MontgomeryÅsberg Depression Scale: reliability and validity. Acta Psychiatrica Scandinavica, 73(5), 544-548.

24 Hays, R. D. \& Morales, L. S. (2001). The RAND-36 measure of health-related quality of life. Annals of medicine, 33(5), 350-357.

25 Van der Zee, K. \& Sanderman, R. (1993). RAND-36. Groningen: Northern Centre for Health Care Research, University of Groningen, the Netherlands, 28.

26 Reisberg, B., Ferris, S. H., de Leon, M. J. \& Crook, T. (1982). The Global Deterioration Scale for assessment of primary degenerative dementia. The American journal of psychiatry, 139(9), 1136-1139.

27 Moerbeek, M., van Breukelen, G. J. \& Berger, M. P. (2003). A comparison between traditional methods and multilevel regression for the analysis of multicenter intervention studies. Journal of Clinical Epidemiology, 56(4), 341-350.

28 Ali, M. M. \& Sharma, S. C. (1996). Robustness to nonnormality of regression-tests. Journal of econometrics, 71(1), 175-205.

29 Arrindell, W. \& Ettema, J. (2003). Symptom checklist SCL-90: handleiding bij een multidimen sionele psychopathologie-indicator. Swets test publishers.

30 Snaith, R., Harrop, F., Newby, t. D. \& Teale, C. (1986). Grade scores of the Montgomery-Åsberg Depression and the Clinical Anxiety Scales. The British journal of psychiatry, 148(5), 599-601.

31 Zimmerman, M., Posternak, M. A. \& Chelminski, I. (2004). Implications of using different cutoffs on symptom severity scales to define remission from depression. International clinical psychopharmacology, 19(4), 215-220.

32 Ware Jr, J. E., Gandek, B., Kosinski, M. et al. (1998). The equivalence of SF-36 summary health scores estimated using standard and country-specific algorithms in 10 countries: results from the IQOLA project. Journal of clinical epidemiology, 51(11), 1167-1170.

33 Samsa, G., Edelman, D., Rothman, M. L. et al. (1999). Determining clinically important differences in health status measures. Pharmacoeconomics, 15(2), 141-155.

34 Ducharme, F., Kergoat, M.-J., Antoine, P., Pasquier, F. \& Coulombe, R. (2013). The Unique Experience of Spouses in Early-Onset Dementia. American journal of Alzheimer's disease and other dementias, epub ahead of print. 
35 Toseland, R. W., McCallion, P., Gerber, T. \& Banks, S. (2002). Predictors of health and human services use by persons with dementia and their family caregivers. Social science \& medicine, 55(7), 1255-1266.

36 Vugt, M. E. d., Stevens, F., Aalten, P. et al. (2005). A prospective study of the effects of behavioral symptoms on the institutionalization of patients with dementia. International Psychogeriatrics, 17(04), 577-589.

37 Werner, P., Stein-Shvachman, I. \& Korczyn, A. D. (2009). Early onset dementia: clinical and social aspects. International Psychogeriatrics, 21(4), 631.

38 Etters, L., Goodall, D. \& Harrison, B. E. (2008). Caregiver burden among dementia patient caregivers: a review of the literature. Journal of the American Academy of Nurse Practitioners, 20(8), 423-428.

39 Pinquart, M. \& Sörensen, S. (2006). Helping caregivers of persons with dementia: which interventions work and how large are their effects? International Psychogeriatrics, 18(04), 577-595. 


\title{
Chapter
}

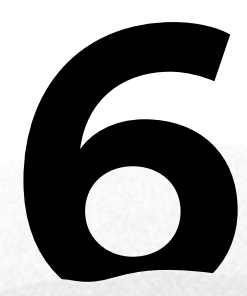

Determinants of Quality of Life in Young onset Dementia

\author{
Joany Millenaar \& Lara Hvidsten Per Kristian \\ Marjolein E. de Vugt \\ Christian Bakker \\ Knut Engedal \\ Deliane van Vliet, \\ Geir Selbæk \\ Raymond T.C.M. Koopmans \\ Torgeir Bruun Wyller \\ Frans R.J. Verhey \\ Aud Johannessen \\ Hege Kersten
}




\section{Abstract}

Background: Promoting adaptation, improving well-being and maintaining an optimal quality of life (QOL) is an important aspect of care for people with dementia. Knowledge about the determinants of QOL helps to identify potential problem areas for early intervention and support, tailored to individual needs. The purpose of this study was to identify determinants of QOL in young onset dementia, and to assess differences in QOL domains between people with Alzheimer's disease $(\mathrm{AD})$ and frontotemporal dementia (FTD).

Methods: 135 people with $\mathrm{AD}$ and 58 people with FTD were included from two prospective cohort studies in Norway and the Netherlands. QOL was assessed with the proxy reported Quality of Life in Alzheimer's Disease questionnaire (QOL-AD). Possible determinants included in the analyses were sociodemographic variables, diagnosis, dementia severity, disease awareness, neuropsychiatric symptoms, number of met and unmet needs and personal and instrumental care provided by the caregiver. The relationship between the determinants and QOL was explored using multiple linear regression. Differences between QOL domains in people with AD and FTD were calculated using Mann Whitney U-tests.

Results: Lower QOL was associated with more severe depressive symptoms, lower disease awareness, and a higher amount of needs, both met and unmet. The other variables were no significant determinants of QOL. People with AD scored lower on the memory and higher on the friends' subscale. No differences were found for the other items.

Conclusion: This study demonstrates a unique set of determinants of $\mathrm{QOL}$ in $\mathrm{AD}$ and FTD. Interventions directed towards these specific factors may improve QOL. 


\section{Introduction}

Dementia is a syndrome caused by a number of neurodegenerative disorders affecting cognitive abilities such as memory and behavior, resulting in progressive loss of independence in daily activities and the ability to participate in social activities ${ }^{1}$. When dementia starts before the age of 65 , it is commonly referred to as young onset dementia (YOD). The prevalence of YOD is estimated between 67 and 81 per 100,000 in the age group 45 to 65 years $^{2,3}$. However, the number of people with YOD is most likely to be underestimated, as there are insufficient studies on the epidemiology of YOD and most prevalence studies are registry based ${ }^{4}$. In contrast to late onset dementia (LOD), YOD is more frequently genetic or metabolic due to rare causes, or secondary to potentially treatable conditions $s^{5,6}$. The subtypes in YOD appear to be more heterogeneous than in LOD. AD is, however, still the most common cause of dementia also in young adults ${ }^{7}$. Frontotemporal dementia (FTD) accounts for a larger proportion of the cases in YOD compared to $\mathrm{LOD}^{2}$. The clinical phenotypes of AD and FTD differ ${ }^{5}$. Due to the early involvement of medial temporal lobe structures, the majority of people with $\mathrm{AD}$ initially have more apparent memory loss. Language and social functioning are generally preserved until later on ${ }^{5}$. However, when $\mathrm{AD}$ starts at a younger age there are more phenotypic variants, including a rather big group of cases with non-amnestic deficits, compared to late onset $\mathrm{AD}^{8}$. FTD is characterized by behavioral disturbances, personality changes, social comportment, loss of empathy and motivation and a decrease in cognition ${ }^{6}$.

People with YOD also differ from people with LOD due to age specific needs with family responsibilities, employment issues and different societal roles and obligations ${ }^{9,10}$. These various responsibilities and roles contribute to a sense of meaning in life and being an engaged individual in daily living ${ }^{11}$. Difficulties in these areas may affect integral parts of a person's sense of selfhood and can lead to a considerable decrease in his or her quality of life (QOL). Furthermore, cognitive, behavioral, and functional symptoms of dementia can significantly impact people's general well-being and $\mathrm{QOL}^{12}$.

Quality of life is initially defined by the World Health Organization as the "individuals' perception of their position in life in the context of the culture and value systems in which they live and in relation to their goals, expectations, standards and concerns". This concept is affected by physical, psychological and social well-being ${ }^{13}$. When the person is affected by a disability or chronic disease, such as dementia, these goals and expectations often have to be adjusted. In order to be able to continue to function with fulfilment, people with dementia have to adapt to these changes and cope with the physical, emotional and social challenges they face ${ }^{14}$. Therefore, it is important that there 
is a shift in focus from symptoms and disability towards the capacity and potential of the person with dementia. This has become a major topic of interest within dementia research ${ }^{15}$. Not everyone is able to adapt to the consequences of the dementia, likely adversely affecting QOL. This will jeopardize the capacity of the person with dementia to fulfil their potential as well as their ability to participate in their environment. In order to improve their QOL, more knowledge about the factors that influence QOL is necessary. This will also allow for identifying potential targets for early intervention.

There has been extensive research on determinants of QOL in late onset dementia. No clear or consistent associations between QOL and socio-demographic variables including age, education and gender were found ${ }^{16}$. A consistent pattern is found in the literature for lower QOL and high levels of depressive symptoms ${ }^{17,18}$ and more dependence in activities of daily living ${ }^{19,20}$. In general, high levels of behavioral problems are associated with decreased QOL ${ }^{16}$. However, there seems to be a difference in the relative importance of the specific behavioral symptoms on QOL ratings ${ }^{21,22}$. The relationship between QOL and cognition as well as dementia severity is less clear. Correlations are generally low ${ }^{16}$ but some studies link better cognitive functioning to higher $\mathrm{QOL}^{23,24}$. QOL has also been associated with an increased amount of unmet needs in the study of Hoe et al. ${ }^{22}$. However, this effect was not shown in another study ${ }^{25}$.

To our knowledge only one study specifically investigated determinants of QOL in persons with YOD ${ }^{25}$. Only depression seemed to be a significant determinant of QOL. In addition, no studies compared QOL in persons with YOD and LOD, raising the question whether there are different determinants involved. Furthermore, it is not clear how QOL differs for the various subtypes of YOD. Especially in people with FTD, initial symptoms predominantly affect personality and behavior, as opposed to memory and attention in $\mathrm{AD}$, this could impact their social health in various ways, affecting their $\mathrm{QOL}$ in different areas. The aim of the current study is to identify and explore determinants of QOL in people with YOD, and to assess differences in specific domains between people with FTD and AD, using data from two European multicenter studies.

\section{Methods}

\section{Study design}

This study used baseline data of two prospective cohort studies; the Dutch NeedYD (Needs in Young onset Dementia) study ${ }^{26}$ and the Nordic multicentre study of quality of life and needs for healthcare services in $\mathrm{YOD}^{27}$. The study protocols were approved by the local ethics committees and informed consent from all participants or their legal representatives was obtained prior to the study. Approval was granted by the Regional 
Committees for Medical and Health Research Ethics in Norway for the exchange of de-identified information from the Nordic YOD-study.

\section{Participants}

Two hundred and nine participants were recruited from university medical centres, regional hospitals, regional community mental health services, and from YOD specialized day care facilities in the Netherlands. Only participants with AD and FTD were selected for the present study. The dementia diagnosis was established according to the criteria from the 4th edition of the Diagnostic and Statistical Manual of Mental Disorders ${ }^{28}$ on the basis of clinical, neuropsychological and neuroimaging data and the Dutch consensus guidelines ${ }^{29}$. In the Nordic cohort, 88 participants were recruited from memory clinics in Norway, Denmark and Iceland. The diagnosis was established according to the consensus criteria for behavioral variant-FTD and the language variants of $\mathrm{FTD}^{30,31}$, and the ICD-10 criteria for AD. Inclusion criteria were symptom onset before the age of 65 , community-dwelling at the time of inclusion, and the availability of an informant with regular contact. Exclusion criteria were people with frontotemporal dementia related to motor neuron disease or other dementias with frontal lobe affection, current alcohol or substance abuse and mental retardation.

\section{Primary outcome}

The Quality of Life-Alzheimer's Disease scale (QOL-AD) was used to assess quality of life ${ }^{32}$. The scale consists of thirteen items including physical health, energy, mood, living situation, memory, family, marriage, friends, chores, fun, money, self, and life as a whole. Each item is scored on a 4-point Likert scale, ranging from poor to excellent. Scores on the individual items are summed to obtain a total QOL score, with a higher score indicating a better quality of life with a maximum score of 52 . If the person with dementia did not have a spouse, the scores on the marriage item was weighted according to the total scale score and imputed ${ }^{20}$. Proxy ratings were used since the study included people in the advanced stages of dementia as well. The QOL-AD is reported to have good inter -rater reliability, fair to good test-retest reliability and excellent internal consistency ${ }^{33}$.

\section{Independent variables}

The independent explanatory variables were selected based on previous findings on determinants of QOL in dementia. Dementia severity was assessed with the Global Deterioration Scale (GDS) ${ }^{34}$ in the Dutch cohort study and with the Clinical Dementia rating $(\mathrm{CDR})^{35}$ questionnaire in the Nordic study. Severity of dementia was reclassified into mild, moderate and severe dementia according to the guidelines of the dementia performance measurement set of the American Medical Association with higher scores indicating more severe dementia ${ }^{36}$. In addition, the Mini Mental State Examination 
(MMSE) ${ }^{37}$ was administered to assess cognitive functioning. The MMSE is a 30 points scale and a higher score denotes better cognitive functioning. Depressive symptoms were assessed with the Cornell Scale for Depression in Dementia (CSDD) and a higher score indicates more depressive symptoms ${ }^{38}$. The Camberwell Assessment of Needs in the Elderly (CANE) was used to explore and quantify the number of met and unmet needs ${ }^{39}$. The CANE investigates 24 domains that cover social, physical, psychological and environmental needs. For each item it assesses whether there is an existing need and if this need is met. For this study the number of existing needs was used for both met and unmet needs with proxy ratings. To assess a wide range of behavioral symptoms the Neuropsychiatric Inventory $(\mathrm{NPI})^{40}$ was used. The symptoms that are included in the questionnaire are delusions, hallucinations, agitation, depression, anxiety, apathy, irritability, euphoria, disinhibition, aberrant motor behavior, night-time behavior disturbances, and appetite and eating abnormalities. The severity scores (range 1-3) of the observed individual neuropsychiatric symptoms were summed to generate a global score with a higher score for more severe behavioral symptoms. The degree of disease awareness was measured with the Guidelines for the Rating of Awareness Deficits (GRAD) ${ }^{41}$ in the Dutch cohort and according to the Reed anosognosia scale ${ }^{42}$ in the Nordic cohort. Both scales define awareness as the presence of explicit knowledge or recognition of own cognitive deficits according to a four-point scale. A higher score denotes better awareness. The time the caregiver spent caring for the person with dementia was obtained through specific items of the Resource Utilization Scale ${ }^{43}$ and measured in hours per month spent on instrumental as well as personal care. Furthermore, demographic information was collected including age, gender and level of education.

\section{Data analysis}

Statistical analyses were performed using the Statistical Package for the Social Sciences (SPSS) version 22.0. Prior to the analysis, all data were checked for missing values, outliers, and normality to ensure there were no violation of assumptions. Differences between the two diagnostic groups were tested with $\chi^{2}$-tests for categorical and t-tests for continuous variables for both the independent variables as well as the scores on the different items of the QOL-AD. In case of non-normality, the non-parametric Mann Whitney U-test was conducted. Tests of significance were performed two tailed, with a significance level of 0.05 . Hierarchical multiple regression was used to assess the ability of the explanatory variables to determine QoL. The blocks of variables were composed as related sets. We started with the sociodemographic variables (age, gender, education) we wanted to control for before testing the predictive value of the disease related factors such as diagnosis, severity and awareness. The consecutive order of the remaining blocks were based on previously reported determinants in late onset dementia. In the first step, demographic variables were entered (age, gender, education), then the dementia 
related variables (diagnosis, severity, awareness) were entered in the second step. In the third step depressive symptoms were added, in the fourth step the total severity score of the neuropsychiatric symptoms were added, met and unmet needs were entered in the fifth step, and finally in the sixth step, hours of instrumental and personal care were added. The $\mathrm{R}$ square change value for each step was used to evaluate the additive explanatory power of each model after adding the next set of variables, while the beta coefficients were used to evaluate the contribution of each variable to the final model. The final model was selected based on the highest predictive value, denoted by the $\mathrm{R}^{2}$.

\section{Results}

\section{Participants}

88 participants were recruited from the Nordic YOD-study, and 160 from the NeedYDstudy. Of the 248 individuals with YOD, 169 had AD and 79 FTD. From the total study population, 193 completed all assessments that were necessary for the regression analysis. There were no significant differences between the participants in the analyses and those that were excluded regarding age, gender, education or diagnosis, nor concerning their median scores on the MMSE, Cornell, NPI or QOL-AD. The mean age was 62 years (IQR 8) with no significant age difference between the two diagnostic groups. Moreover, the groups did not differ in gender, level of education, disease awareness or depression scores. However, individuals with FTD had significantly higher MMSE scores, less advanced dementia, and experienced more behavioral symptoms (table 1).

\section{QOL}

The median total QOL score was 31 (IQR 10) in the AD group and 32 (9.3) in the FTD group. Analysis of the different sub items of the QOL-AD scale showed that people with AD scored lower on the memory subscale $(\mathrm{p}=.003)$, and higher on the friends subscale $(\mathrm{p}=.010)$ compared to people with FTD. No differences were found for the other items (figure 1). The first model in the hierarchical regression analyses showed that the demographic variables accounted for $4 \%$ of the variance in the total QOL score. Entry of the disease related variables accounted for a significant $24 \%$ increase in explanatory value of the model $(\mathrm{p}<.001)$, the addition of depressive symptoms further improved the model ( $9 \%$ increase, $\mathrm{p}<.001)$. However, addition of the global NPI severity score did not yield a significant increase in predictive value $(p=.75)$. Adding the number of met and unmet needs did improve the model further with a $7 \%$ increase $(p<.001)$. The sixth and final model with the hours of instrumental and personal care added did not improve the predictive value of the model ( $1 \%$ increase, $\mathrm{p}=.26)$ (table 2$)$. The final model accounted for $45 \%$ of the variance in the total QOL score. The predictive values of the explanatory variables are also shown in table 2 . Lower QOL was significantly associated with more 
severe depressive symptoms, lower disease awareness, and a higher amount of needs, whether they were met or unmet. There were no significant differences related to dementia severity, behavioral symptoms or personal or instrumental care.

Table 1: Participant characteristics

\begin{tabular}{|c|c|c|c|c|}
\hline & $\begin{array}{c}\text { Total } \\
(\mathrm{N}=193)\end{array}$ & $\begin{array}{c}\mathrm{AD} \\
(\mathrm{N}=135)\end{array}$ & $\begin{array}{c}\text { FTD } \\
(\mathrm{N}=58)\end{array}$ & P-value \\
\hline Age, median (IQR) & $62(8)$ & $62(7)$ & $62(9)$ & .91 \\
\hline Female, $n(\%)$ & $87(45)$ & $67(50)$ & $20(35)$ & .05 \\
\hline \multicolumn{5}{|l|}{ Education, n (\%) } \\
\hline - low & $62(32)$ & $45(33)$ & $17(29)$ & .83 \\
\hline - middle & $68(35)$ & $46(34)$ & $22(38)$ & \\
\hline - high & $63(33)$ & $44(33)$ & $19(33)$ & \\
\hline MMSE, median (IQR) & $23(9)$ & $20(7)$ & $27(4)$ & $<.001$ \\
\hline \multicolumn{5}{|l|}{ Dementia severity, n (\%) } \\
\hline - mild & $118(61)$ & $72(53)$ & $46(79)$ & .003 \\
\hline - moderate & $47(24)$ & $40(30)$ & $7(12)$ & \\
\hline - severe & $28(15)$ & $23(17)$ & $5(9)$ & \\
\hline \multicolumn{5}{|l|}{ Disease awareness, $\mathrm{n}(\%)$} \\
\hline - Severely disturbed & $21(11)$ & $14(10)$ & $7(12)$ & .76 \\
\hline - Moderately disturbed & $44(23)$ & $30(22)$ & $14(24)$ & \\
\hline - Mildly disturbed & $64(33)$ & $43(32)$ & $21(36)$ & \\
\hline - Adequate & $64(33)$ & $48(36)$ & $16(28)$ & \\
\hline Cornell Depression score, median (IQR) & $7(9)$ & $6(8)$ & $8(7)$ & .09 \\
\hline Number of needs, median (IQR) & $9(9)$ & $10(10)$ & $9(7)$ & .11 \\
\hline NPI total score, median (IQR) & $6(10)$ & $4(8)$ & $10(10)$ & .002 \\
\hline
\end{tabular}

Notes: n: number of subjects, IQR: interquartile range, AD: Alzheimer's disease, FTD: frontotemporal dementia, NPI: Neuropsychiatric Inventory.

Figure 1. Mean scores on QOL items Items of QOL

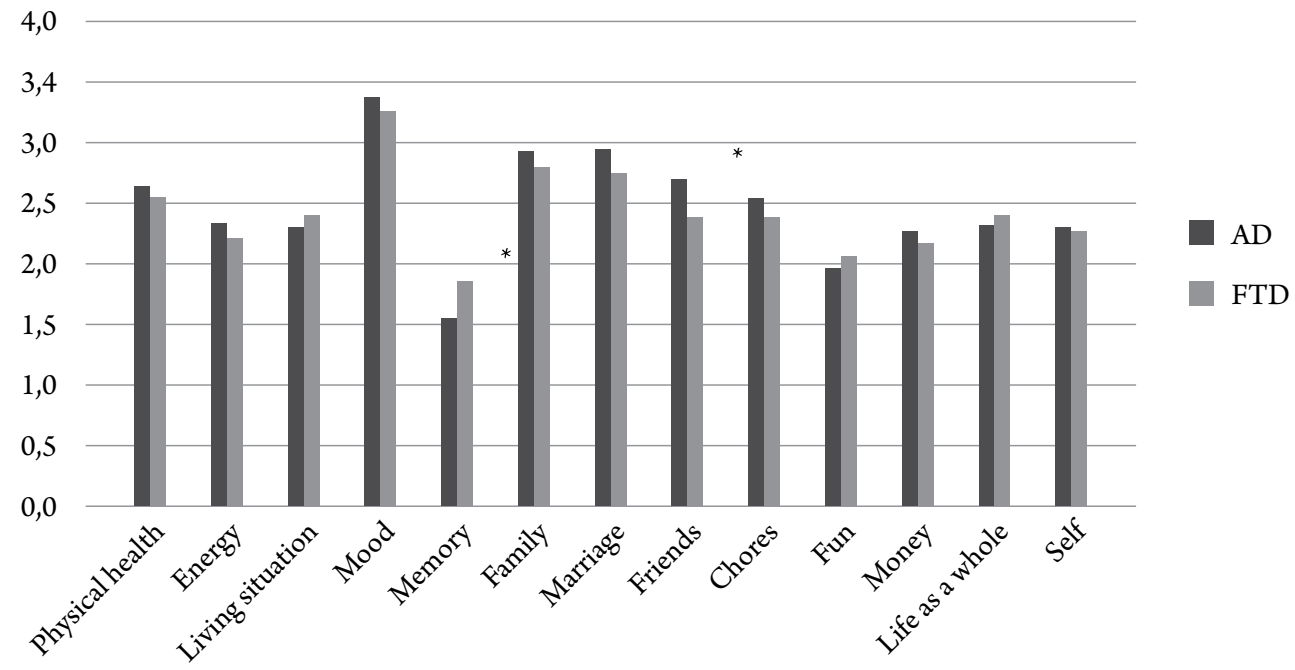


Table 2. Results from the regression analysis

\begin{tabular}{|c|c|c|c|c|c|c|c|c|c|c|c|c|}
\hline \multirow[t]{2}{*}{ Explanatory variables } & \multicolumn{2}{|c|}{ Model 1} & \multicolumn{2}{|c|}{ Model 2} & \multicolumn{2}{|c|}{ Model 3} & \multicolumn{2}{|c|}{ Model 4} & \multicolumn{2}{|c|}{ Model 5} & \multicolumn{2}{|c|}{ Model 6} \\
\hline & $b$ & Sig. & $b$ & Sig. & $b$ & Sig. & $b$ & Sig. & $b$ & Sig. & $b$ & Sig. \\
\hline Age & .017 & .017 & .061 & .44 & .048 & .52 & .047 & .53 & -.022 & .76 & -.025 & .73 \\
\hline Education & 1.783 & 1.783 & .899 & .10 & .810 & .12 & .799 & .12 & .607 & .22 & .603 & .22 \\
\hline Gender & .16 & .16 & .268 & .76 & -.101 & .91 & -.093 & .91 & -.482 & .55 & -.488 & .55 \\
\hline Diagnosis & & & -1.474 & .13 & -1.140 & .22 & -1.197 & .20 & -1.564 & .08 & -1.723 & .06 \\
\hline Severity & & & -2.107 & .01 & -1.937 & .01 & -1.937 & .01 & -1.051 & .15 & -1.354 & .07 \\
\hline Awareness & & & 2.284 & .00 & 1.899 & .00 & 1.942 & .00 & 1.574 & .00 & 1.537 & .004 \\
\hline Depressive symptoms & & & & & -.363 & .00 & -.380 & .00 & -.289 & .00 & -.313 & .001 \\
\hline Behavioral symptoms & & & & & & & .029 & .75 & .085 & .35 & .092 & .31 \\
\hline Unmet needs & & & & & & & & & -.637 & .00 & -.617 & .002 \\
\hline Met needs & & & & & & & & & -.396 & .00 & -.417 & .001 \\
\hline Personal care & & & & & & & & & & & .009 & .10 \\
\hline Instrumental care & & & & & & & & & & & -.002 & .45 \\
\hline $\mathrm{R}^{2}$ & \multicolumn{2}{|c|}{044} & \multicolumn{2}{|c|}{.284} & \multicolumn{2}{|c|}{371} & \multicolumn{2}{|c|}{.371} & \multicolumn{2}{|c|}{.438} & \multicolumn{2}{|c|}{.446} \\
\hline \multicolumn{13}{|l|}{ Change statistics } \\
\hline$-\mathrm{R}^{2}$ & \multicolumn{2}{|c|}{.044} & \multicolumn{2}{|c|}{.241} & \multicolumn{2}{|c|}{.087} & \multicolumn{2}{|c|}{.000} & \multicolumn{2}{|c|}{.066} & \multicolumn{2}{|c|}{.008} \\
\hline$-F$ & \multicolumn{2}{|c|}{2.872} & \multicolumn{2}{|c|}{20.862} & \multicolumn{2}{|c|}{25.452} & \multicolumn{2}{|c|}{.100} & \multicolumn{2}{|c|}{10.741} & \multicolumn{2}{|c|}{1.342} \\
\hline - P-value. F & \multicolumn{2}{|c|}{.04} & \multicolumn{2}{|c|}{.00} & \multicolumn{2}{|c|}{.00} & \multicolumn{2}{|c|}{.75} & \multicolumn{2}{|c|}{.00} & \multicolumn{2}{|c|}{.264} \\
\hline
\end{tabular}




\section{Discussion}

We studied the influence of several variables on quality of life of people with YOD in a unique sample from two large-scale cohort studies. Depressive symptoms and both met and unmet needs were negatively related to QOL. Better disease awareness was, on the other hand, related to a higher QOL score. A comparison of the two diagnostic groups showed no difference in global QOL, but individuals with $\mathrm{AD}$ scored lower on the memory subscale and higher on the friends subscales than people with FTD.

The results implicate that both individuals with FTD and AD face challenges in daily living that negatively impact their $\mathrm{QOL}$ to a similar degree. However, for people with $\mathrm{AD}$, difficulties are more apparent in the memory domain. This is in line with previous research findings emphasizing the early involvement of medial temporal lobe structures in AD initially leading to forgetfulness ${ }^{5}$. The clinical presentation of FTD is on the other hand to a large degree characterized by behavioral disturbances and personality changes ${ }^{6}$, which might explain the lower scores on the friends subscale. Remarkably, this was not shown in the more intimate social circles reflected by the items marriage and family, suggesting that within the home environment the distinct characteristics of FTD impact QOL to a lesser extent. This might partly be explained by the feelings of stigma and taboo many YOD caregivers experience. Dementia in the young is rare and not always understood by the environment. As a consequence, the caregivers may not share information on what is going on with others. This might, in turn, cause a desire to avoid social situation $s^{44}$. This might be even more evident in FTD because of behavioral difficulties such as disinhibition, inappropriate social behavior and impulsivity. In addition, the people close to the person with dementia might be more willing to adjust to the changes in their significant other.

We found that several factors were significantly related to QOL, including depression, needs and awareness. Depression showed the strongest negative relation with QOL, indicating that more depressive symptoms are related to lower QOL. This finding has been a consistent factor in past research as well ${ }^{16}$. The total number of needs was also a determinant of reduced QOL. This could be expected, as different subscales of the CANE are closely related to domains of the QOL-AD, including accommodation, chores, daytime activities, memory, physical health, company and money. Furthermore, both the CANE and the QOL-AD were assessed by caregiver proxies. It did not make a difference whether these needs were met or unmet as they both showed a negative relationship with QOL. So even if the individual with YOD received enough help when there was an existing need, it was associated with lower QOL. This might be explained by being confronted with experienced limitations and an experienced loss of autonomy 
as more help is needed to fulfill existing care needs. A lack of autonomy and dependency on others for daily activities is an important aspect in $\mathrm{QOL}^{45,46}$, and is also one of the domains identified in social health ${ }^{14}$.

Another important variable was disease awareness, which was positively related to QOL, indicating higher QOL with better awareness. According to the model of Clare ${ }^{47}$ several domains are relevant in awareness in Alzheimer's including experiencing the impact of changes and adjusting to changes. Insight into one's limitations is an important prerequisite for making necessary adaptations in life and to keep participating in valued and essential aspects of daily living. This shows that awareness is closely related to acceptance of these changes and has important implication for coping styles and strategies ${ }^{47}$. Coping with the disease and successfully adapting allows people to feel healthy despite the experienced limitations ${ }^{14}$. In addition, higher awareness provides the opportunity for the person with dementia to take an active part in his or her own care planning and future. This involvement in daily decision making can also have a positive effect on reported QOL in the person with dementia ${ }^{48}$. The opportunity for informed decision making requires full disclosure about the diagnosis and its implications from the healthcare professionals. The use of euphemisms or non-disclosure does not only contribute to uphold the stigma associated with dementia ${ }^{49}$, but also limits the empowerment of the person involved.

Previous research has also linked better awareness in the person with YOD to higher QOL in the caregiver ${ }^{50}$. Since the proxy ratings of $\mathrm{QOL}$ in people with dementia may be influenced by the well-being of the caregivers themselves ${ }^{32}$, the relationship of awareness and QOL might be partly mediated by the positive effect of awareness on caregivers. This finding raises the question of the suitability of the proxy ratings to evaluate QOL in people with dementia, and is a limitation of our study. A large majority of people with mild to moderate dementia is perfectly capable of reporting their own QOL, and proxy ratings are often lower than those made by persons themselves ${ }^{16,51}$. These different ratings might be caused by an overcritical attitude of the caregivers or, on the other hand, to an adaptive shift of the person with dementia to their limitations and the resulting adjustment of expectations ${ }^{16}$. Furthermore, QOL in people with dementia is underestimated by caregivers with increased burden ${ }^{21}$ and evaluations of the QOL by proxy seem to be influenced by the caregivers own emotional state and inner experience ${ }^{52}$. However, we were unable to include self-report ratings, since both the NeedYD and the Nordic YOD-study included people with YOD in all stages of the disease, including individuals with severe cognitive impairment. Therefore, the decision was made to use the caregiver perspective. 
The present study is one of the few studies assessing QOL specifically in people with YOD. The strength of the study is that combining two data sets gave information from a large sample of people with YOD including a substantial amount of people with FTD. However, this also comes with limitations as the pooling of the data generated some challenges and some variables were assessed a bit differently. Furthermore, no selfreported measures were available for all participants preventing the possibility to use both self-rated and by proxy reports. The sample characteristics also limit generalizability to the entire YOD population, as we only included people with AD and FTD thereby excluding a considerable proportion of people with YOD with other etiologies. For a better understanding of factors that might improve QOL in the different stages of the disease, longitudinal research is needed. A combined use of quantitative and qualitative methods will further enable the understanding of the concept of QOL, and highlight which domains are particularly important in YOD. Self-report measures of QOL in people in all stages of the disease in future research will contribute valuable complementary information to caregiver reports. How determinants of QOL differ between by proxy and self-reports should be investigated more in depth, also to clarify how these proxy ratings might be biased. Furthermore, it would be interesting to study variables that are more directly related to caregiver characteristics, such as quality of the relationship, caregiver burden, coping, and caring strategies. Our results indicate that merely the quantity of care measured in hours was not a significant determinant for QOL, indicating that other factors related to the caregiving situation might be more important. Especially since caregivers who care for someone with YOD, frequently experience difficulties balancing their multiple roles and responsibilities with the care situation ${ }^{53}$ and report low $\mathrm{QOL}^{25}$ and psychological complaints ${ }^{54}$. Other variables that might be important contributors of the experienced QOL in people with YOD are the availability of stimulating activities and social contact, as they often feel a lack of meaningful activity and a loss of sense of purpose in their daily lives as they are still in an active life phase $\mathrm{e}^{55,56}$.

Taken together, we have identified a unique set of determinants for QOL. These have implications for efforts to enhance QOL in people with YOD. First of all, it is important to detect and treat depressive symptoms. These symptoms are often misdiagnosed or misattributed, and left untreated and significantly decrease QOL ${ }^{48}$. Secondly, interventions should acknowledge the importance of awareness in the person with dementia and the effect it has on their QOL. This allows them to take an active part in the decision making process concerning their own care and future. Thirdly, it is often assumed that QOL is lower with more severe dementia, however this is neither supported by our findings nor by previous studies as dementia severity was not a significant determinant of QOL ${ }^{16}$. Therefore, a shift in focus from disability and loss towards the possibilities and positive aspects in the daily lives of people with dementia, also in the more advanced 
stages, should become an important topic in dementia research ${ }^{14}$. This might be especially relevant for people with YOD, as they are in a more active life phase and want to fulfill a meaningful role and feel useful ${ }^{57}$. Lastly, it is important to target care needs, because they negatively impact QOL and furthermore have been identified as determinants of early nursing home placement ${ }^{58}$. However, the challenge is to find the right balance between providing sufficient help and respecting the autonomy of the person with dementia. 


\section{References}

1 World Health Organisation. (2012). Dementia: A public health priority. Retrieved from [http://www.who.int/mental_health/publications/dementia_report_2012/en/]

2 Harvey, R. J., Skelton-Robinson, M. \& Rossor, M. N. (2003). The prevalence and causes of dementia in people under the age of 65 years. Journal of neurology, neurosurgery, and psychiatry, 74(9), 1206-1209.

3 Ratnavalli, E., Brayne, C., Dawson, K. \& Hodges, J. R. (2002). The prevalence of frontotemporal dementia. Neurology, 58(11), 1615-1621.

4 Alzheimer's Disease International. (2015). World Alzheimer Report 2015. The global impact of dementia. An analysis of prevalence, incidence, cost and trends. London: Alzheimer's disease International.

5 Sampson, E., Warren, J. \& Rossor, M. (2004). Young onset dementia. Postgraduate medical jounal, 80(941), 125-139.

6 Rossor, M., Fox, N., Mummery, C., Schott, J. \& Warren, J. (2010). The diagnosis of young-onset dementia. The Lancet Neurology, 9(8), 793-806.

7 Vieira, R. T., Caixeta, L., Machado, S. et al. (2013). Epidemiology of early-onset dementia: a review of the literature. Clinical Practice \& Epidemiology in Mental Health, 9(1).

8 Koedam, E. L., Lauffer, V., van der Vlies, A. E. et al. (2010). Early-versus late-onset Alzheimer's disease: more than age alone. Journal of Alzheimer's disease, 19(4), 1401-1408.

9 van Vliet, D., de Vugt, M. E., Bakker, C., Koopmans, R. T. \& Verhey, F. R. (2010). Impact of early onset dementia on caregivers: a review. International Journal of Geriatric Psychiatry, 25(11), 1091-1100.

10 Baptista, M. A. T., Santos, R. L., Kimura, N. et al. (2016). Quality of life in young onset dementia: an updated systematic review. Trends in psychiatry and psychotherapy, 38(1), 6-13.

11 Harris, P. B. \& Keady, J. (2009). Selfhood in younger onset dementia: transitions and testimonies. Aging and Mental Health, 13(3), 437-444.

12 Teng, E., Tassniyom, K. \& Lu, P. H. (2012). Reduced quality-of-life ratings in mild cognitive impairment: analyses of subject and informant responses. The American Journal of Geriatric Psychiatry, 20(12), 1016-1025.

13 World Health Organisation Group. (1995). The World Health Organization quality of life as sessment (WHOQOL): position paper from the World Health Organization. Social science \& medicine, 41(10), 1403-1409.

14 Huber, M., Knottnerus, J. A., Green, L. et al. (2011). How should we define health? Bmj, 343.

15 Vernooij-Dassen, M. \& Jeon, Y.-H. (2016). Social health and dementia: the power of human capa bilities. International psychogeriatrics, 28(5), 701.

16 Banerjee, S., Samsi, K., Petrie, C. D. et al. (2009). What do we know about quality of life in dementia? A review of the emerging evidence on the predictive and explanatory value of disease specific measures of health related quality of life in people with dementia. International journal of geriatric psychiatry, 24, 15-24.

17 Logsdon, R. G., Gibbons, L. E., McCurry, S. M. \& Teri, L. (2002). Assessing quality of life in older adults with cognitive impairment. Psychosomatic medicine, 64(3), 510-519.

18 Bosboom, P. R., Alfonso, H., Eaton, J. \& Almeida, O. P. (2012). Quality of life in Alzheimer's disease: different factors associated with complementary ratings by patients and family caregivers. International Psychogeriatrics, 24(05), 708-721. 
Black, B. S., Johnston, D., Morrison, A. et al. (2012). Quality of life of community-residing persons with dementia based on self-rated and caregiver-rated measures. Quality of Life Research, 21(8), 1379-1389.

Conde-Sala, J. L., Garre-Olmo, J., Turró-Garriga, O., López-Pousa, S. \& Vilalta-Franch, J. (2009). Factors related to perceived quality of life in patients with Alzheimer's disease: the patient's perception compared with that of caregivers. International journal of geriatric psychiatry, 24(6), 585-594.

Gómez-Gallego, M., Gómez-Amor, J. \& Gómez-García, J. (2012). Determinants of quality of life in Alzheimer's disease: perspective of patients, informal caregivers, and professional caregivers. International Psychogeriatrics, 24(11), 1805-1815. Hoe, J., Katona, C., Roch, B. \& Livingston, G. (2005). Use of the QOL-AD for measuring quality of life in people with severe dementia - the LASER-AD study. Age and ageing, 34(2), 130-135. Beer, C., Flicker, L., Horner, B. et al. (2010). Factors associated with self and informant ratings of the quality of life of people with dementia living in care facilities: a cross sectional study. PLoS One, 5(12), e15621. Crespo, M., Hornillos, C. \& de Quirós, M. B. (2013). Factors associated with quality of life in dementia patients in long-term care. International Psychogeriatrics, 25(04), 577-585. Bakker, C., de Vugt, M. E., van Vliet, D. et al. (2014). Unmet needs and health-related quality of life in young-onset dementia. The American Journal of Geriatric Psychiatry, 22(11), 1121-1130. van Vliet, D., Bakker, C., Koopmans, R. T. et al. (2010). Research protocol of the NeedYD-study (Needs in Young onset Dementia): a prospective cohort study on the needs and course of early onset dementia. BMC Geriatrics, 10: 13. Hvidsten, L., Engedal, K., Selbaek, G. et al. (2015). Young Onset Dementia study? A Prospective Cohort Study of Quality of Life and Specific Needs in Persons with Young Onset Dementia and their Families. Journal of Clinical Trials, 5(1). American Psychiatric Association (2000). Diagnostic and statistical manual of mental disorders DSM-IV-TR (Text Revision) American Psychiatric Association. Washington, DC. CBO (2005). Guideline diagnosis and pharmacological treatment of dementia. Alphen aan den Rijn: Van Zuiden Communications B.V. Mesulam, M.-M. (2003). Primary progressive aphasia-a language-based dementia. New England Journal of Medicine, 349(16), 1535-1542.

31 Neary, D., Snowden, J. S., Gustafson, L. et al. (1998). Frontotemporal lobar degeneration A consensus on clinical diagnostic criteria. Neurology, 51(6), 1546-1554. Logsdon, R. G., Gibbons, L. E., McCurry, S. M. \& Teri, L. (1999). Quality of life in Alzheimer's disease: patient and caregiver reports. Journal of Mental Health and Aging, 5, 21-32. Thorgrimsen, L., Selwood, A., Spector, A. et al. (2003). Whose quality of life is it anyway?: The validity and reliability of the Quality of Life-Alzheimer's Disease (QoL-AD) scale. Alzheimer Disease \& Associated Disorders, 17(4), 201-208. Reisberg, B., Ferris, S. H., de Leon, M. J. \& Crook, T. (1982). The Global Deterioration Scale for assessment of primary degenerative dementia. The American journal of psychiatry, 139(9), 1136-1139.

35 Hughes, C. P., Berg, L., Danziger, W. L., Coben, L. A. \& Martin, R. (1982). A new clinical scale for the staging of dementia. The British journal of psychiatry, 140(6), 566-572. 
American Medical Association. (2011). Dementia Performance Measurement Set. Retrieved from [https://www.aan.com/uploadedFiles/Website_Library_Assets/Documents/3.Practice_ Management/2.Quality_Improvement/1.Quality_Measures/1.All_Measures/dementia.pdf] Folstein, M. F., Folstein, S. E. \& McHugh, P. R. (1975). "Mini-mental state": a practical method for grading the cognitive state of patients for the clinician. Journal of psychiatric research, 12(3), 189-198. Alexopoulos, G. S., Abrams, R. C., Young, R. C. \& Shamoian, C. A. (1988). Cornell scale for depression in dementia. Biological Psychiatry Biological Psychiatry, 23(3), 271-284.

39 Reynolds, T., Thornicroft, G., Abas, M. et al. (2000). Camberwell Assessment of Need for the Elderly (CANE) Development, validity and reliability. The British Journal of Psychiatry, 176(5), 444-452.

40 Cummings, J. L., Mega, M., Gray, K. et al. (1994). The Neuropsychiatric Inventory comprehensive assessment of psychopathology in dementia. Neurology, 44(12), 2308-2308.

41 Verhey, F. R., Rozendaal, N., Ponds, R. W. \& Jolles, J. (1993). Dementia, awareness and depression. International journal of geriatric psychiatry, 8(10), 851-856.

42 Reed, B. R., Jagust, W. J. \& Coulter, L. (1993). Anosognosia in Alzheimer's disease: relationships to depression, cognitive function, and cerebral perfusion. Journal of Clinical and Experimental Neuropsychology, 15(2), 231-244. Wimo, A., Jonsson, L. \& Zbrozek, A. (2010). The Resource Utilization in Dementia (RUD) instrument is valid for assessing informal care time in community-living patients with dementia. The journal of nutrition, health or aging, 14(8), 685-690.

44 Ducharme, F., Kergoat, M.-J., Antoine, P., Pasquier, F. \& Coulombe, R. (2013). The Unique Experience of Spouses in Early-Onset Dementia. American journal of Alzheimer's disease and other dementias, epub ahead of print. Ettema, T. P., Dröes, R.-M., de Lange, J. et al. (2005). The concept of quality of life in dementia in the different stages of the disease. International Psychogeriatrics, 17(03), 353-370. Andersen, C. K., Wittrup-Jensen, K. U., Lolk, A., Andersen, K. \& Kragh-Sørensen, P. (2004). Ability to perform activities of daily living is the main factor affecting quality of life in patients with dementia. Health and quality of life outcomes, 2(1), 1. Clare, L. (2004). The construction of awareness in early-stage Alzheimer's disease: a review of concepts and models. British Journal of Clinical Psychology, 43(2), 155-175.

48 Menne, H. L., Judge, K. S. \& Whitlatch, C. J. (2009). Predictors of quality of life for individuals with dementia Implications for intervention. Dementia, 8(4), 543-560. Gove, D., Downs, M., Vernooij-Dassen, M. \& Small, N. (2016). Stigma and GPs' perceptions of dementia. Aging \& mental health, 20(4), 391-400.

50 Rosness, T. A., Mjørud, M. \& Engedal, K. (2011). Quality of life and depression in caregivers of patients with early onset dementia. Aging \& mental health, 15(3), 299-306.

51 Vogel, A., Mortensen, E. L., Hasselbalch, S. G., Andersen, B. B. \& Waldemar, G. (2006). Patient versus informant reported quality of life in the earliest phases of Alzheimer's disease.

International journal of geriatric psychiatry, 21(12), 1132-1138. Gomez-Gallego, M., Gomez-Garcia, J. \& Ato-Lozano, E. (2015). Addressing the bias problem in the assessment of the quality of life of patients with dementia: Determinants of the accuracy and precision of the proxy ratings. The journal of nutrition, health \& aging, 19(3), 365-372.

53 Millenaar, J. K., Bakker, C., Koopmans, R. T. et al. (2016). The care needs and experiences with the use of services of people with young onset dementia and their caregivers: a systematic review. International journal of geriatric psychiatry. Epub ahead of print. 
54 Riedijk, S., Duivenvoorden, H., Van Swieten, J., Niermeijer, M. \& Tibben, A. (2009). Sense of competence in a Dutch sample of informal caregivers of frontotemporal dementia patients. Dementia and geriatric cognitive disorders, 27(4), 337-343.

55 Harris, P. B. \& Keady, J. (2004). Living With Early Onset Dementia: Exploring the Experience and Developing Evidence-based Guidelines for Practice. Alzheimer's Care Today, 5(2), 111-122.

56 Roach, P. \& Drummond, N. (2014). 'It's nice to have something to do': early-onset dementia and maintaining purposeful activity. Journal of psychiatric and mental health nursing, 21(10), 889-895.

57 Roach, P., Keady, J., Bee, P. \& Hope, K. (2008). Subjective experiences of younger people with dementia and their families: implications for UK research, policy and practice. Reviews in Clinical Gerontology, 18(2), 165.

58 Bakker, C., de Vugt, M. E., van Vliet, D. et al. (2013). Predictors of the time to institutionalization in young- versus late-onset dementia: results from the Needs in Young Onset Dementia (NeedYD) study. Journal of the American Medical Directors Association, 14(4), 248-253. 


\section{Chapter}

Discussion

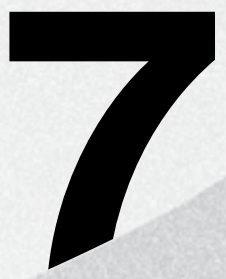




\section{Discussion}

This manuscript is the third thesis to originate from the NeedYD study. van Vliet ${ }^{1}$ previously investigated the impact and clinical characteristics of YOD, and Bakker looked into the amount of met and unmet needs and the use of (in)formal care. The goal of this thesis was to further investigate the specific needs in care and guidance for people with YOD and their caregivers, and to increase our understanding of the impact of YOD on informal caregivers and other family members during the different stages of the disease. We reviewed existing literature to gain more insight into these care needs (chapter 2) and further explored the perspectives of informal caregivers by means of qualitative research methods (chapter 3 and 4). In addition, we compared YOD and LOD caregivers on several measurements related to well-being (chapter 5) and identified determinants of QOL in people with YOD (chapter 6).

\section{Summary of the main findings}

\section{What is known from previous research about the needs of people with YOD and their informal caregivers with regard to available services and access to care?}

Previous research indicates that people with YOD and their caregivers encounter a wide range of difficulties during the disease process and struggle to find the right care. Early recognition and referral was reported as an essential area which required improvement as well as support after receiving the diagnosis. Help was especially needed with learning how to deal with the initial impact of the diagnosis. In the more advanced stages of the dementia caregivers required more support with the increasing demands in caregiving tasks. They expressed difficulties in balancing their role as a caregiver and maintaining their own life. However, finding proper respite care appeared to be very difficult. People with YOD themselves reported unmet needs concerning social company and intimate relationships, however more research is needed as there is a lack of studies representing their voices.

\section{What are the perspectives of caregivers with high and low unmet needs on the impact of YOD?}

When YOD caregivers were asked directly about existing care needs, the results showed that several aspects were more apparent in the caregivers without unmet care needs opposed to the caregivers who reported a high amount of unmet needs. It is important to note that caregivers in both groups were often dissatisfied with the available services. 
However, the difference between the two groups was that caregivers who did not express unmet needs had other ways to deal with their caregiving tasks despite the absence of (good) formal care. It was shown that acceptance and adjustment to changes was a prerequisite to slowly adapt to their new role as caregiver. This is in accordance with previous findings which show that caregivers who are better able to adapt to the changes caused by the dementia have a higher sense of competence in caring and experience less psychological problems $s^{3}$. Furthermore, the caregivers that did not express unmet needs were more focused on positive aspects in stead of the experienced losses. In addition, they often had more social support and openly communicated about the disease. This facilitated asking for help when necessary. Other factors that were more apparent in the caregivers that experienced less unmet needs were related to the person with dementia. Arranging the right care was easier when the person with dementia was aware of the diagnosis and accepted the changes that it caused.

\section{What are the experiences and needs of children living with a parent with young onset dementia?}

Specifically in YOD there is a group of young informal caregivers involved. Children of people with YOD are confronted with a parent with a progressive disease that causes changes in personality, behavior, and cognition. Chapter four describes the impact of dementia on their daily life. They struggle with managing all responsibilities while maintaining a life of their own and showed concerns about the future. The children had various ways of coping with the situation including the process of acceptance, avoidance and actively dealing with the changes. It appeared that they were more concerned about the needs of their parents as opposed to their own and reluctant to search help. However, they still expressed the need for care and support. Many children wanted to know more about dementia but received little information after the diagnosis from either their parents or health care professionals. In addition, they wanted practical guidance in dealing with their parent. Not all children were able to openly communicate about the disease even though they mentioned that it would be nice to talk to the people around them so they knew what was going on in their lives. Sometimes they found it easier to confide in someone other than their parents to avoid burdening them.

\section{What is the psychosocial impact of YOD on caregivers and is this different compared to LOD?}

Results from previous studies were inconclusive when comparing caregiver burden in YOD and LOD caregivers. We assessed sense of competence, health related QOL, depression and physical and psychological complaints in YOD as well as in LOD 
caregivers and hypothesized that YOD caregivers experienced lower levels of well-being because of the specific challenges they face. The results showed that caregivers in both groups experience high levels of physical and psychological complaints, mild depressive symptoms, a low sense of competence and low HRQoL. There appeared to be no difference in the presence and course of most outcome measures except for health related QOL on both the physical and mental domain. These results indicate that the caregivers in the YOD group experience as much complaints as LOD caregivers, but feel more limited in daily functioning due to these complaints, as reflected by the lower HRQoL scores.

\section{What are determinants of QOL in people with YOD?}

We identified and explored determinants of QOL in people with YOD, and assessed differences in specific domains between people with Frontotemporal dementia (FTD) and Alzheimer's disease (AD). Data from two European multicenter studies were used. Several factors were negatively related to QOL in the person with dementia including depressive symptoms and needs, both met and unmet. Disease awareness on the other hand was related to higher QOL scores. The global QOL score did not differ between people with FTD and AD, however, people with AD scored higher on the friends subscale and lower on the memory subscale compared to people with FTD.

\section{Conceptual issues}

When $\mathrm{AD}$ was first discovered it was defined as a presenile dementia, referring only to people who developed the disease before the age of 65. It was separated from senile dementia, which was supposed to be a consequence of aging. However, in the 1970's, $\mathrm{AD}$ became part of the same disease spectrum as senile dementia again, dissolving the distinction between presenile and senile dementia ${ }^{4}$. Nowadays, most people view dementia as a disease of old age, as it is most common in the elderly. However, in the last years this traditional view of dementia is once again challenged, as people are starting to raise awareness for people with dementia at a younger age defining YOD as a separate concept again.

From a biological standpoint YOD differs from LOD as the genetic burden is higher and they more often have rare dementia subtypes other that $\mathrm{AD}^{5,6}$. However, both in the elderly and in younger individuals, neurodegenerative diseases are the leading cause for developing dementia. In the very young (younger than 45 years of age), AD is not common and autoimmune or inflammatory, metabolic, vascular and infectious causes are more prevalent ${ }^{7}$. Furthermore, in LOD, a 'pure' form of AD or vascular dementia is 
rare and late-life brain atrophy and the accompanying cognitive decline is more often caused by an accumulation of environmental and genetic factors ${ }^{8}$. Besides these biological underpinnings, people with YOD and their specific care needs, should also be viewed in light of different cohort effects. Age effects are simply based on year of birth and the influence of getting older while cohort effects also describe the socialization of different birth cohorts over time 9 . Individuals who participated in the NeedYD study are from another cohort than people who suffer from LOD within the same given period of time. Experiences and care needs of the younger individuals in our study might therefore also be affected by their different values and views. The generation that was born between 1945 and 1954 are called the babyboomers, this generation grew up in the welfare state and within a more individualised society. They experienced a diminution in religious practice, major changes in the standard male-female relationships and an increase of labour opportunities for women ${ }^{10}$. It is proposed that this generation has a better understanding of their rights, more often question the present-day standards and values and have higher expectations toward public services ${ }^{11}$. Therefore the needs of people with YOD in our study may be influenced by a cohort effect as well.

In addition to these cohort effects, the life cycle approach to human development ${ }^{12}$ also poses an important perspective in differentiating YOD from LOD. Mid-life is defined by building a life and career and contributing to a wider society. An individuals identity is primarily defined by relationships with others and work. After the age of 65 this shifts to reviewing your life accomplishments and manage the impending end of life. In this view, people with YOD are affected within the active life phase, and this prevents them from fulfilling specific age related goals. The disruption of the life cycle often leads to the view of feeling 'to young' to have dementia and suggests that coping is therefore conceptually different than in $\mathrm{LOD}^{13}$.

In conclusion, specifically when the dementia starts at a younger age, themes addressing acceptance and the experienced losses might carry additional weight. These younger individuals still have expectations for the future and might be more focused on what could have been. Because dementia at a young age is less common than late onsetdementia, caregivers might not have been prepared for their role as caregiver. Therefore, addressing feelings of being different and being isolated is important. Nonetheless, several findings from the studies of this thesis might be similar in people caring for someone with dementia at older ages as well. For example, in studies concerning dementia at an older age the threat of autonomy and being a meaningful member of society is reported as well ${ }^{14}$. Differences between YOD and LOD should be viewed as dimensional and the dichotomous diversion should be more balanced. We should be cautious not to polarize and oversimplify the distinction between YOD and LOD by treating them 
as two completely separate entities. We have to focus more on each individuals needs, providing care that is suitable for someone's personal values and individual life cycle. Services should be responsive to the concept of the person being central and acknowledge the personhood of the individual with dementia regardless of the age of onset ${ }^{15}$.

\section{Methodological considerations}

\section{Study design}

The study design of NeedYD was based on several historical cohort studies conducted within multiple Dutch Alzheimer centers to enable comparison of the data. The longitudinal follow up of the NeedYD study was highly structured with regular intervals. This provides the opportunity to see how variables change over time and to investigate specific patterns on a group level as well as on individual levels. The design furthermore allows us to study predictive values of included variables on specific outcomes. That is, you can examine antecedents and consequences and make some speculations about causality. Using a longitudinal design also poses some threats ${ }^{16}$. When selecting a sample for longitudinal research it is desirable to include people who are available and cooperative over the entire length of the study to reduce attrition. However, this can be very challenging and creates a sampling bias. People who are keen to participate in the study are likely to be quite different from the noncooperative ones with regard to characteristics such as experienced burden or disease severity. Unfortunately we have no information about the number of participants who refused to participate or who were not eligible because of the inclusion criteria. Next to the selection bias, another inevitable issue is selective attrition. Our sample represents a vulnerable target group as the dementia is progressive in nature and after two years, about a quarter of the participants were lost due to drop out or death. When restricting the analyses to participants with complete follow up measurements, results might potentially be biased, as individuals in the more advanced stages are more likely to drop out.

In chapter 5 linear mixed models was used to analyze the data, which allows the use of all data without requiring imputation of missing data. All participants irrespective of them completing all assessments were included in the analysis as an individual intercept and slope is estimated using all available measurements up to the time of drop-out. Furthermore completers were compared to the non-completers showing that the individuals in the non-completer group were older and had a more advanced dementia. Consequently, the levels of burden might have been an underestimation. Another potential threat to the validity of a longitudinal design is related to testing participants multiple times. Participating in a longitudinal study might cause heightened awareness in the participants about the investigated phenomena, making the sample less representative of the 
underlying population. Talking regularly about experienced difficulties and burden might have increased the participants' awareness of their needs. In addition, most study participants expressed that it was good to have someone to talk to about what they were going through. They reported the frequent visits by the researchers as a positive experience and felt like they were finally being heard.

\section{Sample selection}

The main strength of these studies is the relatively large sample of people with YOD and their caregivers despite the low prevalence of YOD. Previous studies presented data from much smaller samples and did not have access to a comparable sample of people with LOD as well. Participants were recruited trough diverse health care settings across the Netherlands including university medical centers, regional hospitals, regional community mental health services and specialized day care facilities. Unfortunately this also poses a possible bias as only people who were already in contact with care providers were included and people with YOD who do not use, or have no access to specialist facilities were excluded. These individuals might experience even more difficulties with access to care and have a high amount of specific unmet needs as they receive no help. The quality assessment of several YOD studies in chapter 2 revealed that it is often unclear how the diagnosis was established in the studied samples. In our study the dementia diagnosis was carefully established according to the criteria from the 4th edition of the Diagnostic and Statistical Manual of Mental Disorders ${ }^{17}$, clinical, neuropsychological and neuroimaging data and the Dutch consensus guidelines ${ }^{18}$. However, generalizability was limited due to the exclusion of several diagnostic categories including dementia caused by human immuno-deficiency virus (HIV), traumatic brain injury, Down's syndrome, Huntington's chorea or alcohol related dementia. These diagnoses were excluded because of the additional problems they pose for the person with dementia, which would influence our findings.

In chapter 5, a comparison group of people with LOD from another cohort study was added to the dataset which allowed us to investigate the differences. This study had a similar design, and similar assessment measures and diagnostic criteria as the NeedYD study ${ }^{19}$. However, they also differed in several ways. First of all, even though essentially the same design was used in both cohorts, slightly different recruitment strategies were used which may have influenced the results. In the LOD group, people were mostly included shortly after receiving the diagnoses while in the YOD group, they were also included a while after receiving the diagnosis. Therefore the YOD group is a more heterogeneous group concerning disease severity and ADL disability. However, we aimed to reduce possible bias by including differing characteristics as covariates when comparing the two groups. In addition, an important aspect that should be considered is 
that most caregivers in the YOD group were partners. In the LOD group there were not only partners but also children who cared for their parent with dementia. Therefore, the relationship between the person with dementia and the caregivers was added as a possible confounder in the analyses as well.

\section{Assessments}

A strength of the study is the mixed methods approach, qualitative assessments were added next to the quantitative assessments. Quantitative research is in general viewed as more objective and generalizable and qualitative research on the other hand does not lend itself to detailed statistical analysis. However, qualitative research is suitable to provide an in-depth and complex picture of the issues younger people with dementia and their caregivers face within the context. However, the use of structured interviews also poses some difficulties as it is susceptible to interpretation by the researcher. To prevent this, in chapter 3 and 4 all interviews were separately coded and categorized by two different researchers, who thoroughly discussed their findings until consensus was reached regarding the categories and themes. Furthermore in qualitative studies the sample size is small and should not be seen as a representative sample of the population. The findings are more explorative in nature and can be used to identify areas of interest for future investigation.

Another methodological consideration is the use of proxy ratings for measurements in the person with young onset dementia concerning needs, quality of life and depressive symptoms. When the dementia severity increases it will become more and more difficult for the person with dementia to express their thoughts and wishes. In chapter 3, care needs were assessed in the caregivers instead of the person with dementia. A previous study has shown that there is fair agreement about the areas in which needs occur, but caregivers seem to report more needs than the person with dementia themselves ${ }^{20}$. In addition, the Camberwell assessment of needs is a very extensive structured interview and the participants with YOD experienced difficulties reflecting on all domains. Only about $70 \%$ of the participants were able to complete the assessment. Since the goal of chapter 3 was to provide input for the development of an educative intervention for caregivers, the use of proxy rated measurements seemed suitable. In chapter 6 we only used the by-proxy ratings as well, even though the majority of people with mild to moderate dementia is perfectly capable of reporting their own $\mathrm{QOL}^{21}$. The by proxy ratings of the caregivers for the QOL of the person with YOD are often lower ${ }^{22}$. This is probably caused by an overcritical attitude of the caregivers or to an adaptive shift of the person with dementia to their limitations and the resulting adjustment of expectations ${ }^{21}$. Furthermore, the by proxy ratings are influenced by the well-being and experienced burden in the caregiver. Unfortunately self-report measures were not available for the 
participants of the Nordic study, preventing the possibility to use both self-rated and by proxy reports. However, people with YOD in all stages of the disease were included, including individuals with severe cognitive impairment, which might have made it difficult for them to reflect on all domains.

\section{Clinical implications}

In order to support caregivers and people with YOD and provide effective and efficient care, knowledge about their needs and experiences is essential. The findings in this manuscript provide some implications for clinical practice.

Both in chapter 2 and 3 it was shown that the diagnostic process was often perceived as very challenging and early recognition and referral was reported as a principle area which required improvement. People struggle to obtain appropriate help in time and this has a profound impact on their well-being. After receiving the diagnosis people experience a sense of stigma around YOD. If people with YOD and their caregivers feel like they can not share the diagnosis and accompanying problems with others around them this can cause feelings of isolation and increase reluctance to seek help. Therefore, raising awareness and receiving help with the disclosure of the diagnosis and its consequences might increase understanding of the impact and difficulties of dementia at a younger age. This stresses the need for better support from healthcare professionals not just with improving the diagnostic process but with providing guidance after receiving the diagnosis as well. Our research also shows that a family centered approach is required in which service providers focus on the needs of the entire family. Healthcare professionals should be aware of the possible involvement of children as they need more specific information and guidance as well after their parent receives the diagnosis. However, they may be reluctant to ask for support themselves. The children feel more comfortable talking to someone they are familiar with. Therefore, they may benefit from a more personal approach, for example with a case manager, who can gradually establish a relationship of trust and who is familiar with their home situation. A case manager can evaluate the needs of the whole family and help with the organization of specific care. This will relieve some of the strain in the healthy parent which is important to reduce the pressure on the children.

Our findings also underline some specific recommendations in the care for the person with YOD. In chapter 6 several factors were identified that were related to their QOL. One of the most important determinants of low QOL is the presence of depressive symptoms. Unfortunately these symptoms are often misdiagnosed or misattributed, and consequently left untreated ${ }^{23}$. More attention is warranted for the detection and 
treatment of depressive symptoms. Needs, both met and unmet, negatively affect QOL as well. More help is needed to fulfill existing care needs and the person with YOD is confronted with limitations and experiences loss of autonomy. Dependency on others for daily activities is an important aspect in $\mathrm{QOL}^{24}$. This might be even more relevant in younger individuals as they are in a more active life phase and want to fulfill a meaningful role and feel useful ${ }^{25}$. Therefore, formal and informal caregivers should try to find the right balance between providing sufficient help and respecting the autonomy of the person with dementia. This asks for a shift in focus from disability and loss towards the possibilities in daily lives and the empowerment of people with YOD in directing their own care. Furthermore, services should be dedicated to preventing social isolation. In the review it is shown that the need for stimulating activities and social contact is high as people with YOD are still in an active life phase. However, the advanced age of individuals in the mainstream dementia facilities can cause reluctance to attend. Therefore it is important to offer age-appropriate services that focus on socializing and engaging in meaningful activities.

The findings of this thesis furthermore provide an in depth perspective on the caregivers experiences and emphasize specific themes that could be addressed in future interventions. Developing effective interventions may save costs in the long-term ${ }^{26}$, particularly when alleviating some of the caregivers distress can postpone early nursing home placement $^{27}$. For example, psycho-education could be used to inform caregivers about the diagnosis and the challenges they may face in the future. However, our results show that besides providing information about YOD, interventions should also focus on increasing the sense of competence of the caregiver in caring for the person with dementia and highlight the positive aspects in daily life rather than experienced losses. An important element to achieve this is addressing acceptance and adjusting expectations. This was seen as a prerequisite to adapt to the role as caregiver. A way to do this could be trough peer contact with caregivers who share the same faith. This could help to show caregivers that they are not alone and that others are dealing with comparable issues. However, there are several challenges. First of all, since YOD is less common than LOD it might be difficult to get enough caregivers together and to set up regular caregiver groups throughout the country. Secondly, because of the caregivers tasks and obligations besides caregiving in daily living such as work it might be difficult for them to frequently visit facilities such as peer contact groups. Thirdly, caregivers tend to have problems with leaving the person with dementia alone to attend face to face sessions ${ }^{28}$. This might be even more problematic for YOD caregivers as our results show that they have difficulties handing over the care and finding suitable facilities to do so. A solution to provide accessible support tailored to the needs of YOD caregivers could be the use of online interventions. The internet is increasingly used for disease management support in the 
community, including for dementia caregivers ${ }^{29}$. These younger caregivers might feel even more comfortable than LOD caregivers in using modern technology and they can decide for themselves where and when to use the program. Such an online intervention program to support dementia caregivers was recently developed in the Netherland ${ }^{30}$. An important aim of this program was to enhance acceptance of the disease, coping with changes and providing insight into caregiver management strategies. Such a program could be easily tailored to the specific needs of YOD caregivers by adding specific modules related to the issues they face. In addition, more recently an e-health intervention to assist caregivers in coping with YOD was developed, based on the recommendations of our studies ${ }^{31}$. Thinking about alternative ways to provide suitable care might be especially important in YOD. Even though specific care needs are identified, the prevalence of YOD is much lower compared to LOD. Therefore, providing dedicated YOD services for everyone in need might be challenging within the current health care system with restricted financial means.

\section{Future research directions}

The results of this thesis have several implications for future research. We have established specific needs in care of people with YOD and their caregivers. However, in order to translate these findings to specific guidelines for clinical practice we should know more about the magnitude of the issue of YOD. There is no solid information available about the epidemiology of YOD, making it is difficult to make statements about the number of people that are affected. The current numbers are most likely an underestimation and therefore large community based prevalence studies are required. This information enhances evidence-based practice for developing suitable policies and establishing dedicated services.

Another important recommendation for future studies is to focus on the specific needs and experiences reported by people with YOD themselves. There is a lack of data representing their voices and the use of self-report measures will contribute valuable complementary information to caregiver reports. In addition, more in depth investigation is necessary to assess differences between by proxy and self-reports and to clarify how proxy rating may be biased. Furthermore, the identification of specific care needs in YOD provides valuable information for the development of specific interventions to support people with YOD and their caregivers. More research is necessary into developing these interventions, as described in the clinical implications, and to test whether they are effective to support people with YOD and their caregivers. 


\section{Conclusions}

This thesis improves our understanding of the specific problems people with YOD and their caregivers encounter and illustrates the profound impact the disease has on everyone involved. We should be cautious not to oversimplify the distinction between YOD and LOD by treating them as two completely separate entities. However, specific themes carry additional weight when the dementia starts at a younger age, including the importance of a family centered approach. Because dementia at a young age is less common than LOD and occurs at an active life phase, caregivers might not have been prepared for their role as caregiver and focus more on what could have been. To promote living well with YOD despite the encountered difficulties people should be encouraged to focus on the positive aspects in daily living. In addition we should find a way to provide dedicated YOD services within the possibilities of the current health care system. 


\section{References}

1 Van Vliet, D. (2012). Young onset dementia, characteristics and impact. Ridderkerk: Ridderprint.

2 Bakker, C. (2013). Young onset dementia, care needs and service provision. Nijmegen: GVO Drukkers \& Vormgevers.

3 de Vugt, M. E. \& Verhey, F. R. (2013). The impact of early dementia diagnosis and intervention on informal caregivers. Progress in neurobiology, 110, 54-62.

4 Katzman, R. (1976). The prevalence and malignancy of Alzheimer's disease. Archives of neurology, $33,217-218$.

5 Rossor, M., Fox, N., Mummery, C., Schott, J. \& Warren, J. (2010). The diagnosis of young-onset dementia. The Lancet Neurology, 9(8), 793-806.

6 Vieira, R. T., Caixeta, L., Machado, S. et al. (2013). Epidemiology of early-onset dementia: a review of the literature. Clinical Practice \& Epidemiology in Mental Health, 9(1). Kelley, B. J., Boeve, B. F. \& Josephs, K. A. (2008). Young-onset dementia: demographic and etiologic characteristics of 235 patients. Archives of neurology, 65(11), 1502-1508. Fotuhi, M., Hachinski, V. \& Whitehouse, P. J. (2009). Changing perspectives regarding late-life dementia. Nature Reviews Neurology, 5(12), 649-658. Wolbers, M. H. (2010). Blijvende gevolgen van een gebrekkige start? Tijdschrift voor Arbeids vraagstukken, 26(2), 223-239. van Maarseveen, J. \& Harmsen, C. (2011). Demografische levensloop van babyboomers: terugblik en perspectief. Bevolkingstrends, 15-26. Steinhorn, L. (2006). The greater generation: In defense of the baby boom legacy. Macmillan. Erikson, E. H. (1993). Childhood and society. WW Norton \& Company. Clemerson, G., Walsh, S. \& Isaac, C. (2013). Towards living well with young onset dementia: An exploration of coping from the perspective of those diagnosed. Dementia, epub ahead of print. Steeman, E., Casterlé, D., Dierckx, B., Godderis, J. \& Grypdonck, M. (2006). Living with earlystage dementia: A review of qualitative studies. Journal of advanced nursing, 54(6), 722-738. Edvardsson, D., Winblad, B. \& Sandman, P.-O. (2008). Person-centred care of people with severe Alzheimer's disease: current status and ways forward. The Lancet Neurology, 7(4), 362-367. Schmidt, K. R. T. \& Teti, D. M. (2005). Issues in the use of longitudinal and cross-sectional designs. Handbook of research methods in developmental science, 3-20. American Psychiatric Association (2000). Diagnostic and statistical manual of mental disorders DSM-IV-TR (Text Revision) American Psychiatric Association. Washington, DC. CBO (2005). Guideline diagnosis and pharmacological treatment of dementia. Alphen aan den Rijn: Van Zuiden Communications B.V.

19 Vugt, M. E. d., Stevens, F., Aalten, P. et al. (2005). A prospective study of the effects of behavioral symptoms on the institutionalization of patients with dementia. International Psychogeriatrics, 17(04), 577-589.

Bakker, C., de Vugt, M. E., van Vliet, D. et al. (2014). The relationship between unmet care needs in young-onset dementia and the course of neuropsychiatric symptoms: a two-year follow-up study. International Psychogeriatrics, 26(12), 1991-2000. Banerjee, S., Willis, R., Matthews, D. et al. (2007). Improving the quality of care for mild to moderate dementia: an evaluation of the Croydon Memory Service Model. International journal of geriatric psychiatry, 22(8), 782-788. Vogel, A., Mortensen, E. L., Hasselbalch, S. G., Andersen, B. B. \& Waldemar, G. (2006). Patient 
versus informant reported quality of life in the earliest phases of Alzheimer's disease. International journal of geriatric psychiatry, 21(12), 1132-1138.

23 Menne, H. L., Judge, K. S. \& Whitlatch, C. J. (2009). Predictors of quality of life for individuals with dementia Implications for intervention. Dementia, 8(4), 543-560.

24 Ettema, T. P., Dröes, R.-M., de Lange, J. et al. (2005). The concept of quality of life in dementia in the different stages of the disease. International Psychogeriatrics, 17(03), 353-370.

25 Roach, P., Keady, J., Bee, P. \& Hope, K. (2008). Subjective experiences of younger people with dementia and their families: implications for UK research, policy and practice. Reviews in Clinical Gerontology, 18(2), 165.

26 Pinquart, M. \& Sörensen, S. (2006). Helping caregivers of persons with dementia: which interventions work and how large are their effects? International Psychogeriatrics, 18(04), 577-595.

27 Etters, L., Goodall, D. \& Harrison, B. E. (2008). Caregiver burden among dementia patient care givers: a review of the literature. Journal of the American Academy of Nurse Practitioners, 20(8), 423-428.

28 Lewis, M. L., Hobday, J. V. \& Hepburn, K. W. (2010). Internet-based program for dementia caregivers. American journal of Alzheimer's disease and other dementias, 25(8), 674-679.

29 Boots, L., Vugt, M., Knippenberg, R., Kempen, G. \& Verhey, F. (2014). A systematic review of Internet-based supportive interventions for caregivers of patients with dementia. International journal of geriatric psychiatry, 29(4), 331-344.

30 Boots, L. M., de Vugt, M. E., Withagen, H. E., Kempen, G. I. \& Verhey, F. R. (2016). Development and initial evaluation of the web-based self-management program "partner in balance" for family caregivers of people with early stage dementia: an exploratory mixed-methods study. JMIR research protocols, 5(1).

31 Kurz, A., Bakker, C., Böhm, M. et al. (2016). RHAPSODY-Internet-Based Support For Caregivers of People with Young Onset Dementia: Program Design and Methods of a Pilot Study. International Psychogeriatrics, epub ahead of print. 
Summary

Samenvatting

Knowledge valorization

Dankwoord

Curriculum Vitae

List of publications

Thesis defences from MHeNS 


\section{Summary}

Age is the most important risk factor for developing dementia, and therefore it is most common in the elderly. However, some individuals develop symptoms of the disease before the age of 65, which is referred to as young onset dementia (YOD). Over the last decades YOD is recognized as a condition with great impact due to the burden it places on the young individuals and their environment. The onset of the dementia is in an active stage of life when people usually expect many productive years ahead of them. The greater part of care in YOD is provided by family and relatives and these informal caregivers are often dedicated to provide care by themselves for as long as possible. However, most family caregivers feel like they are not sufficiently prepared for their role as caregiver. Supporting informal caregivers is important as they play a crucial role in enhancing the wellbeing and care of the person with dementia. However, relatively little is known about the specific problems and needs families experience during the different stages of YOD. Furthermore, services for dementia in general are often specifically designed for the elderly, and might have difficulties in addressing the challenges younger individuals face. The general aim of this thesis was to investigate the specific needs in care and guidance for people with YOD and their caregivers, and to explore the impact of YOD on informal caregivers and other family members during the different stages of the disease.

Data was mainly used from the Needs in young onset dementia (NeedYD) study. This longitudinal study includes both people with YOD and their caregivers with measurements every six months for the first two years, and follow up measurements after three, four and six years. Chapter 2 and 3 are part of the Research to Assess Policies and Strategies for Dementia in the Young (RHAPSODY) project. A general introduction, the study rationale and research questions are discussed in the introduction of this thesis (chapter 1).

In chapter 2, existing literature is reviewed to get more insight into the care needs and experiences with the use of services of people with young onset dementia and their caregivers. Previous research indicates that people with YOD and their caregivers encounter a wide range of difficulties during the disease process and struggle to find the right care. Early recognition and referral was reported as an essential area which requires improvement as well as support after receiving the diagnosis. In the more advanced stages of the dementia caregivers require more support with the increasing demands in caregiving tasks. They expressed difficulties in balancing their role as a caregiver and maintaining their own life. However, finding proper respite care appeared to be very difficult. People with YOD reported unmet needs concerning social company and intimate relationships. 
In chapter 3 and 4 needs and experiences with care are further explored by means of interviews with both caregivers, as well as children living at home. Caregivers were often dissatisfied with the available services. However, caregivers who did not express unmet needs were able to deal with their caregiving tasks despite the absence of (good) formal care. Acceptance and adjustment to changes was a prerequisite to adapt to their new role as caregiver. Furthermore, they were mainly focused on positive aspects in stead of the experienced losses compared to caregivers with more unmet needs. In addition, they often had more social support and openly communicated about the disease. It was also shown that arranging the right care was easier when the person with dementia was aware of the diagnosis and accepted the changes that it caused. The children of people with YOD struggled with managing all responsibilities while maintaining a life of their own and showed concerns about the future. They were more concerned about the needs of their parents as opposed to their own and reluctant to search help. However, they still expressed the need for care and support.

In chapter 5 YOD and LOD caregivers were compared with regard to several measurements related to well-being. The results showed that caregivers in both groups experienced high levels of physical and psychological complaints, mild depressive symptoms, a low sense of competence and low health related quality of life (HRQOL). There appeared to be no difference in the presence and course of most outcome measures except for HRQOL on both the physical and mental domain. These results indicate that the caregivers in the YOD group experience as much complaints as LOD caregivers, but feel more limited in daily functioning due to these complaints, as reflected by the lower HRQOL scores.

In chapter 6 determinants of QOL were identified in people with YOD, and assessed whether there were differences in specific domains for people with FTD and AD. Several factors were negatively related to QOL in the person with dementia including depressive symptoms and needs, both met and unmet. Disease awareness on the other hand was related to higher QOL scores. The global QOL score did not differ between people with FTD and AD, however, people with AD scored higher on the friends subscale and lower on the memory subscale compared to people with FTD.

In chapter 7 the main findings are discussed together with methodological considerations. In addition, implications for people with YOD, their caregivers and healthcare professionals are addressed, as well as recommendations for future research. 


\section{Samenvatting}

Leeftijd is de belangrijkste risicofactor voor het ontwikkelen van dementie en daarom komt het voornamelijk voor bij ouderen. Er zijn mensen die al voor hun $65 \mathrm{e}$ levensjaar symptomen van de ziekte ontwikkelen. In de laatste decennia is er steeds meer aandacht voor de enorme impact die dementie op jonge leeftijd heeft op zowel de mensen met dementie zelf als hun naasten. Deze mensen ervaren specifieke problemen die samenhangen met de relatief jonge en actieve levensfase. Het grootste gedeelte van de zorg wordt door mantelzorgers gegeven, die toegewijd zijn om zelf zo lang mogelijk de zorg in handen te houden. Helaas voelen de meesten zich niet voldoende toegerust en voorbereid om deze rol op zich te nemen. Ondersteuning van mantelzorgers is belangrijk omdat ze een cruciale rol spelen in het verbeteren van het welzijn van de persoon met dementie. Er is echter relatief weinig bekend over de specifieke problemen en zorgbehoeften die gezinnen ervaren tijdens de verschillende fases van de ziekte. Daarnaast zijn de meeste zorgfaciliteiten gericht op ouderen en voldoen daarom waarschijnlijk niet aan de wensen van de jongere individuen. Het doel van dit proefschrift was het onderzoeken van de specifieke behoeften met betrekking tot zorg en begeleiding voor mensen met dementie op jonge leeftijd en hun mantelzorgers. En te kijken naar de impact van de ziekte op mantelzorgers en andere familieleden tijdens de verschillende fases van de ziekte.

Er is voornamelijk gebruik gemaakt van gegevens van de Needs in young onset dementia (NeedYD) studie. Dit is een longitudinale studie met zowel personen met dementie als hun mantelzorgers die zes jaar lang gevolgd zijn. Hoofdstuk 2 en 3 maken onderdeel uit van het Research to Assess Policies and Strategies for Dementia in the Young (RHAPSODY) project. In hoofdstuk 1 wordt er een algemene introductie over het onderwerp gegeven en worden de rationale en vraagstellingen van het onderzoek beschreven.

In hoofdstuk 2 is bestaande literatuur besproken om meer inzicht te krijgen in de zorgbehoeften en de ervaringen met het gebruik van faciliteiten van jonge mensen met dementia en hun mantelzorgers. Voorgaande onderzoeken tonen aan dat ze een scala aan problemen ervaren en daarbij niet de juiste zorg kunnen vinden. Negatieve ervaringen in de diagnostische periode en het wegblijven van begeleiding na deze periode was een veelvoorkomend thema. In de latere fases van de ziekte hadden de mantelzorgers behoefte aan mee steun bij de toenemende zorgtaken. Ze gaven aan dat het steeds moeilijker werd om hun zorgtaken te combineren met andere sociale rollen en aspecten in hun leven. De jonge mensen met dementie rapporteerden onvervulde zorgbehoeften op het gebied van gezelschap en intieme relaties.

In hoofdstuk 3 en 4 werden de zorgbehoeften en ervaringen verder in kaart gebracht 
met behulp van interviews met mantelzorgers en thuiswonende kinderen. Mantelzorgers gaven vaak aan niet tevreden te zijn met de beschikbare faciliteiten. Echter, mantelzorgers die geen zorgbehoeften rapporteerden hadden een manier gevonden om met hun zorgtaken om te gaan ondanks het gebrek aan (goede) formele zorg. Acceptatie en het meegaan met veranderingen waren hierbij belangrijke voorwaarden om zich aan te passen aan hun nieuwe rol als mantelzorger. Daarnaast was het belangrijk om zich met name te richten op de positieve aspecten van het zorgen in plaats van het ervaren verlies als gevolg van de dementie. Ook hadden de mantelzorgers zonder zorgbehoeften vaak meer sociale steun. Thuiswonende kinderen gaven aan dat ze moeite hadden met hun eigen leven leiden naast alle verantwoordelijkheden die op hun pad kwamen. Daarnaast maakten ze zich ook vaak zorgen om de toekomst. De kinderen waren met name gericht op de zorgbehoeften van hun ouders en niet op die van henzelf.

Uit de resultaten in hoofdstuk 5 blijkt dat mantelzorgers die zorgen voor iemand met dementie op oudere leeftijd en degenen die zorgen voor iemand op jongere leeftijd zich beiden onvoldoende toegerust voelen om mantelzorg te geven. Daarnaast ervaren de meeste mantelzorgers fysieke en psychologische klachten zoals hoofdpijn, vermoeidheid of somberheid en milde depressieve symptomen. Ook de kwaliteit van leven werd in beide groepen laag beoordeeld. Er bleek een verschil te zijn tussen de twee groepen wat betreft de kwaliteit van leven. Mantelzorgers van de mensen met dementie op jonge leeftijd beoordeelden hun kwaliteit van leven lager dan de mantelzorgers van de mensen met dementie op oudere leeftijd. Deze resultaten geven aan dat mantelzorgers in beide groepen klachten ervaren maar dat de mantelzorgers in de jonge groep zich meer beperkt voelen in hun dagelijkse leven door deze klachten.

In hoofdstuk 6 zijn een aantal determinanten van kwaliteit van leven geïdentificeerd in jonge mensen met dementie. Ook is er gekeken naar verschillen tussen mensen met Alzheimer en fronto-temporale dementie op specifieke domeinen van kwaliteit van leven. Een aantal factoren waren negatief gerelateerd aan kwaliteit van leven, waaronder depressieve symptomen en (tegemoetgekomen) zorgbehoeften. Ziekte inzicht werd daarentegen geassocieerd met een hogere kwaliteit van leven. De globale scores waren niet verschillend tussen mensen met Alzheimer en fronto-temporale dementie. Wel scoorden mensen met Alzheimer hoger op het onderdeel vrienden en lager op het onderdeel geheugen.

In hoofdstuk 7 worden de resultaten samengevat, de theoretische en methodologische aspecten besproken en implicaties van de bevindingen voor de klinische praktijk en toekomstig onderzoek gegeven. 


\section{Knowledge valorization}

The aim of this thesis was to investigate the specific needs in care and guidance for people with YOD and their caregivers, and to explore the impact of young onset dementia (YOD) on informal caregivers and other family members during the different stages of the disease. With this valorization paragraph we describe how the results are of value for societal and economic application.

\section{Societal relevance}

Dementia is a worldwide public health priority. In 2015 the number of people with dementia is estimated at 47.5 million and is expected to increase in the upcoming years with a new case every four seconds implying a total number of 7.7 million new cases each year worldwide. In 2015, the total estimated cost of dementia is 818 billion dollars which is predicted to rise to a trillion in 2018. In addition to the expenses for the society, the disease has an enormous impact upon the quality of life of the person with dementia as well as their family and caregivers. Because age is the most important risk factor for developing dementia, it is most prevalent in the elderly and mostly associated with advanced age. However, some people develop symptoms of the disease before the age of 65. According to estimations of the Dutch Alzheimer society there are around 12.000 individuals with YOD in the Netherlands but unfortunately there is no solid information available about the number of people with YOD.

Dementia at a young age has gained more attention over the last years, however, people who are involved still experience feelings of stigma. As dementia in the young is rare it is not always recognized by the environment and the individuals with dementia and their caregivers often feel misunderstood and left on their own. As described in this thesis, most dementia services are often specifically designed for the elderly, and might have difficulties in addressing the needs of younger individuals. Therefore it is important to raise awareness about YOD in the general population and to educate healthcare professionals on how to support people with YOD and their family members.

Since there is no cure available, an important aspect of care for persons with dementia is promoting well-being and maintaining an optimal quality of life (QOL). The informal caregivers play a crucial role in enhancing the well-being of the person with dementia as they provide the greater part of care and are often dedicated to do this by themselves for as long as possible. Unfortunately, these caregivers often do not feel sufficiently prepared for their role as caregiver and this might be even more common in YOD compared to late onset dementia (LOD) as it is more rare. The daily care for someone with dementia requires continuous adaptation to changing and demanding situations for an 
extensive period of time and can result in adverse physical and psychological outcomes. In order to support people with YOD and their caregivers and provide effective and efficient care, knowledge about their needs and experiences is essential. This knowledge can be used to develop effective interventions which may save costs in the long-term, by postponing early nursing home placement.

\section{Target groups}

Our findings are relevant for people with YOD and their caregivers, health care professionals and policy makers. Our studies emphasize that these younger individuals have specific needs and therefore it is important to raise awareness about the occurrence of YOD and the accompanying issues, as it has consequences for service provision. Better support from health care professionals is necessary and difficulties in essential areas in service provisions are described in this thesis. This is not just important for the problematic diagnostic period but for providing guidance after receiving the diagnosis as well.

The findings of this thesis are important for informal caregivers as well as they provide an in depth perspective on the caregivers experiences and emphasize specific themes that could be addressed in future interventions. The caregivers experience high levels of burden and a considerable number of psychosocial problems related to their younger phase of life, including relational difficulties, family conflict, employment and financial issues. The increasingly time consuming tasks together with other responsibilities such as working and being a parent cause double demands. Knowledge about the problems these young caregivers face are important to improve support for informal caregivers. Our results are relevant for people with YOD as well as it describes encountered problems throughout the disease trajectory and identifies factors to improve their QOL. Caregivers should try to find the right balance between providing sufficient help and respecting the autonomy of the person with dementia as the experienced loss of autonomy negatively affects their QOL. This asks for a shift in focus from disability and loss towards the possibilities in daily lives and the empowerment of people with YOD in directing their own care.

\section{Products}

Based on the recommendations of this thesis an e-health intervention to assist caregivers in coping with YOD was developed (http://www.rhapsody-project.eu). The program consists of multiple modules that address the specific issues people with YOD and their caregivers face. This program is now evaluated in a pilot study conducted in England, France and Germany. The development of the RHAPSODY program also provided some important insights for the adaptation of a blended e-health intervention that was recently developed and evaluated by Alzheimer Centre Limburg (Partner in Balans). 
This program aims to enhance caregivers sense of competence in dealing with the caregiving situation. Our knowledge will be used to tailor the program to the needs of younger individuals. Presenting such a program complementary to formal care, shortly after receiving the diagnosis might help the caregivers with the acceptance process, and to regain control over the caregiving situation. Specifically in YOD alternative ways to provide care might be necessary as establishing regular dedicated services can be challenging, for example in low populated areas or for people who are still working and have limited availability during the day.

\section{Innovation}

The NeedYD study is a unique large scale cohort study which resulted in practical information for daily practice to improve care for people with YOD and their caregivers. The combined use of both qualitative and quantitative measures provided a thorough understanding of their experiences and needs. Our work is the result of a good combination of different disciplines, experts and networks, trough several national and international collaborations. Multiple Alzheimer centers, care facilities and research groups were involved to enhance our knowledge about YOD and to accelerate the progress in YOD research. Our work is also a good example of how previous results can be used to design new projects. By doing this we aim to make a difference for everyone involved by using their own experiences to improve care.

\section{Implementation}

The participants of the NeedYD study and involved care facilities were updated about the study progress and the results trough a newsletter. Furthermore, results were presented at several national and international congresses, symposia and Alzheimer café's. Workshops were provided to health care professionals to raise awareness about the experiences of people with YOD and the caregivers and also specifically about the needs of the children. In addition, our findings were used for the content development of an informative YOD website for people in the Netherlands and Belgium www.jongdementie.info. To translate our findings to specific guidelines for clinical practice and to further disseminate our work, we have close connections with the YOD knowledge center. This Dutch knowledge center aims to improve the quality of YOD care by connecting specialized caring facilities, developing specific guidelines, supporting scientific research and trough the dissemination of research findings. 


\section{Curriculum Vitae}

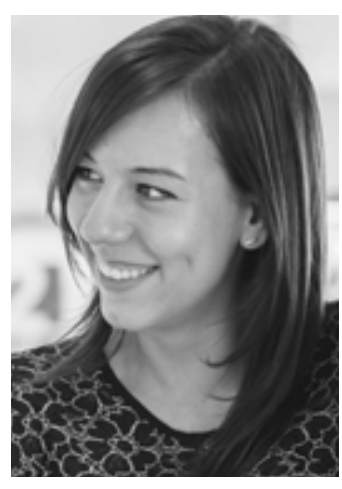

Joany Millenaar werd op 6 september 1988 geboren in Maastricht. Nadat ze in 2006 de middelbare school afrondde ging zij aan de Universiteit Maastricht psychologie studeren. Ter afsluiting van de research master neuropsychologie liep ze zowel een klinische- als een wetenschapsstage op de afdeling Psychologie en Psychiatrie van het Academisch ziekenhuis in Maastricht. Tijdens deze stageperiode maakte ze kennis met de NeedYD studie en schreef een scriptie over het beloop van gedragsproblemen bij jonge mensen met dementie. Na het afronden van haar master startte ze aansluitend als promovendus in 2012, waar ze werkte aan dit proefschrift. Naast het doen van onderzoek vervulde ze ook onderwijstaken op verschillende faculteiten en was ze werkzaam als neuropsycholoog op de geheugenpoli met als voornaamste taak diagnostische werkzaamheden en de verslaglegging hiervan. Ook was ze medebehandelaar bij een groepsbehandeling voor mensen met milde geheugenproblemen en coach voor mantelzorgers van mensen met dementie bij de online cursus 'Partner in Balans'. Een subsidieaanvraag om deze cursus aan te passen voor een jongere doelgroep werd in 2016 toegekend. Momenteel werkt Joany als postdoc-onderzoeker aan verschillende projecten over dementie op jonge leeftijd bij de afdeling Psychiatrie \& Neuropsychologie van de Universiteit Maastricht en Alzheimer centrum Limburg. 